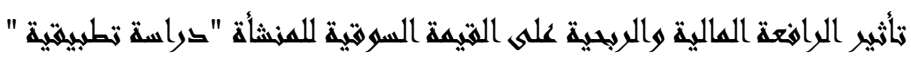

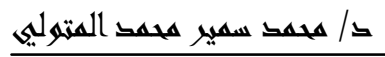

تأثير الرافعة المالية والربحية على القيمة السوقية للمنشأة

"دراسة تطبيقية "

د/ محمد سمير محمد المتولي

مدرس إدارة الأعمال

المعهد العالي للارسات التعاونية والإدارية

dr_mohamed_samir88@yahoo.com

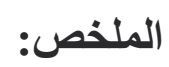

تهرف هذه الدراسة إلى استكثاف تأثئير الر افعة المالية والربحية على القيمة السوقية

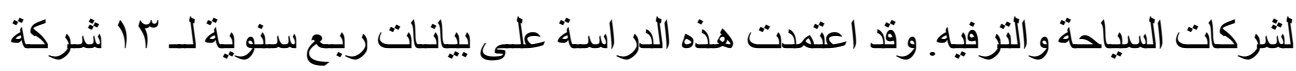

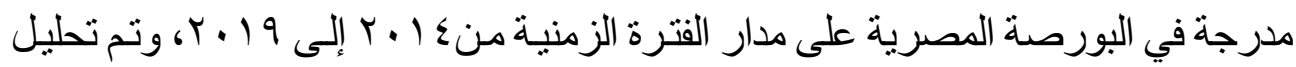

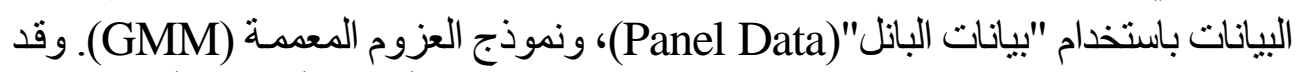

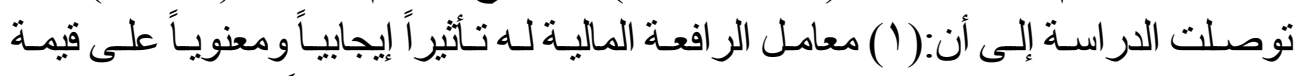

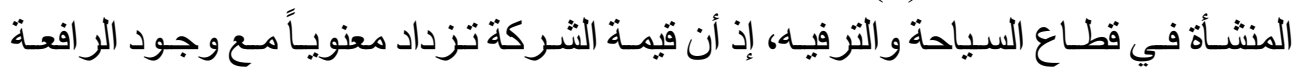

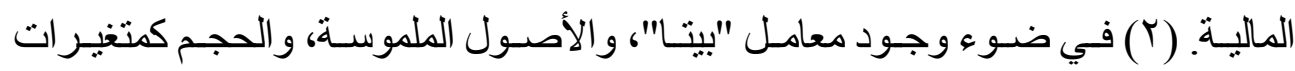

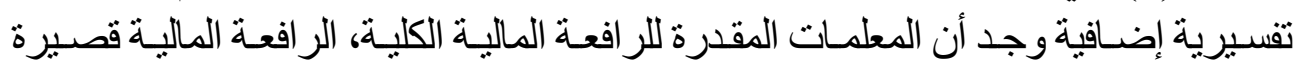

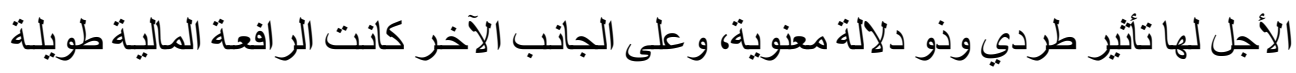

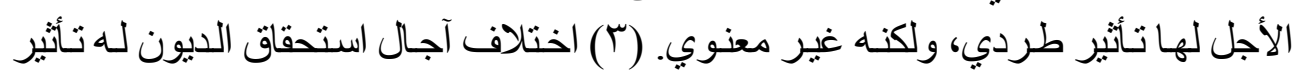

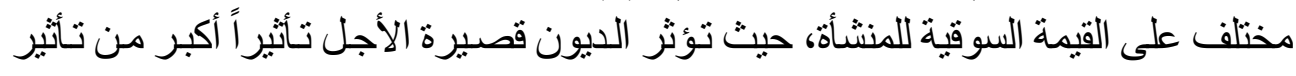

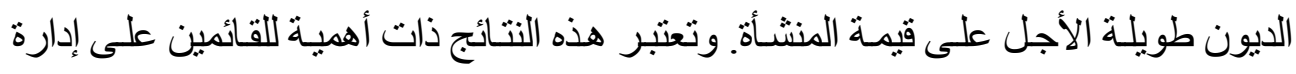

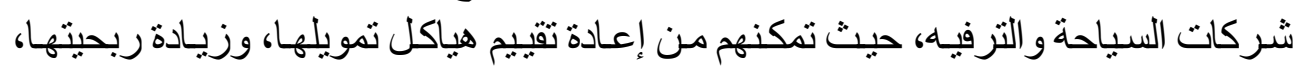
ومن ثم زيادة قيمتها السوقية.

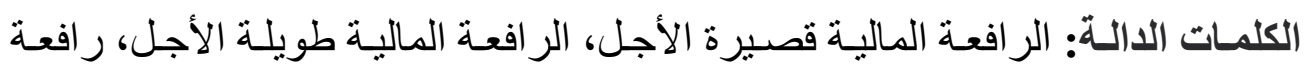
مالية، الربحية، مؤشر " توبين كيو".

العدد الرابع r.r.

المجلد الثاني عشر 


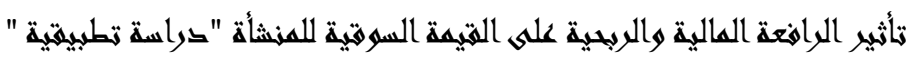
د/ هحمל سمير هحمت المترليه

\title{
The effect of financial leverage and profitability on the
} firm market value

"Applied study"

\author{
Dr. Mohamed Samir Mohamed El-Metwally
}

The Higher Institute for Cooperative and Administrative Studies

\section{Abstract:}

This study aims to explore the impact of financial Leverage and profitability on the market value of Tourism and Leisure companies. This study relied on quarterly data for 13 companies listed on the Egyptian Stock Exchange over the period from 2014 to 2019. The data analyzed using Panel Data, as well as the Generalized Momentum Model (GMM). The study found that:

1. The coefficient for financial Leverage is positive and significant in tourism \& Leisure sector. The value of the company increases with the presence of financial Leverage.

2. In the light of the presence of the coefficient "beta", tangible assets, and size as additional explanatory variables, it was found that the estimated parameters of total financial Leverage, shortterm financial Leverage have a positive and significant effect. On the other hand, the long-term Leverage had a positive, but not significant, effect،

3. The different maturities of debts have a different effect on the market value of the enterprise، as short-term debts have a 


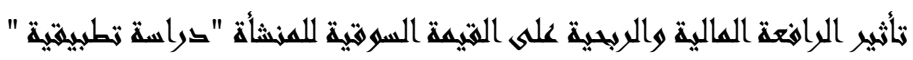
د/ هحمت سمير هحمد المترليه

greater impact than the effect of long-term debts on the value of the enterprise. These results are of great importance to those managing tourism and leisure companies, as they enable them to re-evaluate their financing structures, increase their profitability, and thus increase their market values.

Keywords: Short Financial Leverage, Long Financial Leverage, Financial Leverage, Tobin's q.

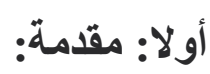

يشهي الاقتصاد المصري حركة تطور ملحوظة في مجال الاستثمار و التمويل

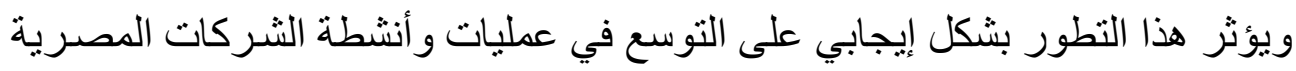

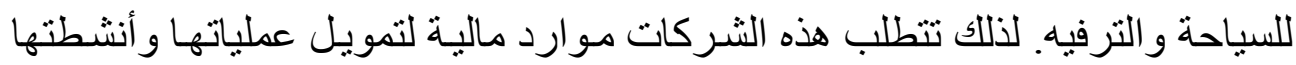

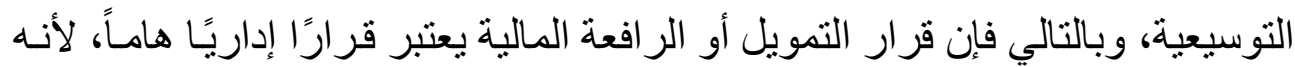

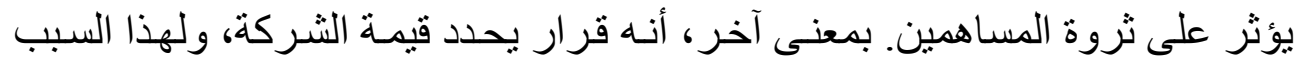

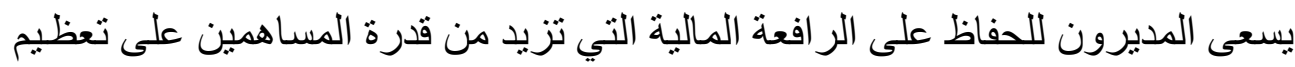

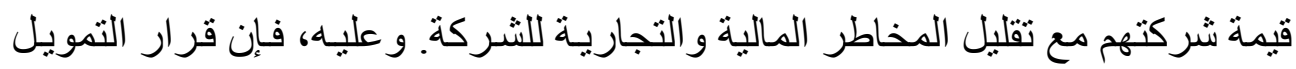

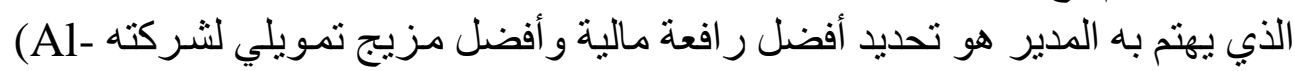

.Nsour \& Jresat, 2018)

ويشير هيكل التمويل إلى البدائل المختلفة التي تستخدمها الثركات لتمويل

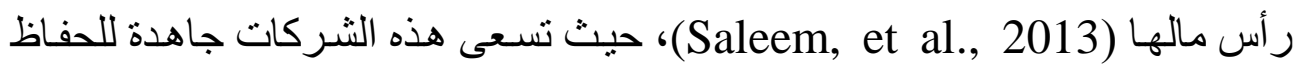

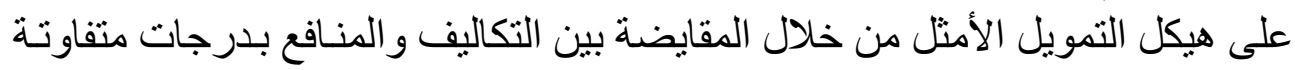

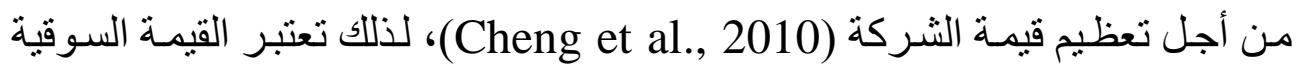

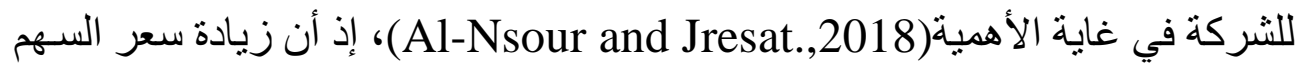

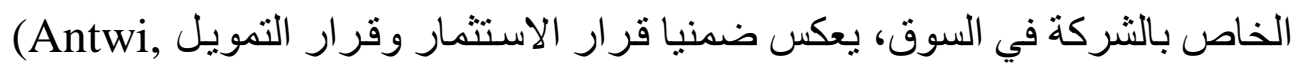
رet al., 2012) رفاهية المساهمين وحملة الأسهر. 


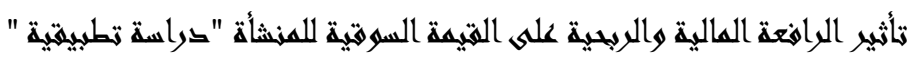

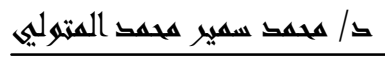

وجدير بـالذكر أن قيمـة الثـركة تتأثر بالعديـد مـن العو امـل الهامـة مـن بينهـا

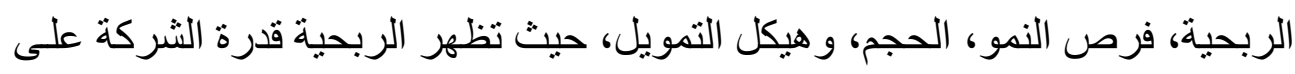

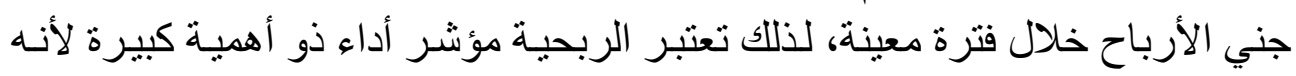

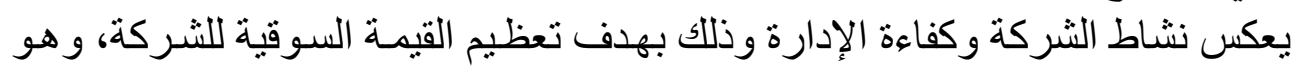

من الأهداف الأساسية للثركة (Dang \& Do., 2021).

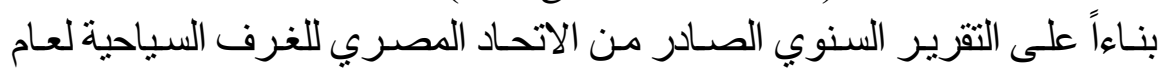

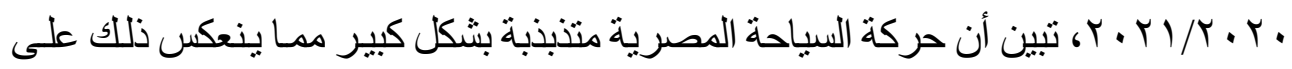

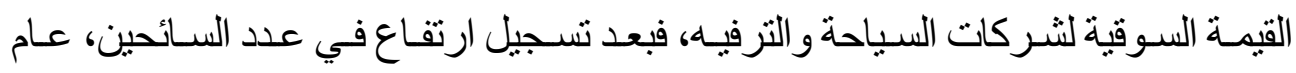

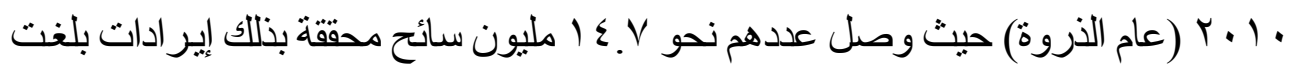

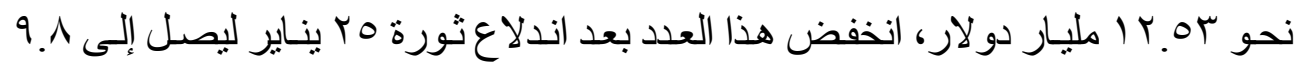

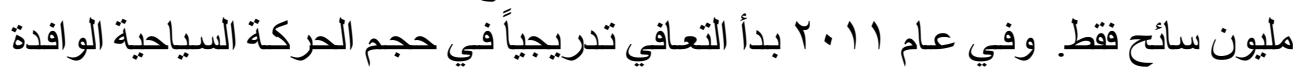

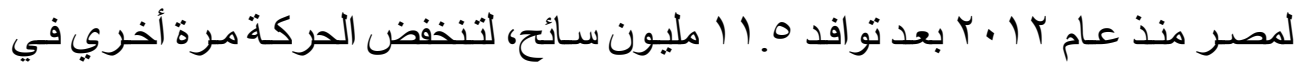

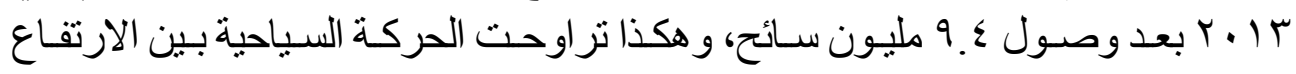

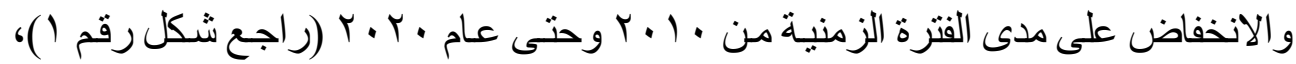

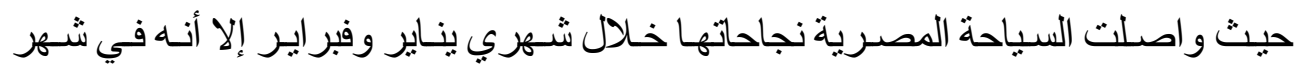

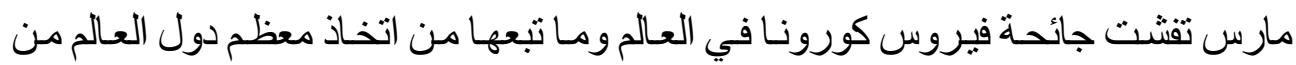
إجراءات تعليق حركة الطير ان الدولي لتتوقف الحركة السياحية تماما في البلاد مما أدى إلى إنى

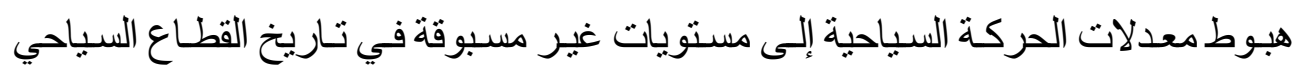
المصري كما يوضحه الثكل التالي: 


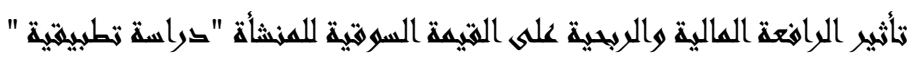

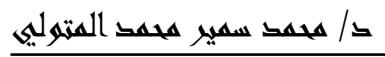

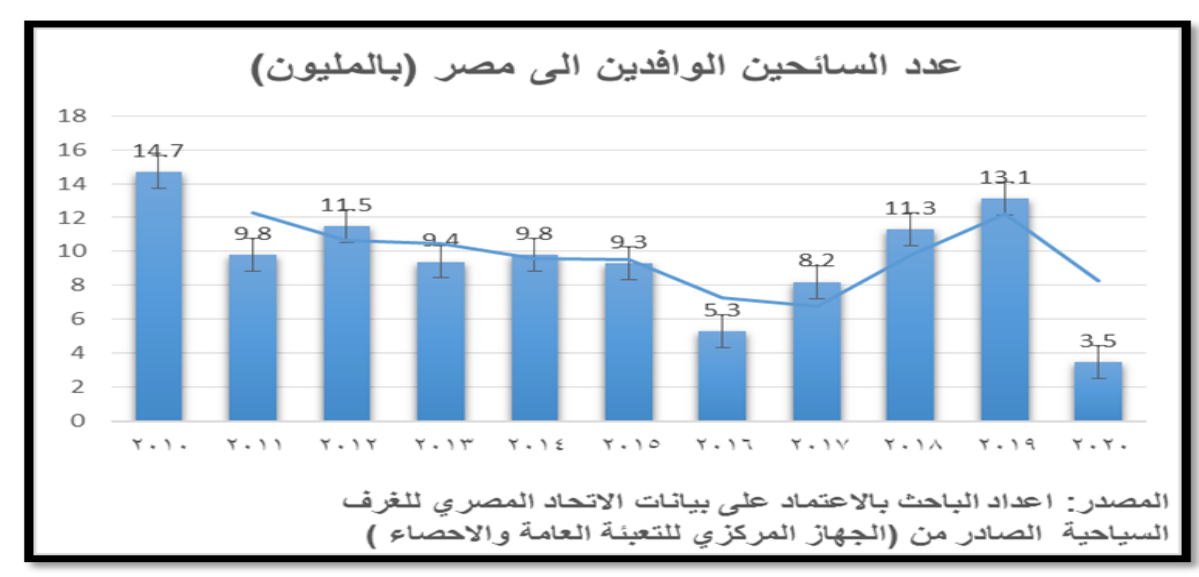

و لا شك أن تذبذب عدد السائحين يكون له تأثنير اً سلبياً على شـركات السياحة

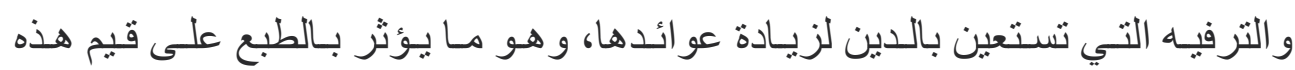

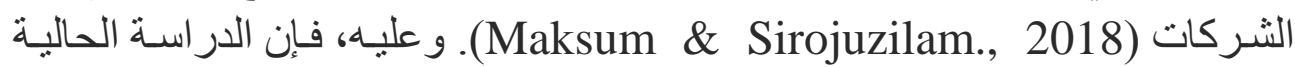

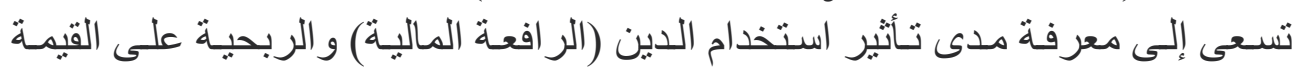

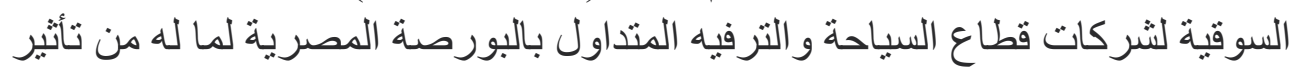
قوي على الاقتصاد المصري.

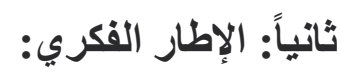

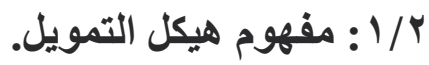
باستقر اء العديد من الأدبيات حول مفهوم هيكل التمويل لوحظ أنه لا يوجد إجماع

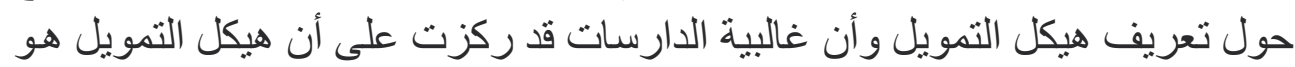

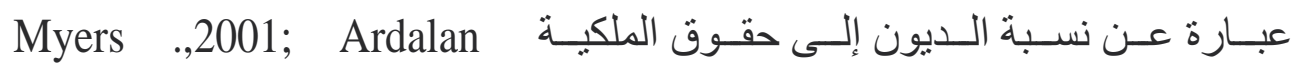
(Ripamonti, 2020 ; udrajat 2018) \&Setiyawati., 2021)

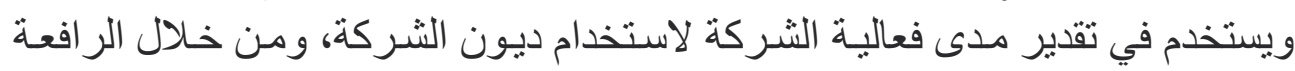

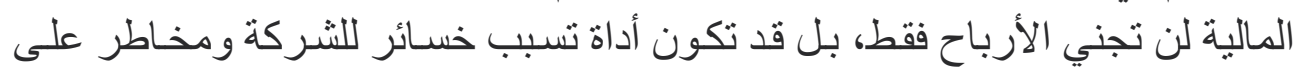

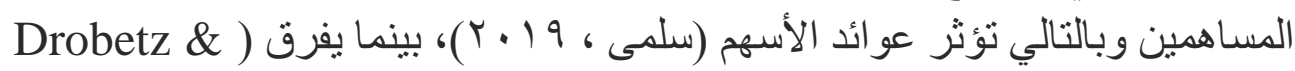




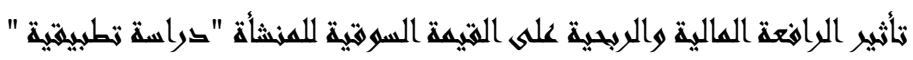
د/ هحمد سمير هحمد المترليه

(fix., 2003 وتعتبر الأكثر استخداما.

على الرغم من اختلاف الدارسات السابقة حول مداخل هيكل التمويل، إلا أنه في

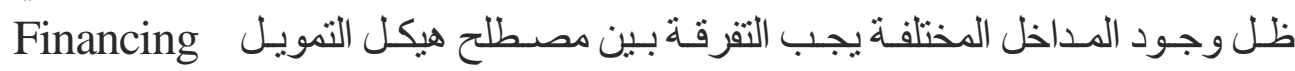
Structure و مصطلح هيكل رأس المسال Capital Structure ، حيث بشئير مصطلح

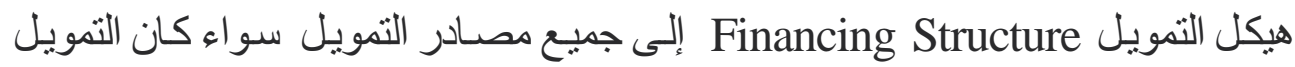

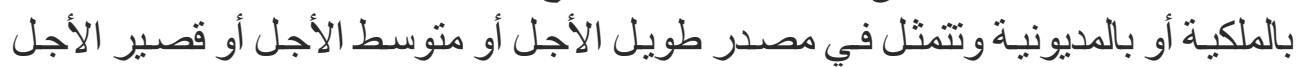

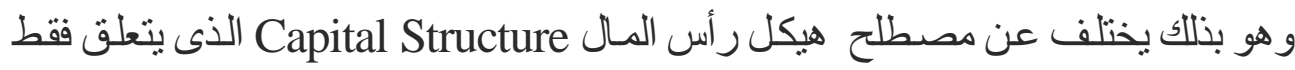

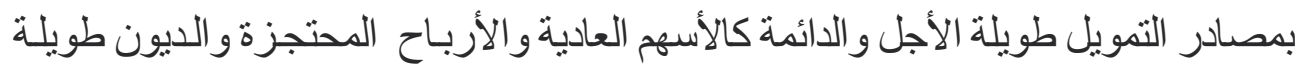
الأجل، إذ أن هيكل رأس مال الثركة هو جزء من هيكلها المالي(Michalak., 2015).

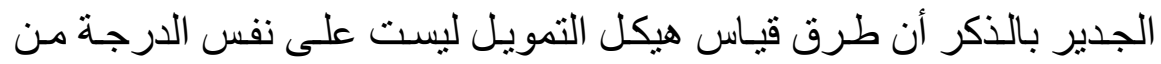

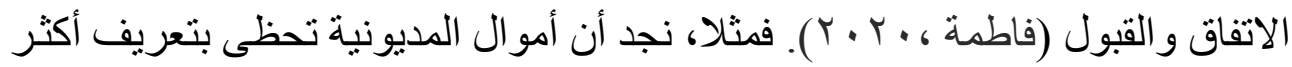

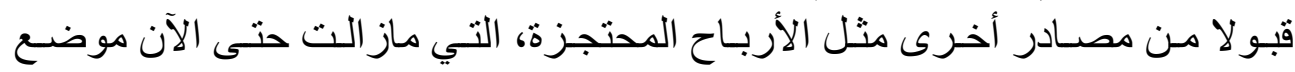

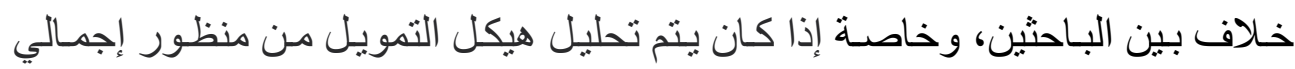

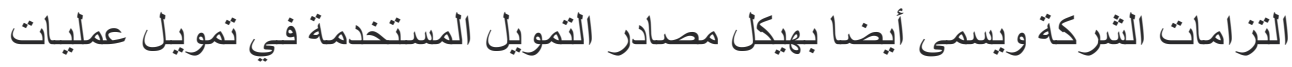

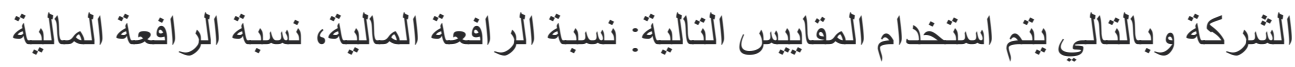

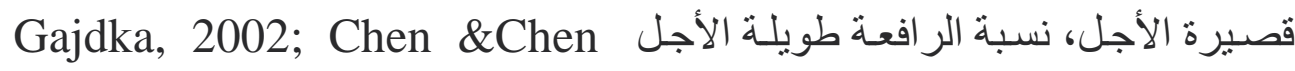
(2011; Jiahui;2015;). أمـا من منظور العلاقة بين حقوق الملكية ور أس المـال

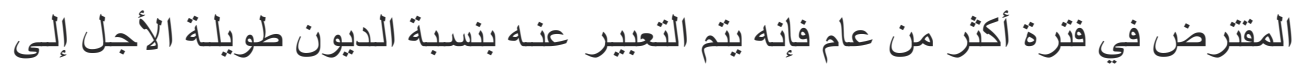

حقوق الملكية (Pomykalska \& Pomykalski, 2017; kruk,2021). أما إذا كان هيكل التمويل يعكس حقوق الملكية و الديون طويلة الأجل و الديون

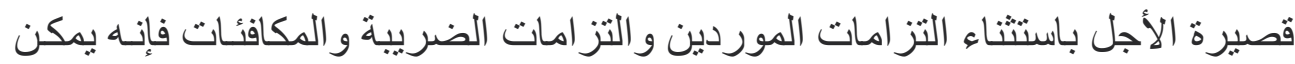

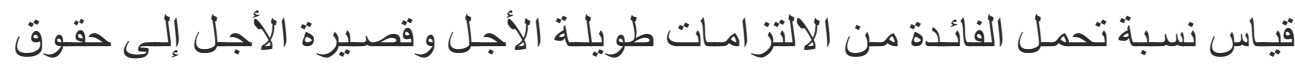
الملكية)(Gostkowska \& Drzewicka, 2014;kruk,2021) 


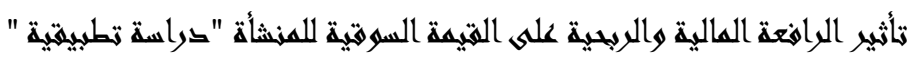

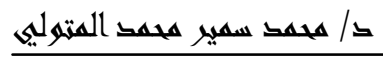

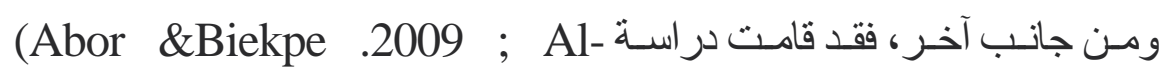

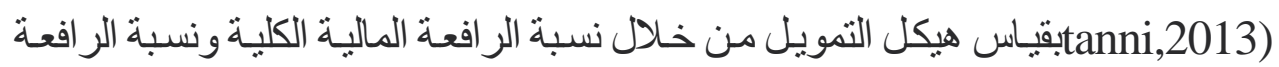

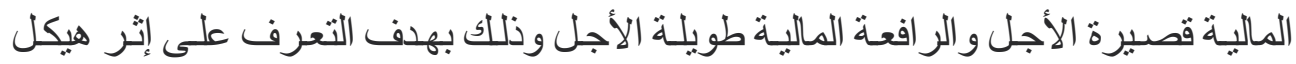

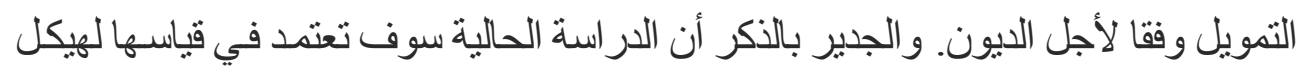

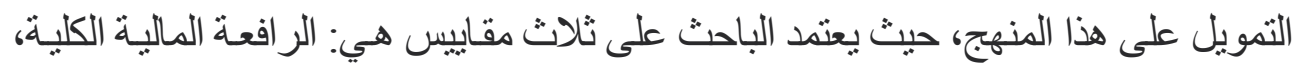

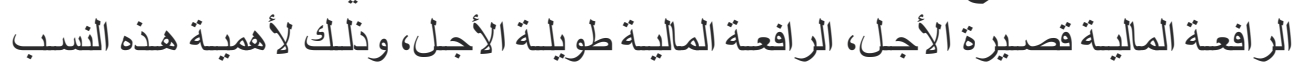

وتأثير ها على قيمة المنشأة (Alipour et al,2015)

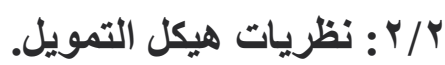

شهدت النظرية المالية الحديثة تطور اً بفضل العـالمين موديجلياني ميلر إذ مئر

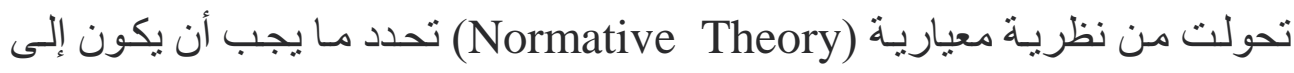
نظرية إيجابية (Positive Theory) تسعي إلى تفسير السلوك التمويلي للمنشـأة في

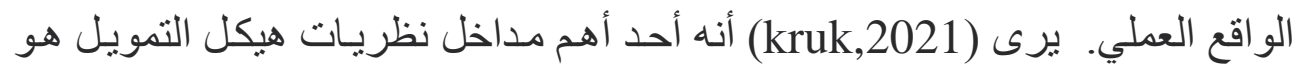
النظر إلى سوق تنافسي تام الكفاءة Perfect Market أو غير تام للكفاءة Market الافتر اضات التي تقوم عليها لا تعكس الو اقع الاقتصـادي.

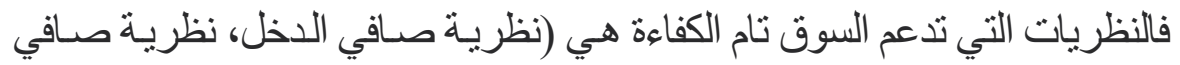

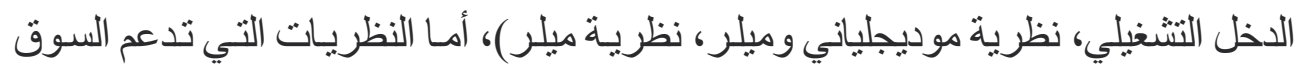

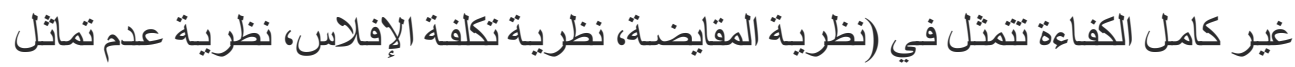

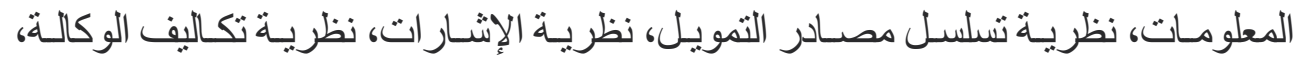
نظرية المنافسة لسيطرة الثركات، نظرية الموقف في السوق للمنتجات و عو امل الإنتاج ) .

وقد أشـار كلا من (kruk,2021; Dulinec , 2015) إلى أن النظريـات الرئيسة لهيكل التمويل هي: 


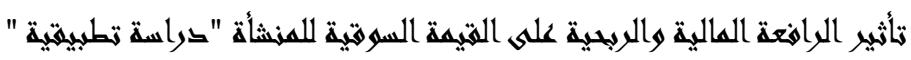
ك/ محمد سمير هحمت المتروليى

\section{The Trade-off Theory نظرية المقايضة \\ The Pecking Order Theory نظرية الالتقاط التدريجية \\ The Signaling Theory نظرية الإشار الات}

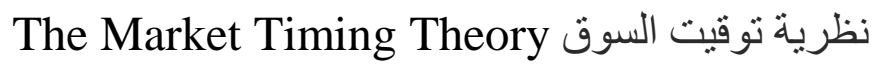

وتعتبر در اسـة "موديجلياني وميلر " من الدر اسـات الرائدة في العلاقة بين هيكل

التمويل وتكلفة رأس المال وقيمة المنشأة. و التي توصلت دئت إلى أن حياديـة تأثير تركيبـة هيكل

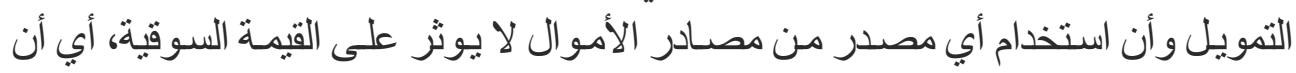

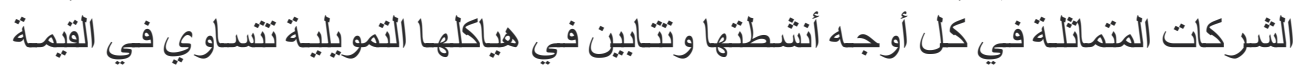

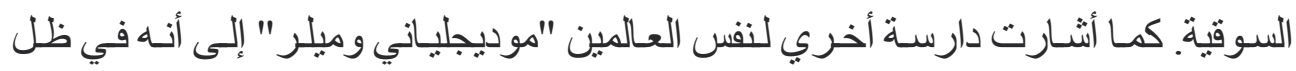

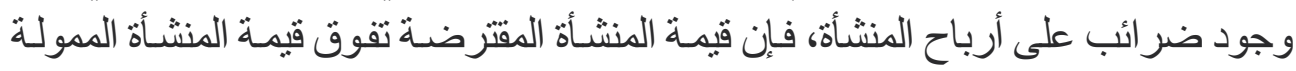
بالكامل من أمو ال الملكية بمقدار القيمة الحالية للوفر الضرئية فئي.

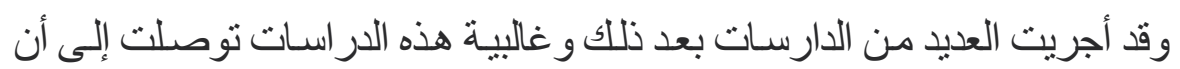

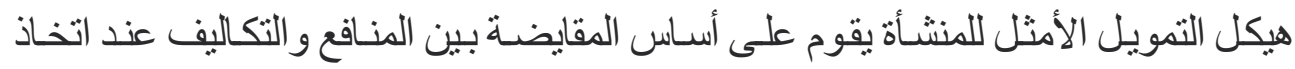

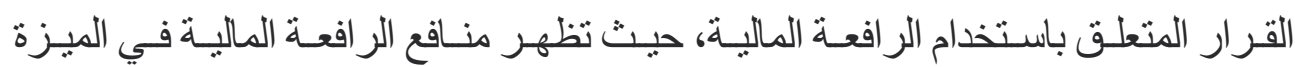

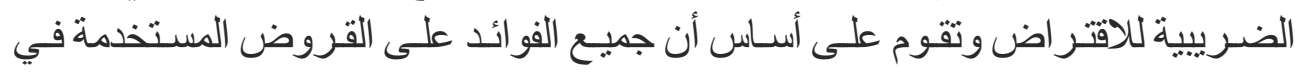

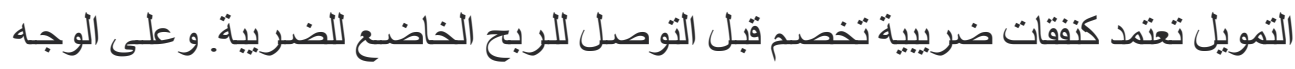

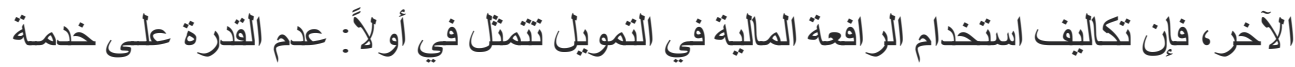

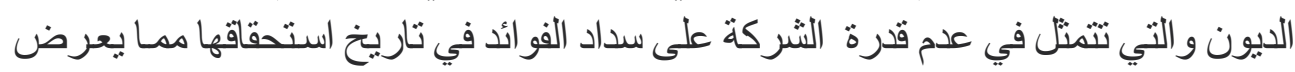

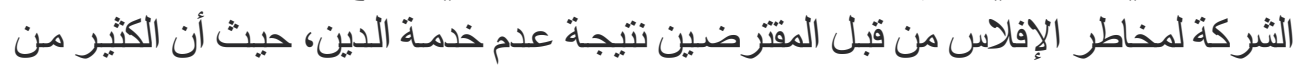

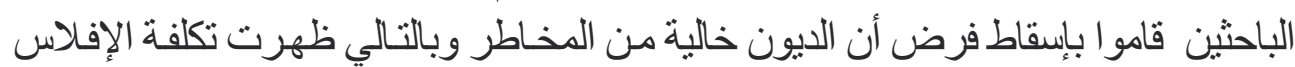
كأثر سلبي للاقتر اض وبذللك تمت صياغة نظريـة المقايضـة (Trade - Off theory)

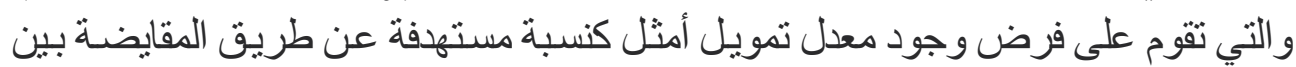

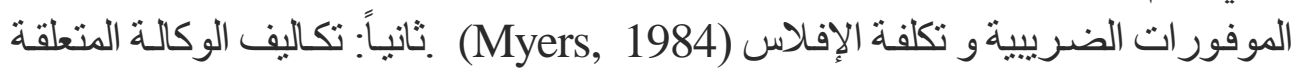

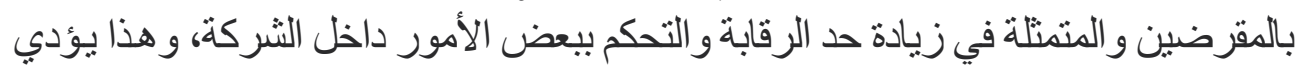

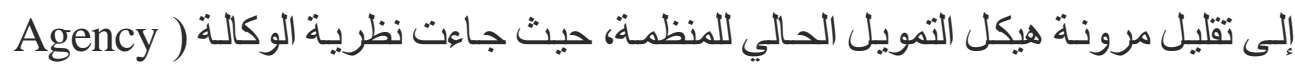




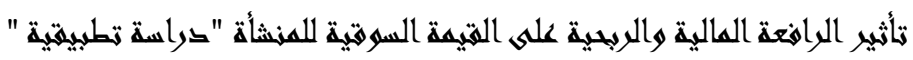

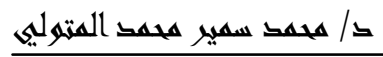

(Theory يقترح) (Jensen \& Meckling ,1976) تكلفة وكالة الديون، وأن هذه التكلفة تلعب دوراً

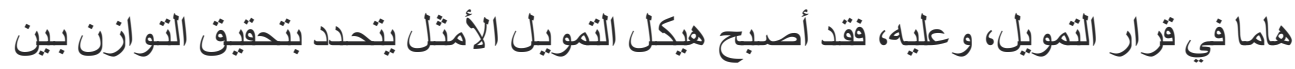

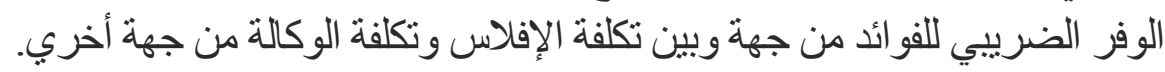

The Pecking ( بعد ذلك ظهرت نظرية الالتقاط التدريجي لمصادر التمويل

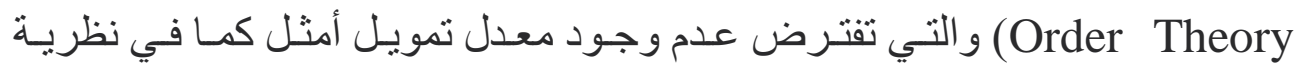

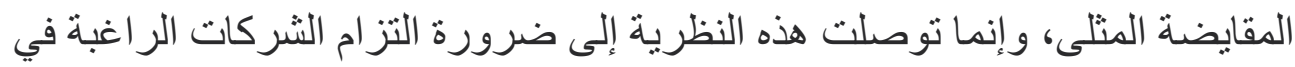

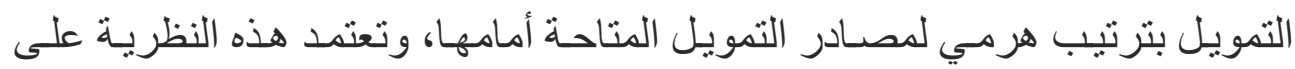

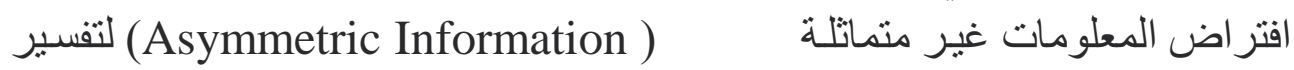

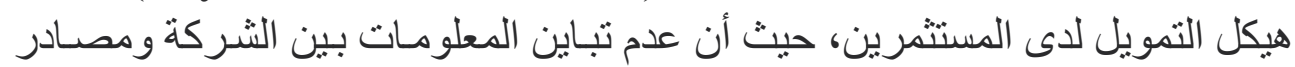
التمويل يؤدى إلى اختلاف في تكاليف التمويل، الأمر الذي يدفع المديرين إلى الـى تفضيل

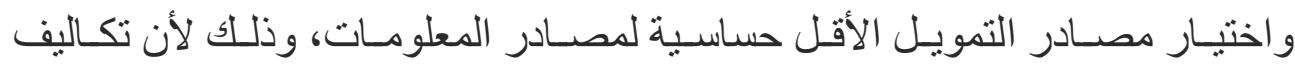

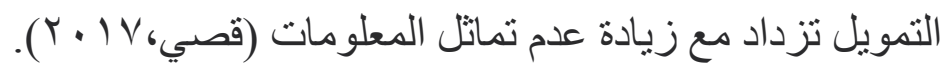

تستند نظريـة الإشـارة (Signaling Theory) على افتر اض أن المعلومـات التي يتلقاها كل طرف ليست هي نفسها. بمعنى آخر ، ترتبط نظرية الإشارة بعدم تماثلى

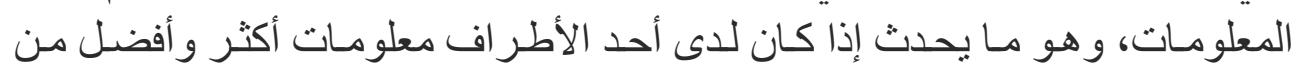

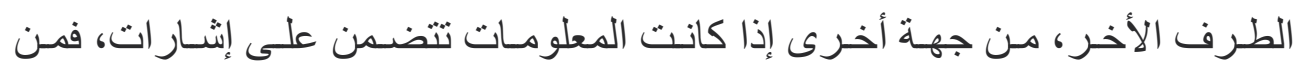

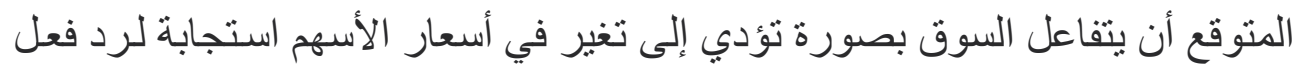

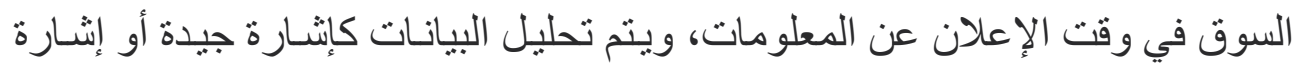

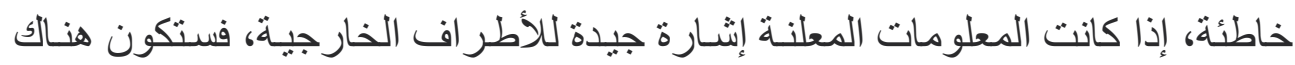
زيادة في أسعار الأسهم (Mahdaleta et al.,2016).

وفيما يتعلق بنظرية توقيت السوق (The Market Timing Theory) نجد أن هذه النظرية تعتمد على در اسة (Baker\&Wurgler,2002) التي أشارث إلى أنه

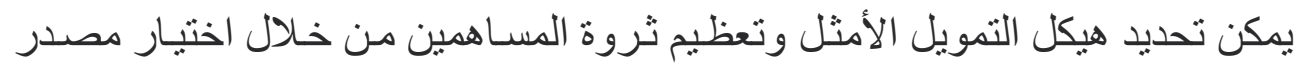




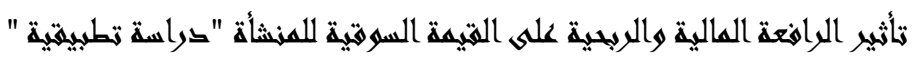

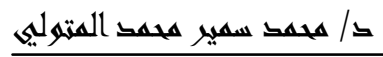

التمويل المناسب الذي يتفق مع توقيت الحاجة إلى التمويل، كمـا توصلت تلك الدر اسـة

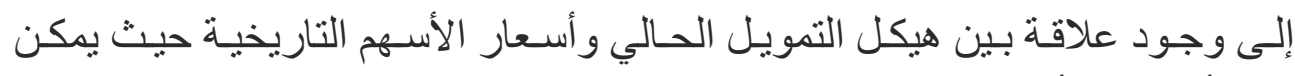

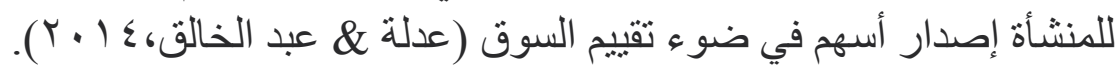

r/r ب قيمة المنشأة وعلاقتها بهيكل التمويل.

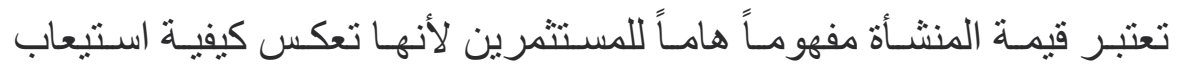

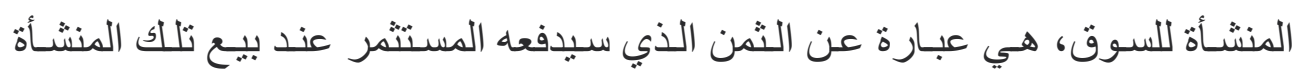
(Wira,2021). حيث أن تعظيم القيمة السوقية لشركة بالتبعية يؤدي إلى تعظيم ثروة

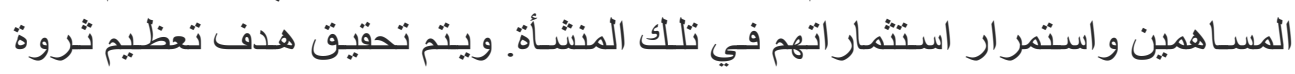

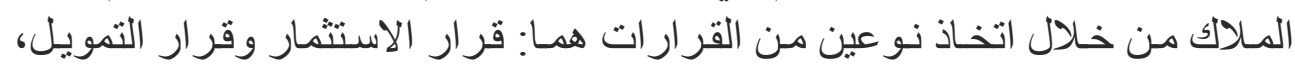

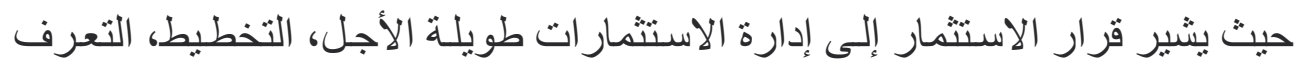

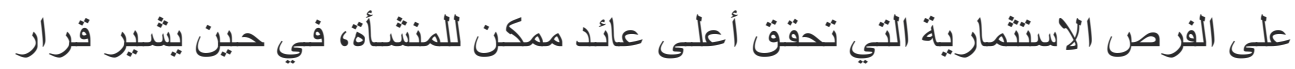

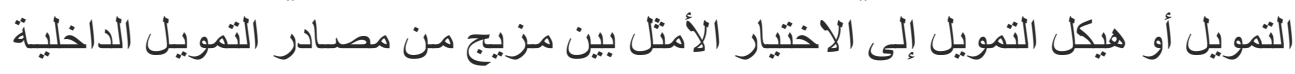

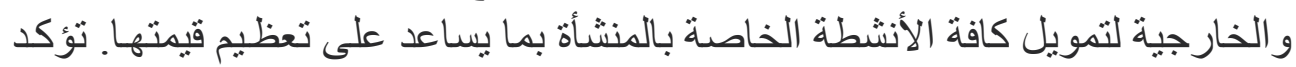

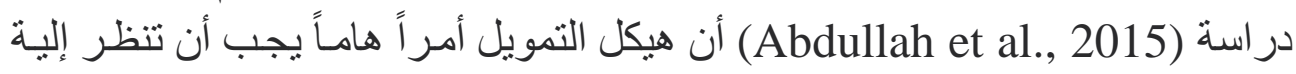

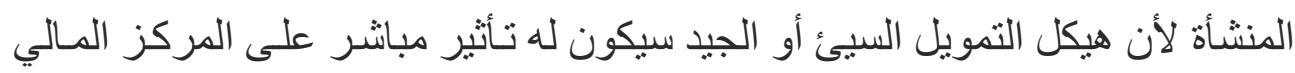
للمنشأة مما سيؤثر في النهاية على قيمة المنشأة (Khan et al., 2013). نظر اً لأهمية قيمة المنشأة فقد قامت العديد من الدر اسـات بمحاولة تحسين دقة تقدير

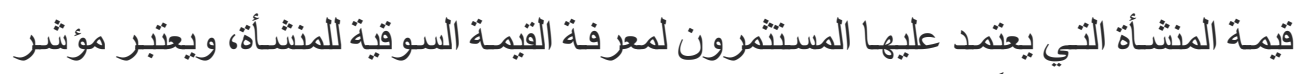

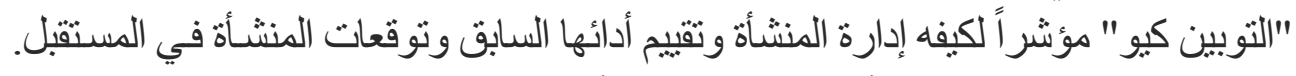
يرى (Putu et al. 2014) أن قياس قيمة المنشأة من خلال قائمة المركز المـالي بالاعتمـاد

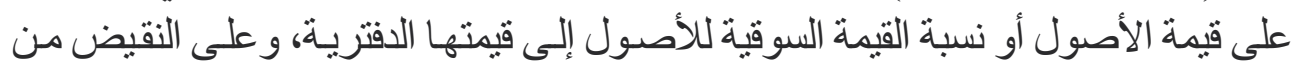
ذللك، ققد قام (Maksum et al,2018; Mathanike et al.,2015;Mohohlo,2013) بتقدير قيمـة المنشأة بالاعتمـاد على قائمـة الدخل من خـلال الأربـاح، المبيعات و غير هـا من

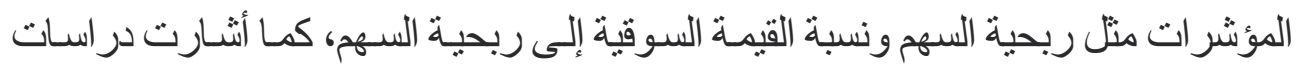




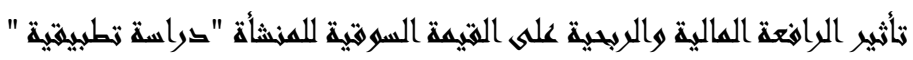
ك/ همبت سمير هحمد المتوليى

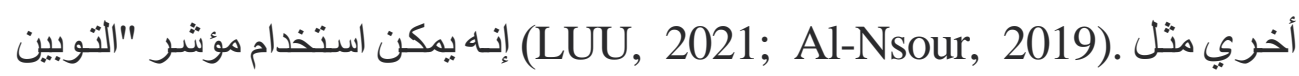

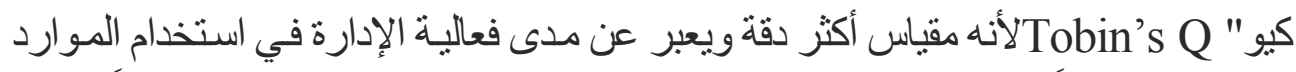

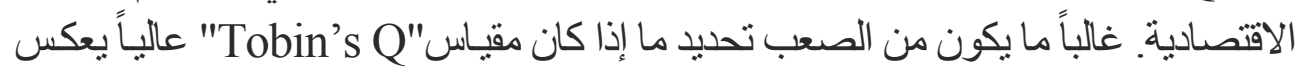

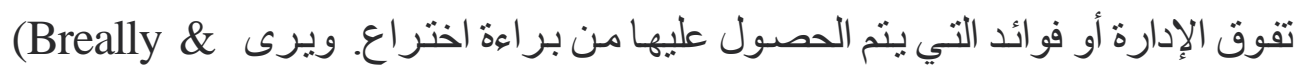

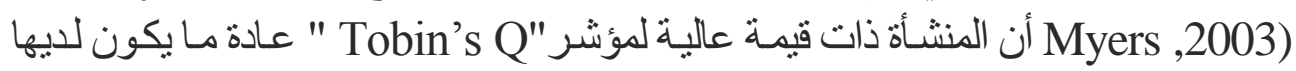

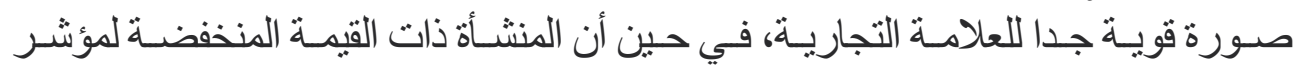
في الغالب ما تكون صغيرة أو تو اجه منافسة محدودة.

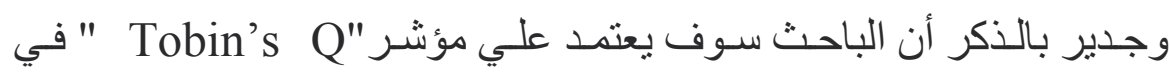

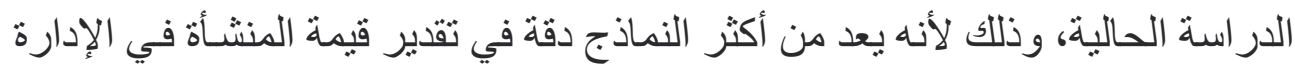

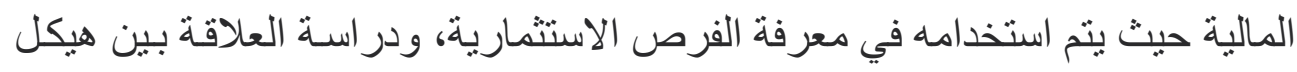

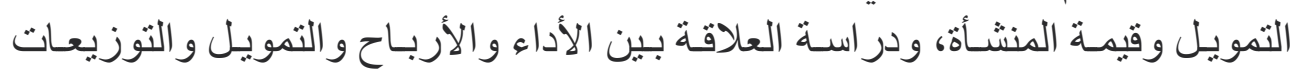

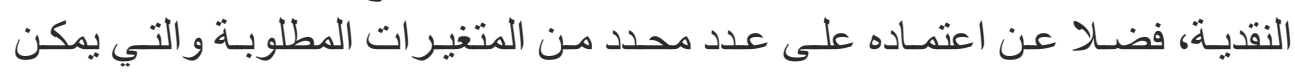

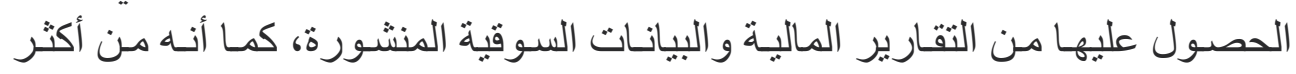
النماذج قبو لاً لسهولة تقدير قيمة المنشأة وتفسير هالئان (Ibrahim et al 2020).

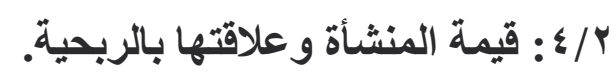

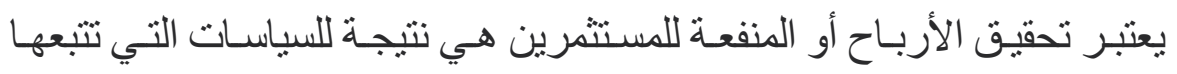

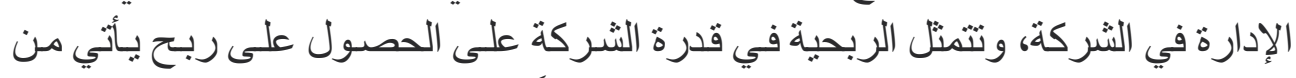

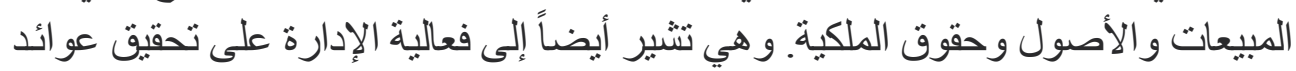

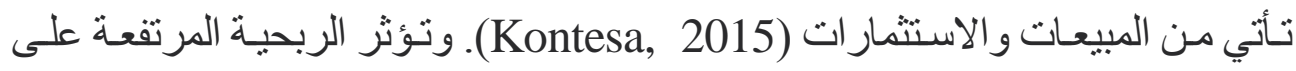

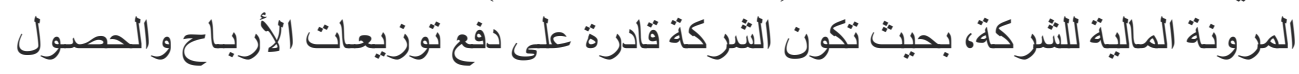

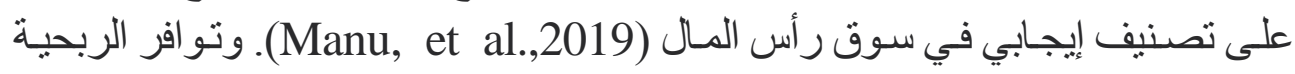

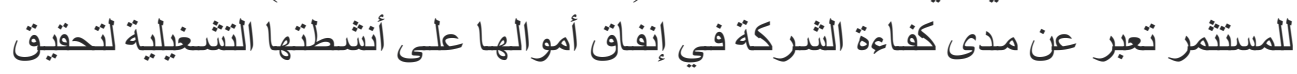

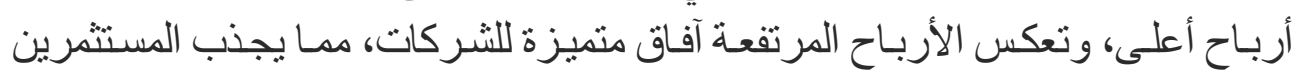

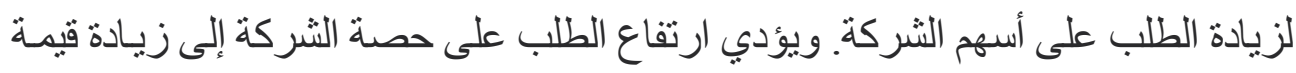




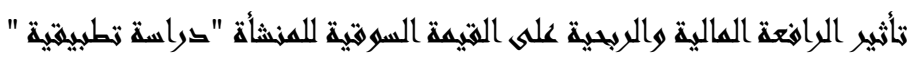

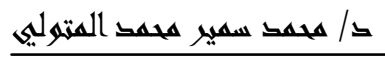

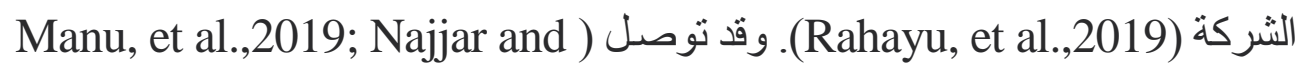
(Al-Najjar, 2017; Kontesa,2015) إلى أن اللربحية تأثير إيجابي على قيمة الثركة.

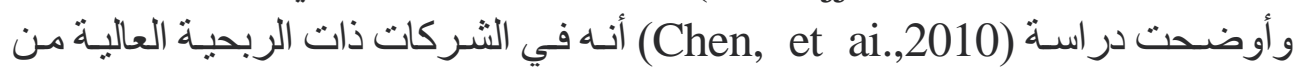
المرجح أن يكون لديها قيم أعلى.

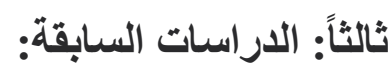

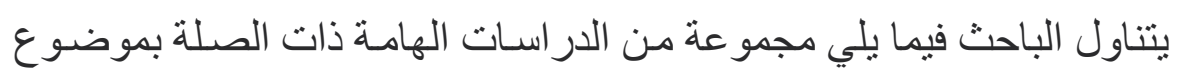
البحث، حيث يتم عرض هذه الدراسات على الني النحو التالي:

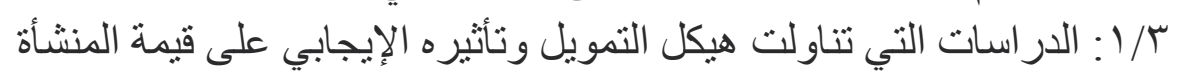

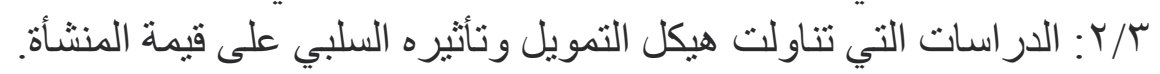

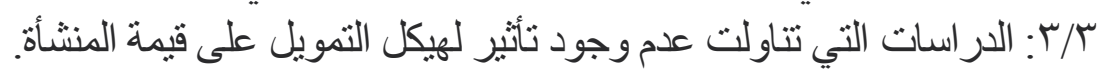

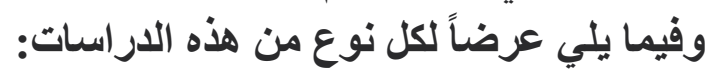

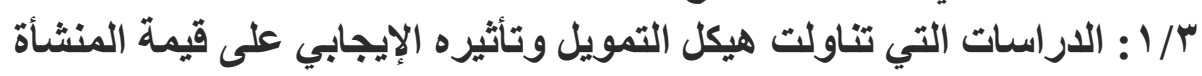

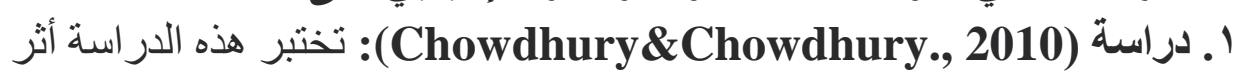

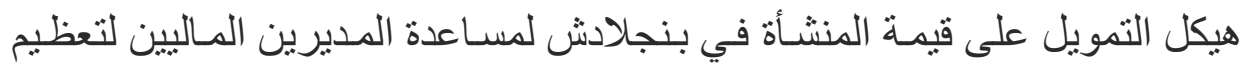

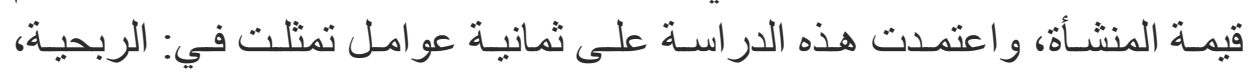

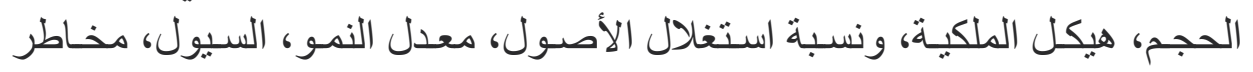

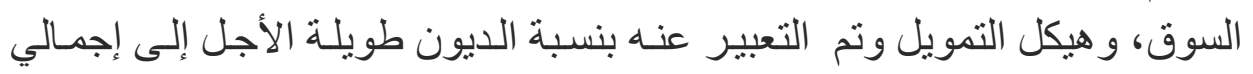

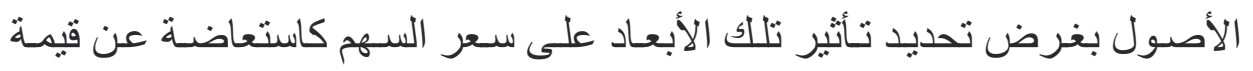

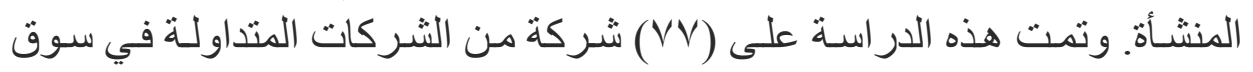

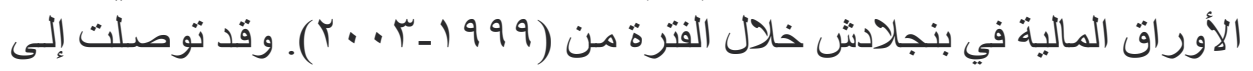

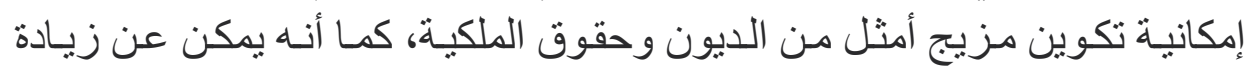

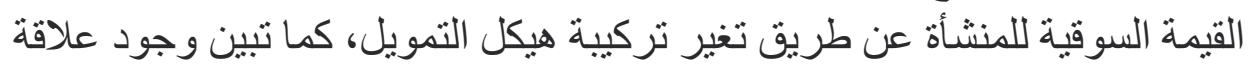

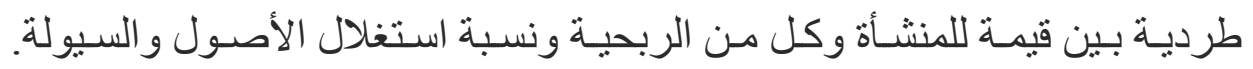

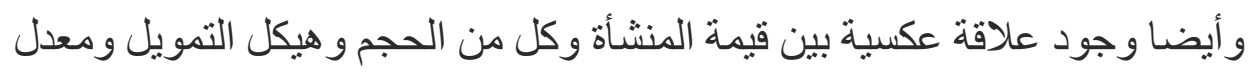
النمو و هيكل الملكية. 


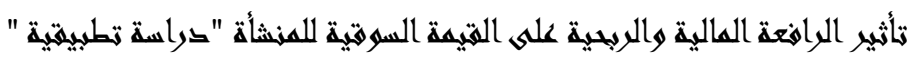

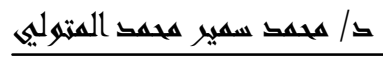

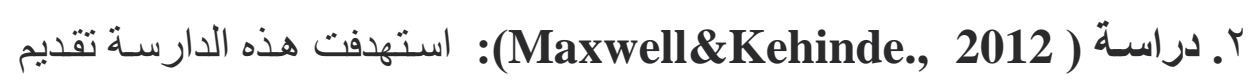

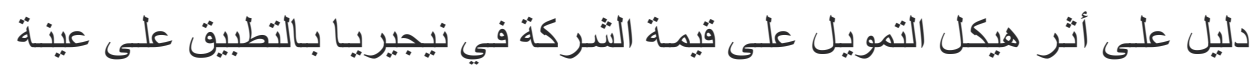

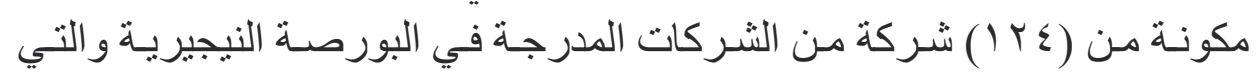

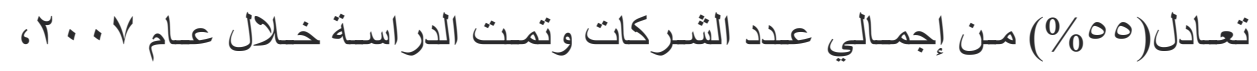

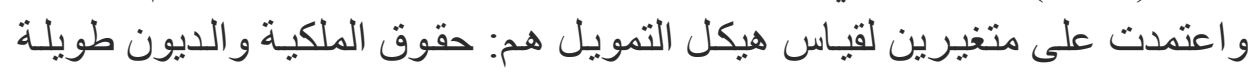

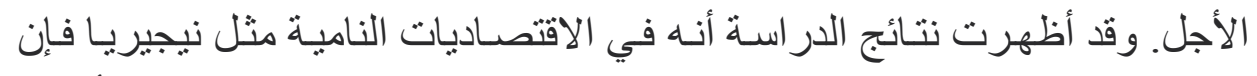

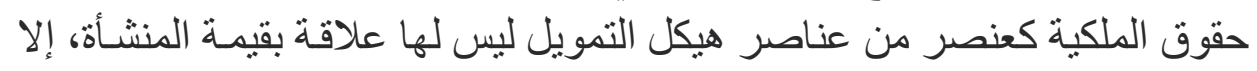
أن الديون طويلة الأجل تعتبر من المحددات الأساسية لقيمة المنشأة.

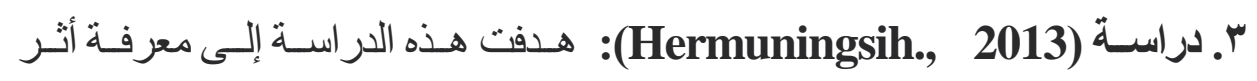

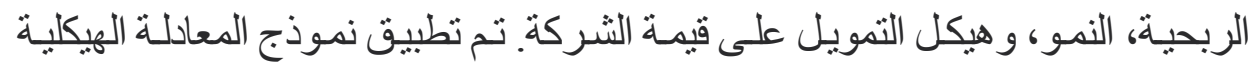

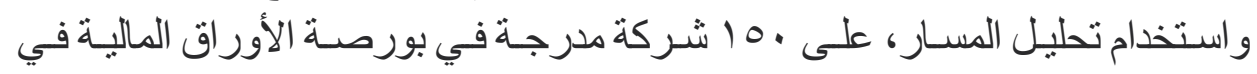

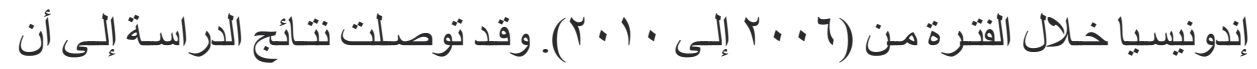

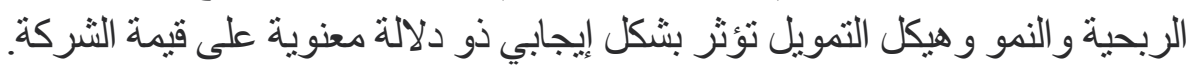

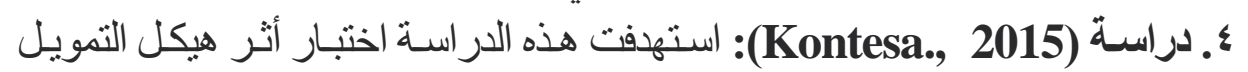

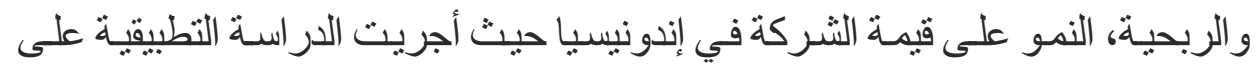

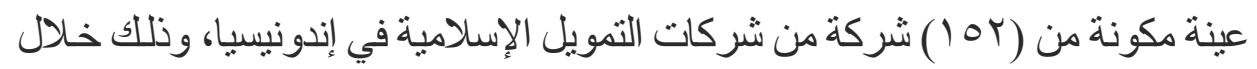

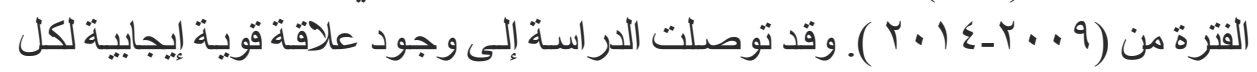
من هيكل التمويل والنمو و الربحية على قيمة الثركة.

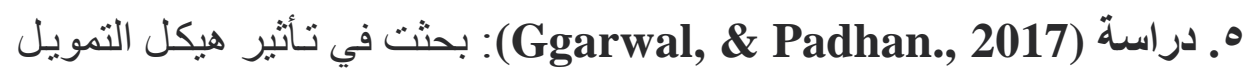

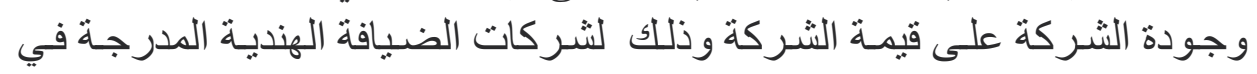

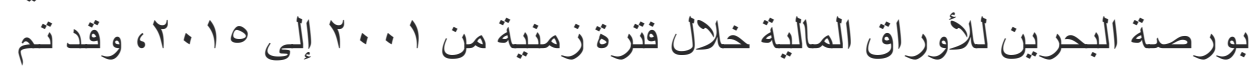

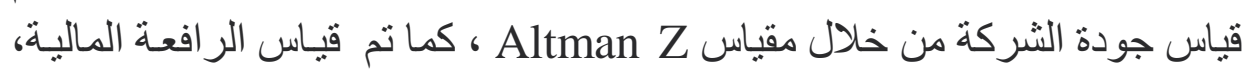

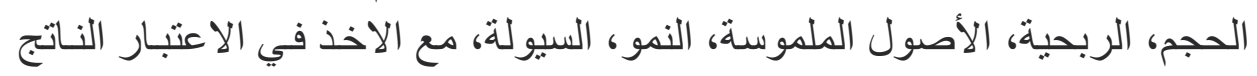

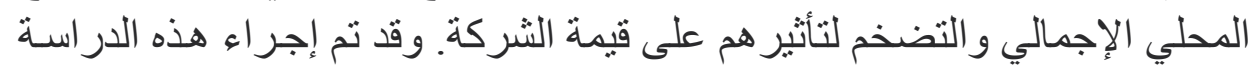

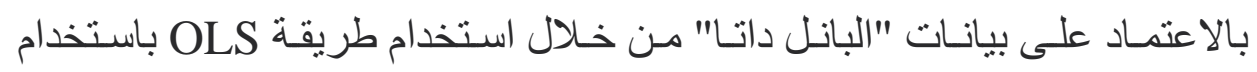




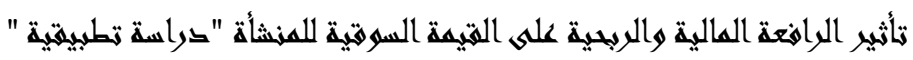

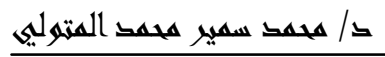

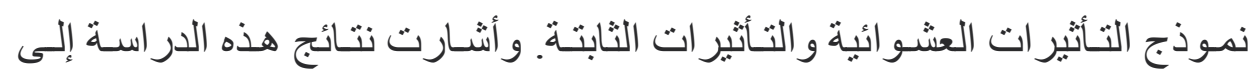

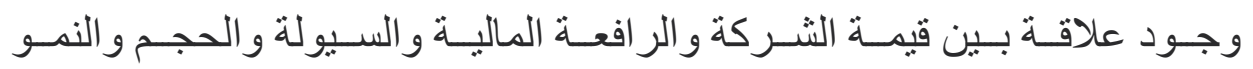
الاقتصادي، وأثبت الدر اسة أن نظرية "موديجلياني وميلر " حول هيكل التمويل لا لا تنطبق على قطاع الضيافة الهندي، ومن الأهمية العملية لمالكي الفنادق إعادة تقيهيم هيكل التمويل لتحسين جودة الثركة و الأداء السوقي للشركة التهن.

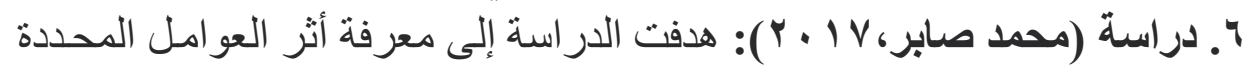

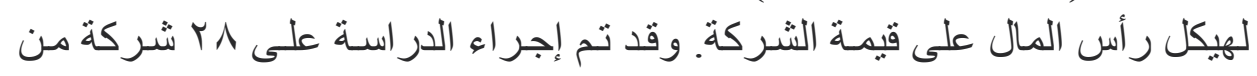

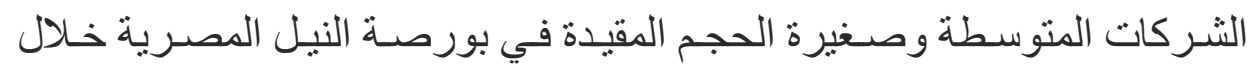

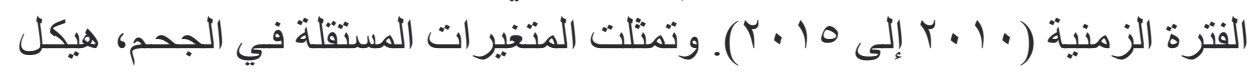

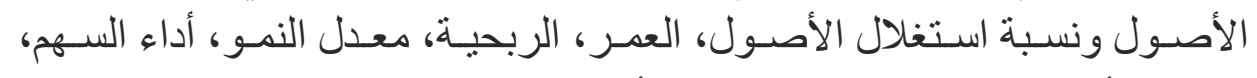

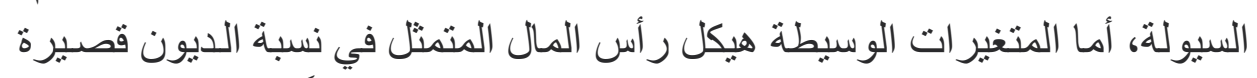

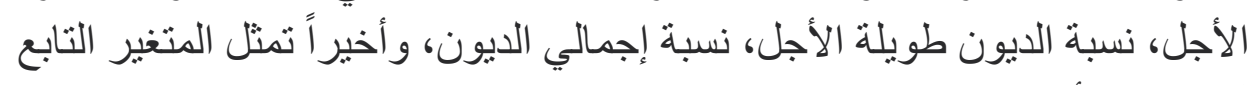

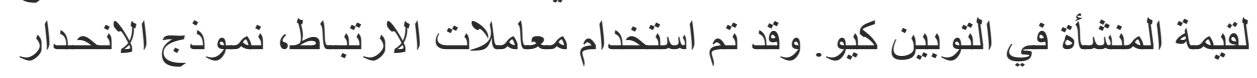

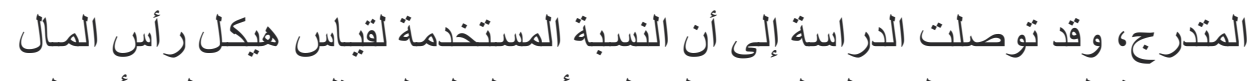

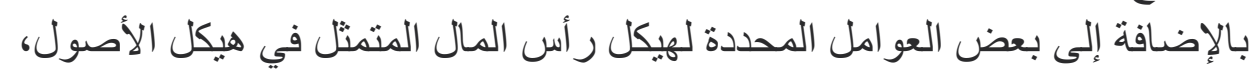
السيولة، نسبة استغلال الأصول توثر على قيمة الشركة. V. دراسـة (Maksum \& irojuzilam., 2018): هدفت إلى معرفة مـا إذا كانت

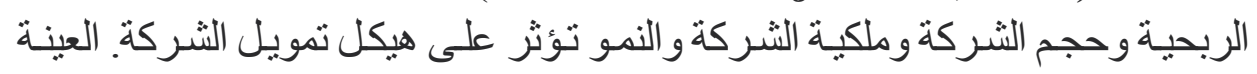

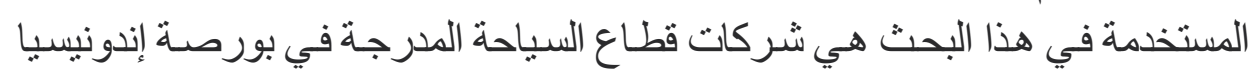

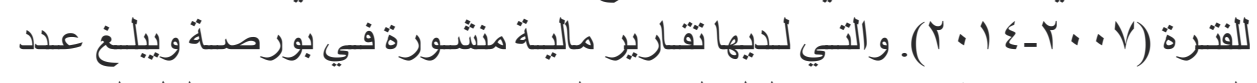

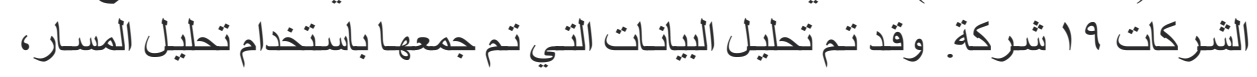

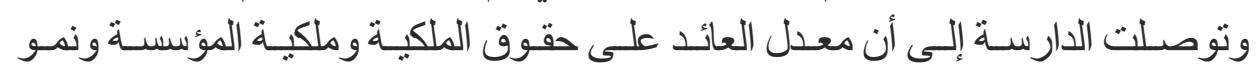

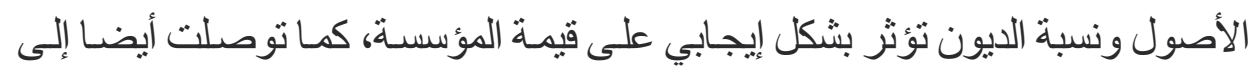
أن حجم الثركة، يتبعه انخفاض في قيمة الثركة. 


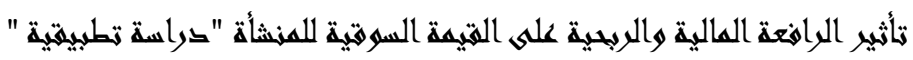

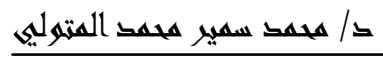

ب/Y آلاراسات التي تناولت هيكل التمويل وتأثثره السلبي على قيمة المنشأة. ا ـ دراسة : استهدفت معرفة أثر هيكل ر أس المـال

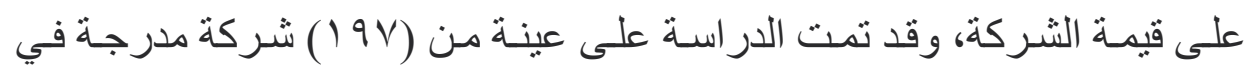

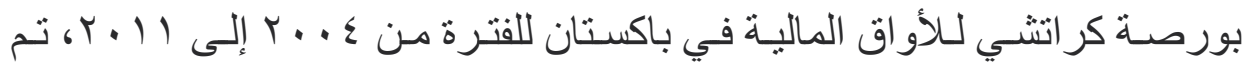

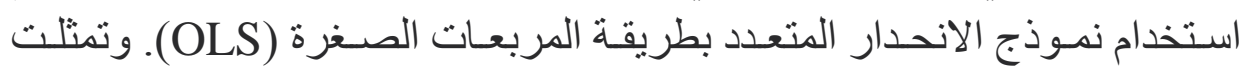

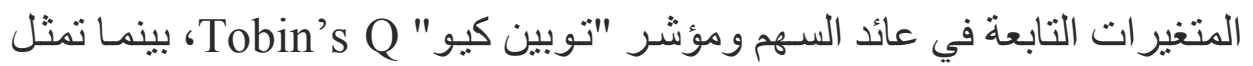

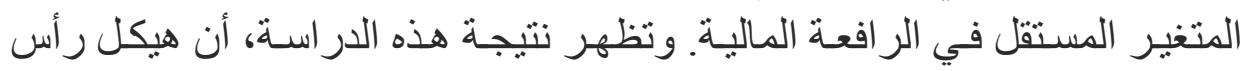

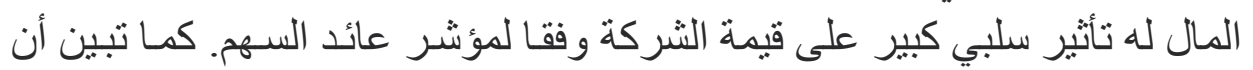

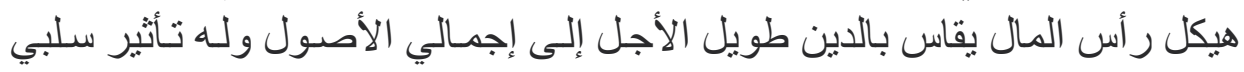

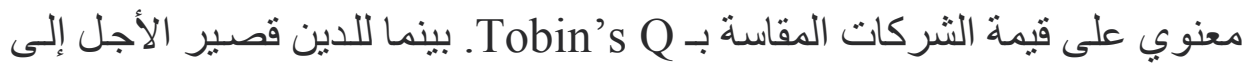

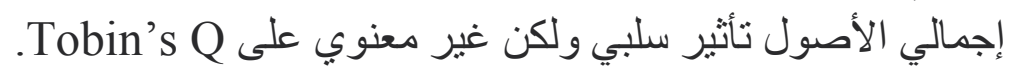
Y. دراسة (Ishari, 2016): هدفت الدر اسة إلى التعرف على على مدئ مدى تأثير الر افعـة

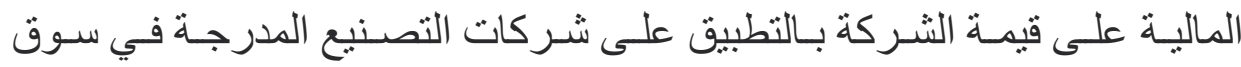

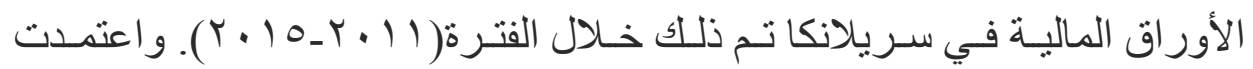

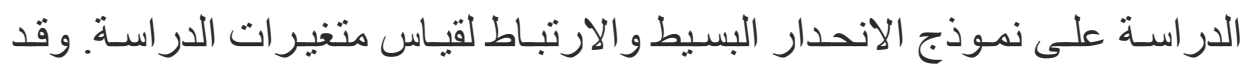

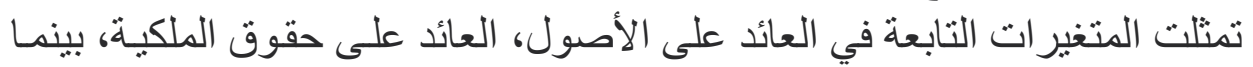

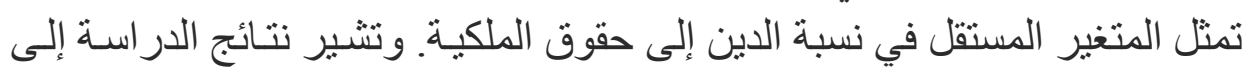

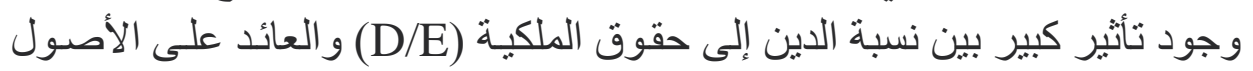

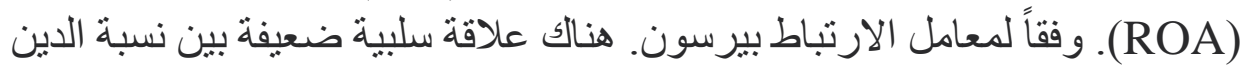

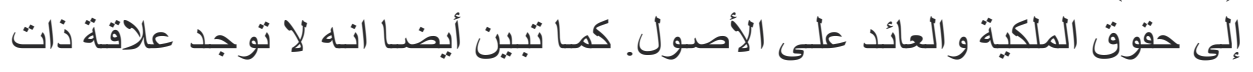
دلالة إحصائية بين نسبة الدين إلى حقوق الملكية و العائد على حقوق الملكية.

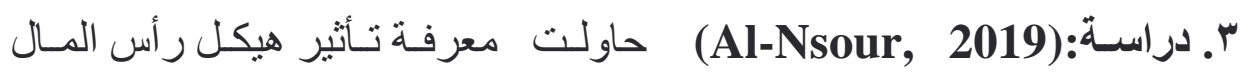

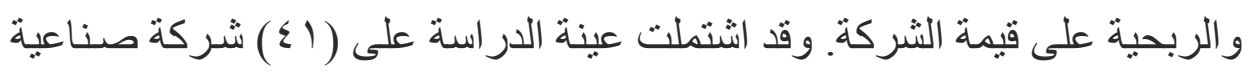

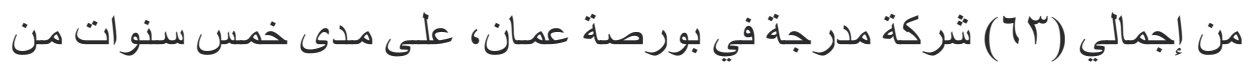

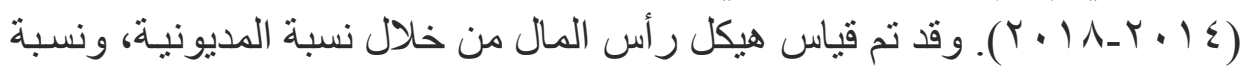




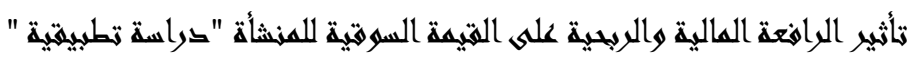

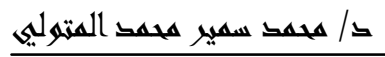

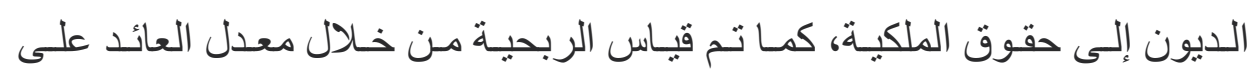

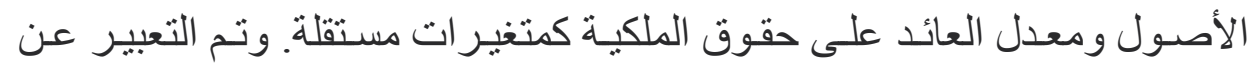
المتغير تابع بـ "Tobin's Q"، و استخدام أسلوب الانحدار المتعدد لتحليل تأثنير

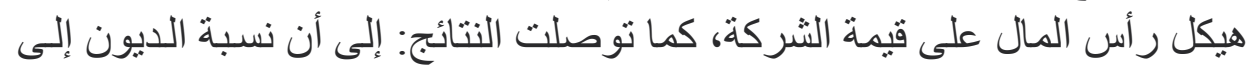

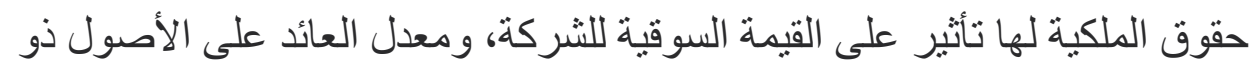

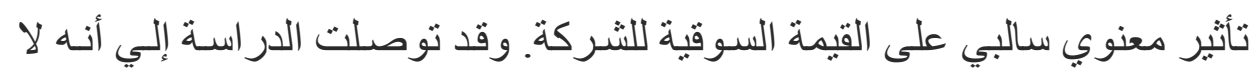
يوجد تأثثر بين جميع المتغير ات المستقلة على قيمة الثركة.

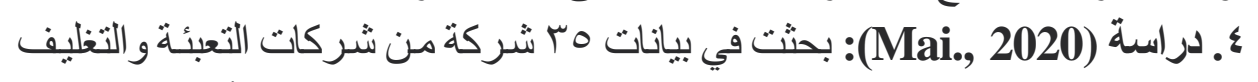

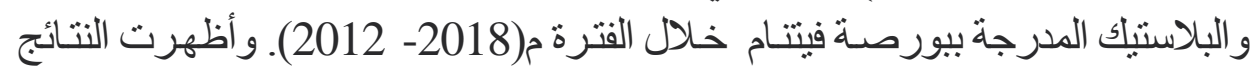

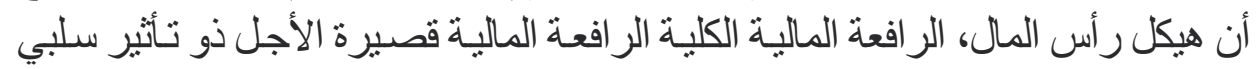

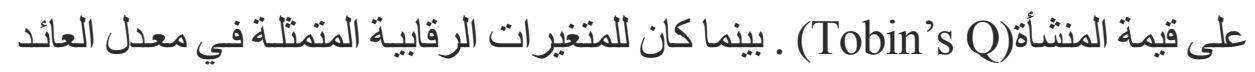
على الأصول وحجم الأصول له تأثنير إيجابي على قيمة الثركة. •. دراسـة (Dang \&Do., 2021): هدفت الدر اسـة إلى معرفة مـا إذا كان هيكل فئل

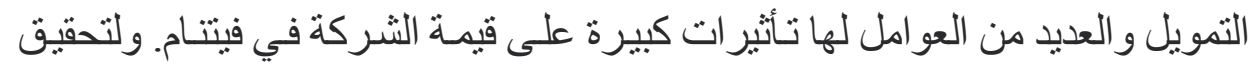

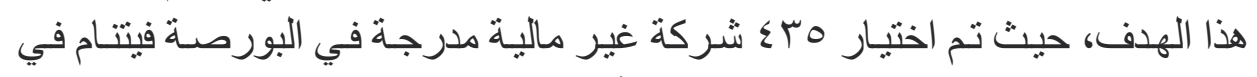

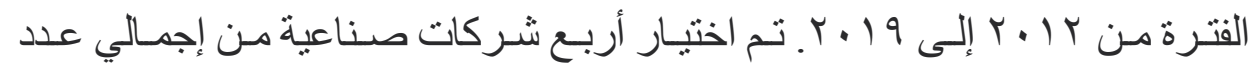

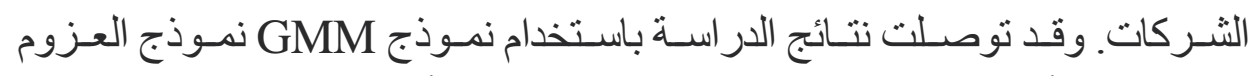

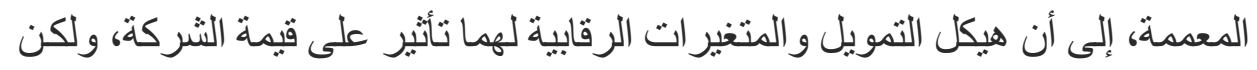

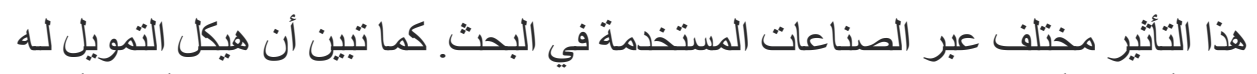

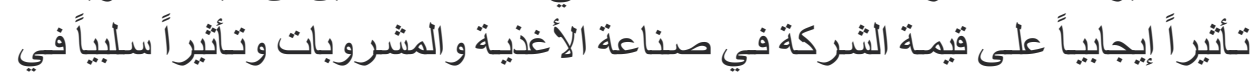

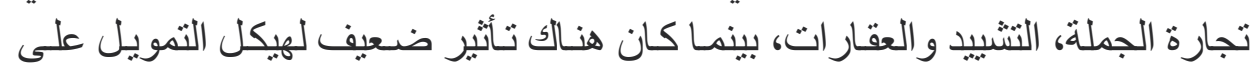
الصناعات الأخرى بصرف النظر عن حجم الثركة. 


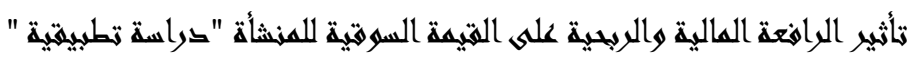

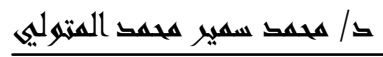

ب/ ب/ الدراسات التي تناولت عدم وجود تأثثر لهيكل التمويل على قيمة المنشأة.

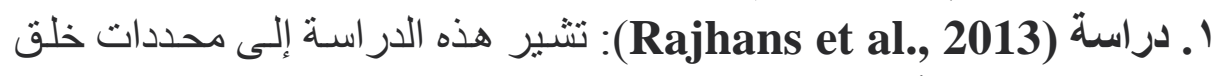
القيمة للشركات على أساس القيمة السوقية في هذه الصناعات المختلفة. ومن خـلال

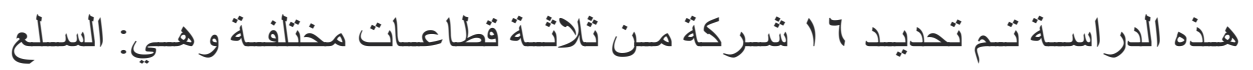

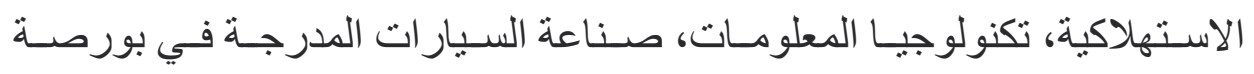

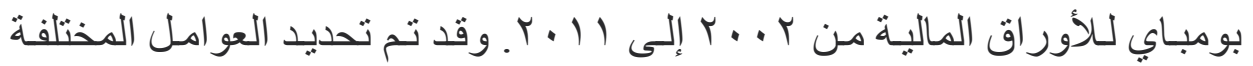

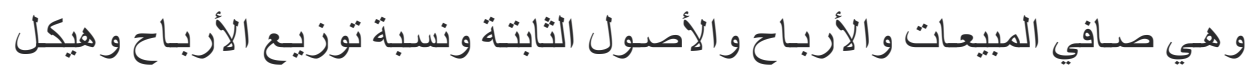

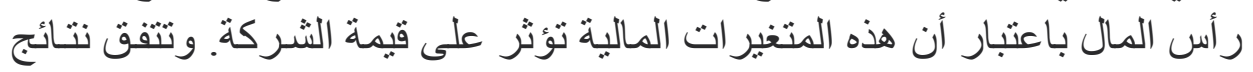

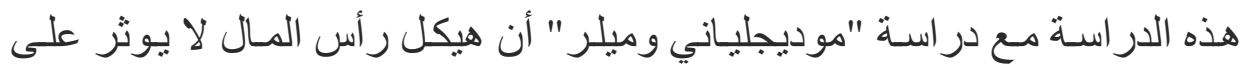

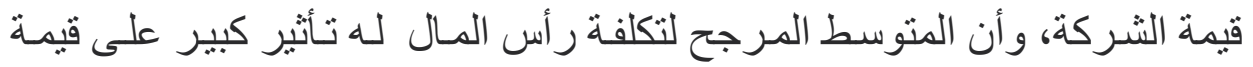
الثركة بالإضـافة إلى العو امل الأخرى التي تم تحديدها في النموذج المقترح حوهي الأصول الثابتة و صافي المبيعات و الأرباح. r. دراسـة (Asiri et al., 2014): اسـتهدفت قيـاس وتفسير الر افعـة الماليـة

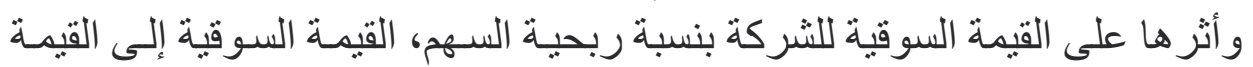

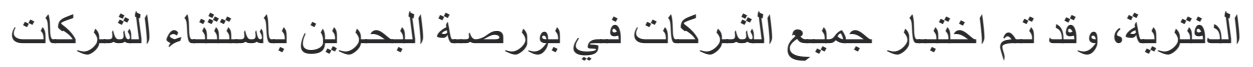

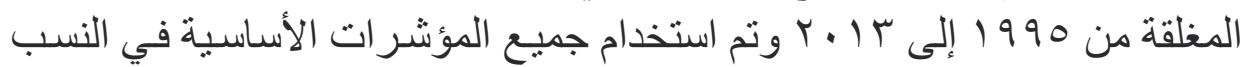

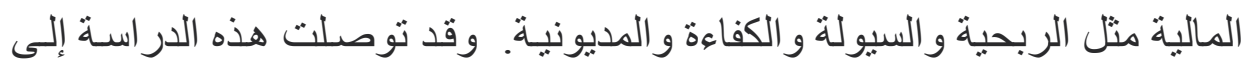

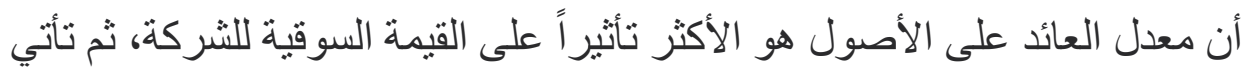

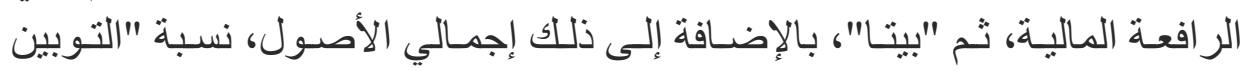

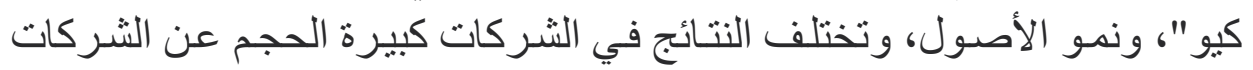

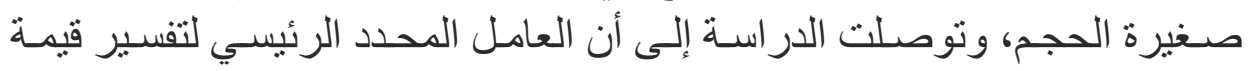
الثركة هو معدل العائد على الأصول. بـ دراسة (Pandya, 2016): استهدفت قياس تأثير الر افعـة المالية على القيمـة

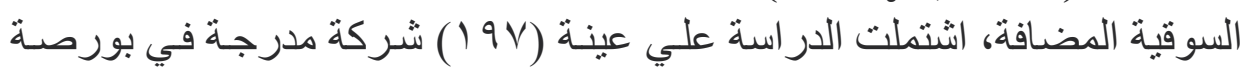

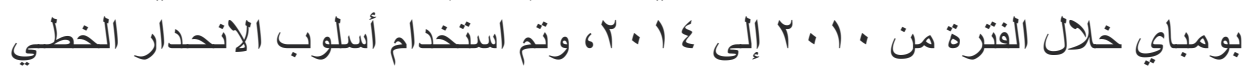




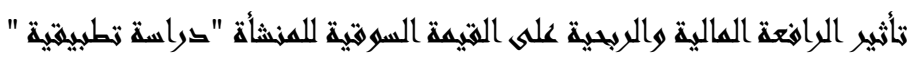

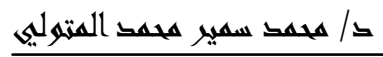

البسيط و المتعدد، كما استخدمت الدر اسة نسبة حقوق الملكية ونسبة تغطية الفو ائد،

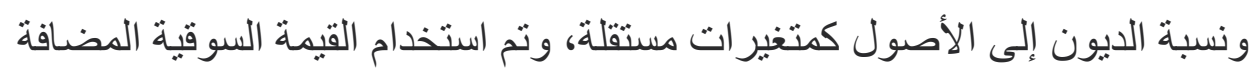

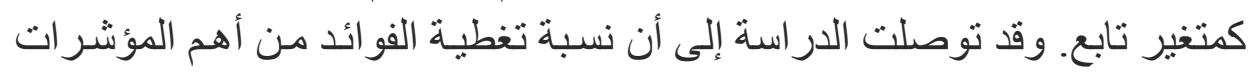
تأثثيراً على القيمة السوقية المضافة، وأن نسبة حقوق الملكية ونسب الدين ليس لهما

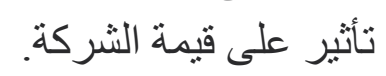
تعليق الباحث على الاراسات السابقة وتحديد الفجوة البحثية:

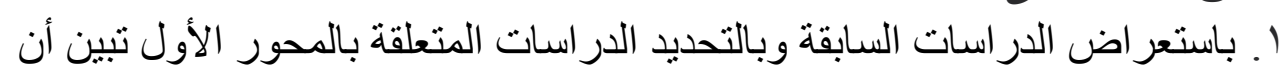

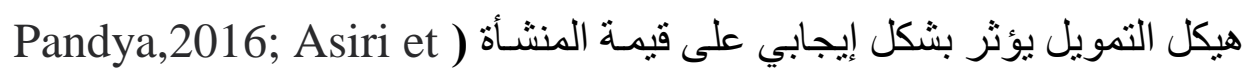
(al., 2014; Rajhans et al, 2013; Modigliani \&Miller,1958 . قد توصـلت در اسـات المحسور الثـاني أن هنـالك تـأثثر أ سـلبياً على قيمـة المنشـأة \& Padhan., 2017; ‘Maksum \& irojuzilam., 2018; ggarwal) ، Ishari. , 2016; Kontesa. , 2015; Maxwell\&Kehinde. , 2012) في حين أن در اسات المحور الثالث لم تبين وجود تأثثر لهيكل التمويل على قيمـة

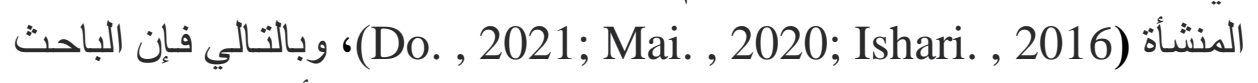
سوف يقوم بالكثف عن العلاقة بين الر افعة المالية وقيمة المنشأة.

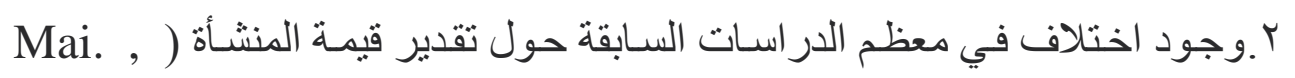

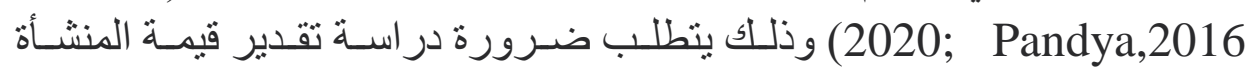
و التعرف على الطريقة الأكثر دقة لتقدير قيمة المنشأة.

". بوجود اختلاف بين معظم الدارسات السـابقة حول مقاييس هيكل التمويل ) Al-Nsour,

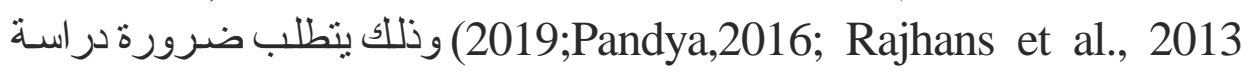
مقاييس هيكل التمويل والتعرف على المقاييس الأكثر ملائمـة للتعبير عن هيكل التمويل في الثركات محل الدر اسة وخاصة في البيئة المصرية.

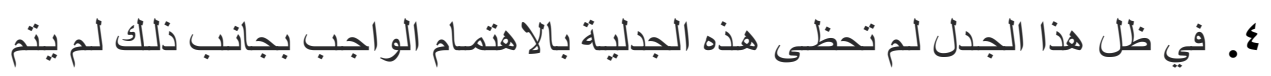
اختبار تلك الجدلية في الدر اسات العربية على شركات السياحة والترفيـه في البيئة 


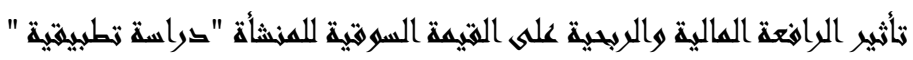

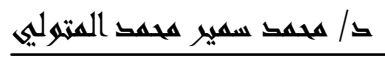

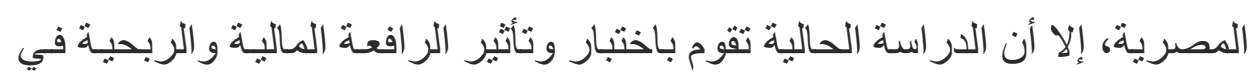

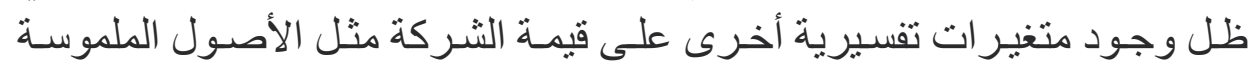
و الحجم و المخاطرة.

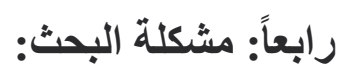

تحاول العديد من الدراسات التي تم عرضهـ التها الإجابـة على سؤ الين أساسبين:

السؤال ( (1): هل يمكن للشركة زيادة القيمة السوقية للأسهم العادية عن طريق الإجية استبدال

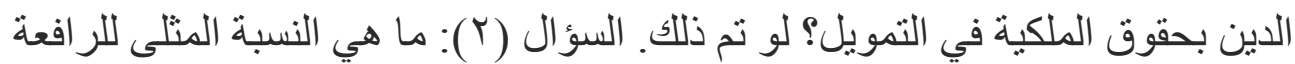

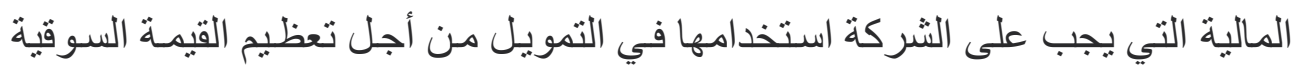
للشركة؟، وبناءاً على ذلك كيف تختار الشركة نسبة الدين وحقوق الملكية في هيكل

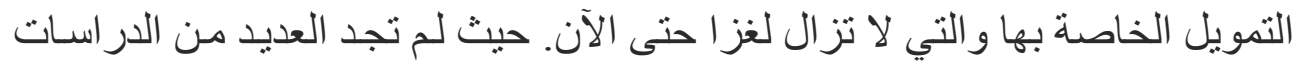

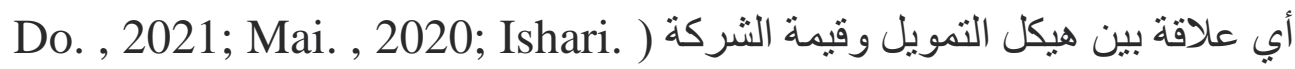
2016 ,)، بالإضافة إلى أن العديد من الأبحاث الأخرى تئيد أنه أن هنالك علاقة بين هيكل

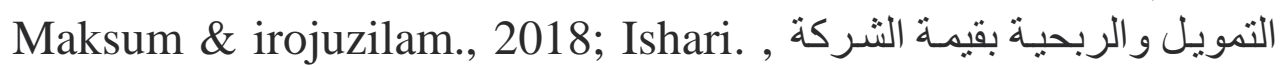
(2016) (Asiri et al., 2014)، بكلمات أخري، برتبط هيكل التمويـل بقيمـة الثـركة

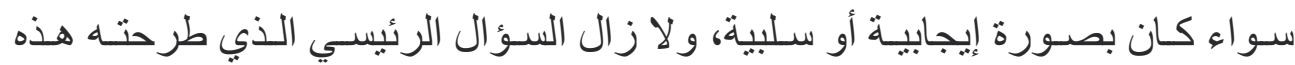

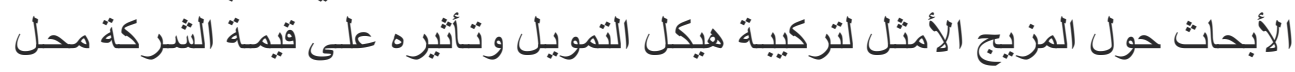

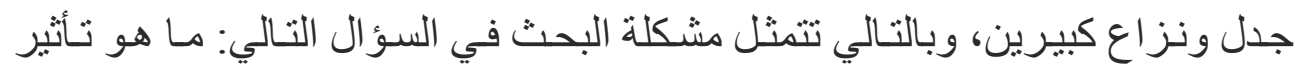

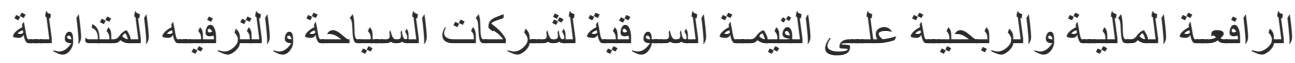

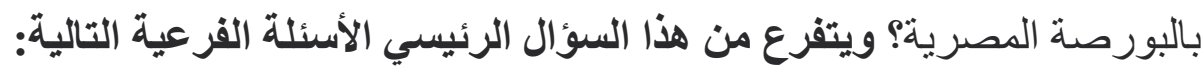

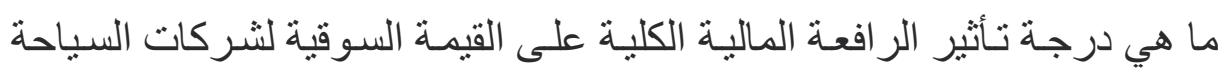

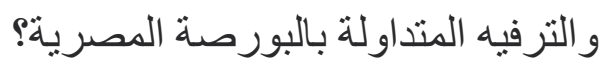

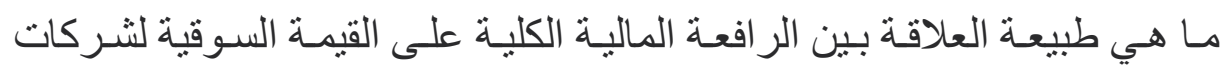

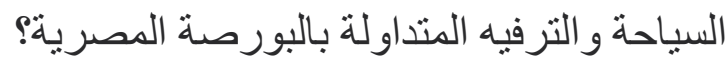




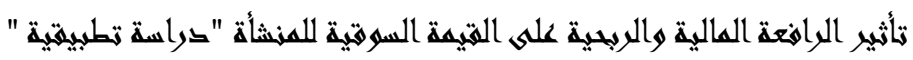

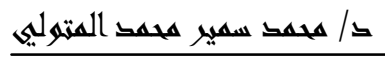

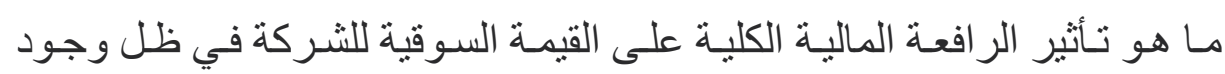

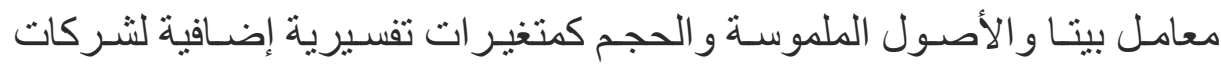

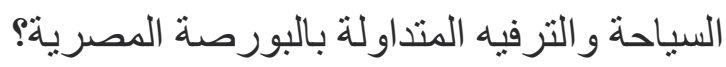

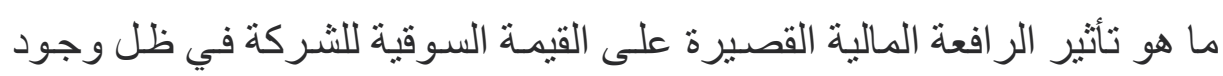

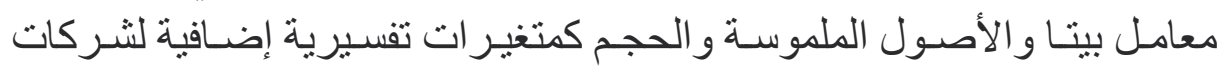

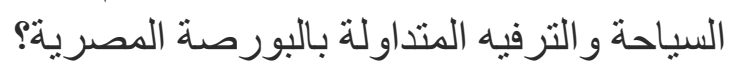

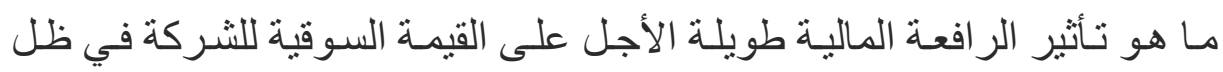

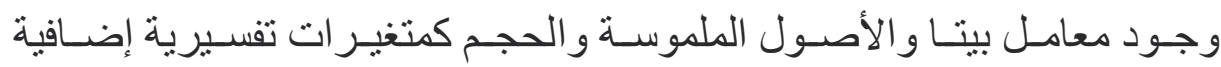

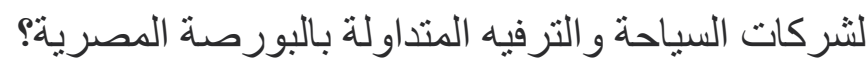

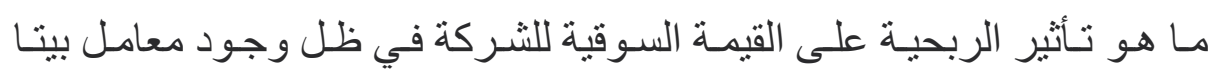

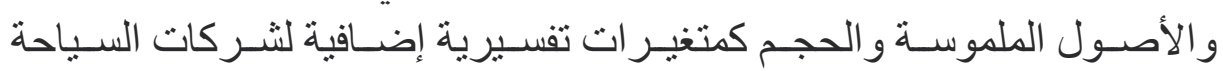
و الترفيه المتداولة بالبورصة المعبة المصرية؟

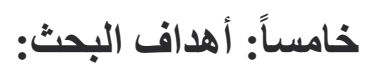
يمكن استعراض أهم أهداف البحث على الته التحو التالي:

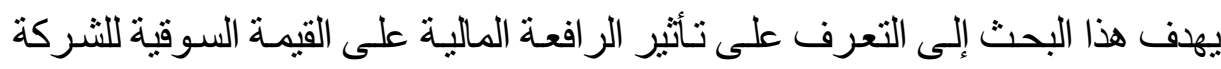
بالنسبة لشركات السياحة و الترفيه المتداولة بالبورصة المصرية

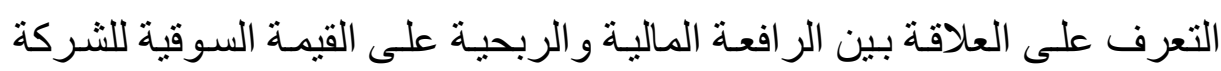

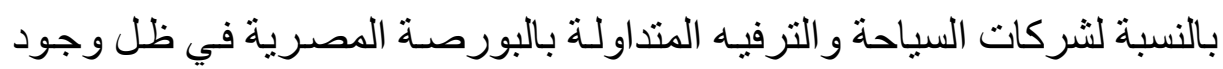

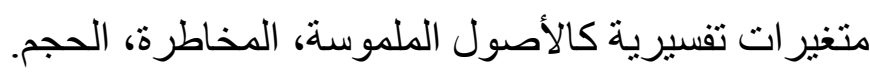

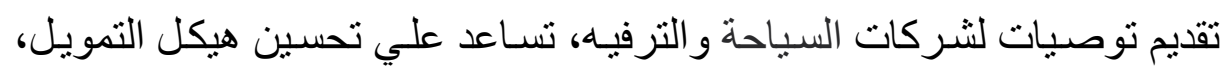
وزيادة الربحية مما ينعكس على تعظيم القيمة السوقية للشركة. سادساً: أهمية البحة الربة:

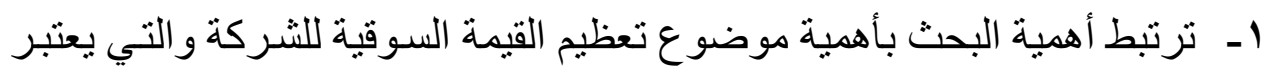

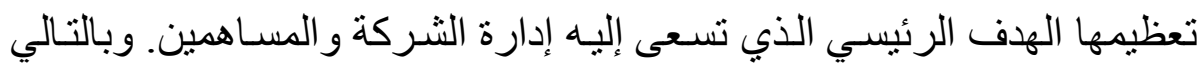

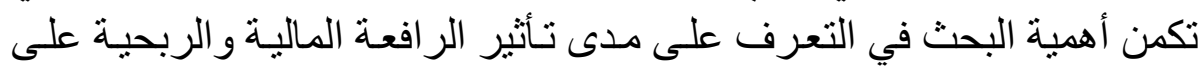




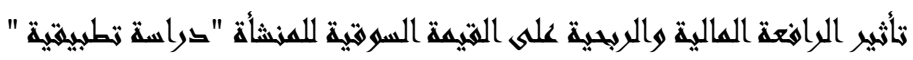

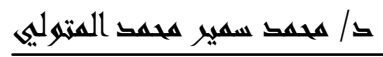

القيمة السوقية لشركات السياحة و الترفيه، وذلك لتمكين المديرين بصفة عامـة

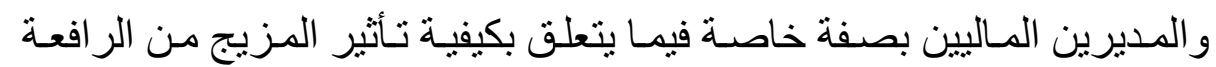

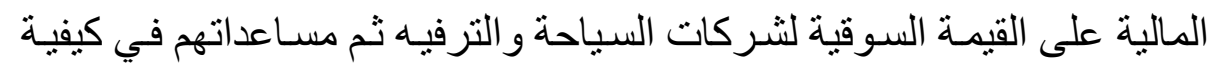

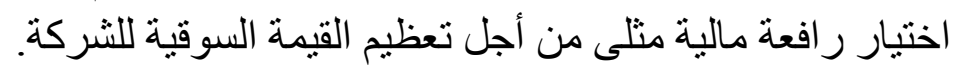

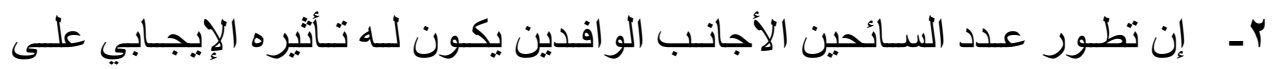

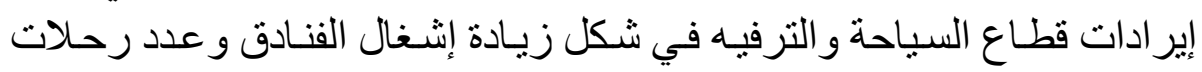

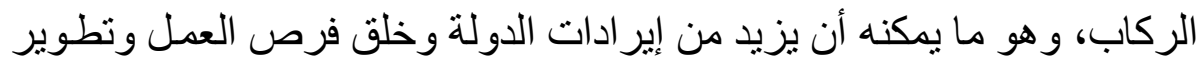

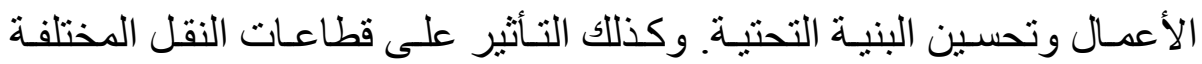

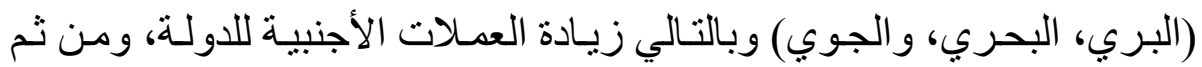
التأثير على قيمة شركات السياحة و الترفيه التي تستعين بالدين لزياديادة عو ائدها

.(Maksum \& Sirojuzilam., 2018)

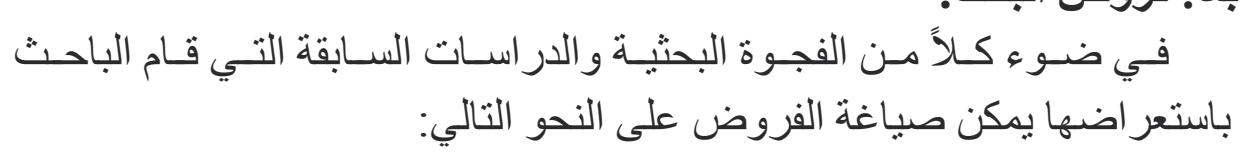
الفرض الأول: لا يوجد تأثير معنوي للر افعـة الماليـة الكليـة على القيمـة السـوقية

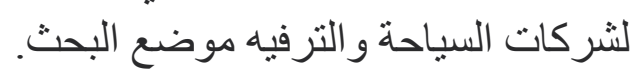

الفـرض الثاني: لا توجد علاقـة ذات دلالـة إحصــائية بـين الر افعـة الماليـة الكليـة و القيمة السوقية لشركات السياحة و الترفيه موضع البحثة.

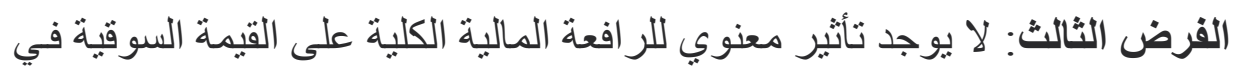

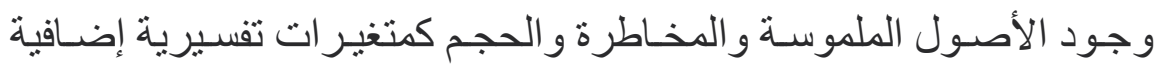

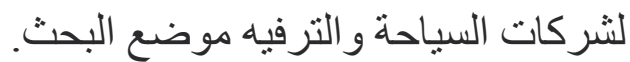

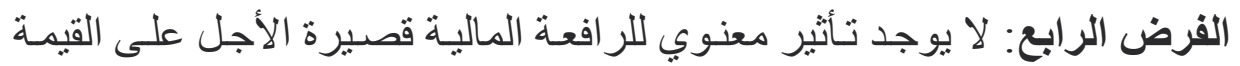

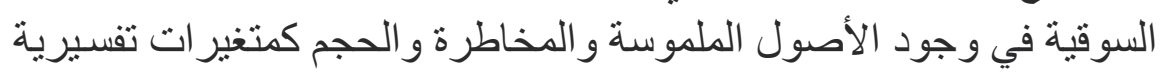
إضافية لثركات السياحة و الترفيه موضع البحث. البرد. 


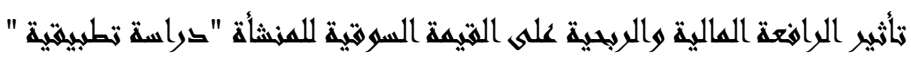
د/ هحمد سمير هحمد المترليه

الفرض الخامس: لا يوجد تأثنير معنوي للر افعـة الماليـة طويلـة الأجل على القيمـة

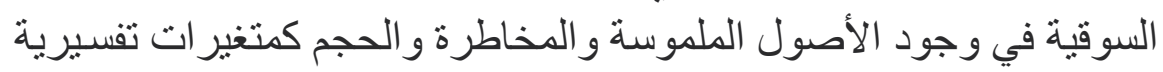
إضافية لشركات السياحة و الترفيه موضع الاصو البحث.

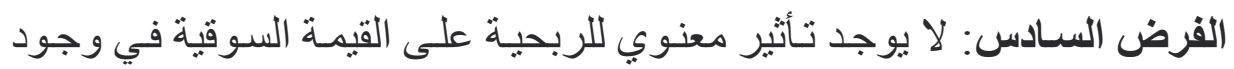
الأصول الملموسة و المخاطرة و الحجم كمتغير ات تفسيرية إضـافية لشـركات

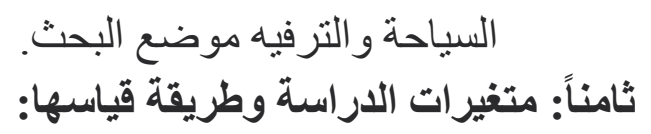

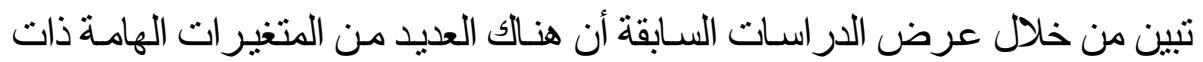

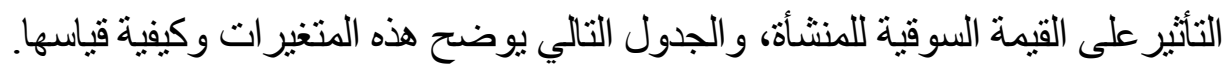

\begin{tabular}{|c|c|c|c|}
\hline المصدر & طريقة القياس & المتغير & رمز المتغير \\
\hline \multicolumn{4}{|c|}{ المتغيرات المستقلة In Depended Variables } \\
\hline \multirow{2}{*}{$\begin{array}{l}\text { (Antwi, et al.,2012; Ahmed Sheikh } \\
\text { and Wang., 2013; Asiri, et al.,2014; } \\
\text { Laz_ar., 2016; Rahman, et al .,2020) }\end{array}$} & إجمالي الديون/ إجمالي الاصول & الرافعة المالية الكلية & TFL \\
\hline & مربع الر افعة المالية الكلية & مربع الر افعة المالية & $\mathrm{TFL}^{2}$ \\
\hline $\begin{array}{l}\text { (Mateev,et al ., 2013; Handoo and } \\
\text { Sharma.,2014)( Rahman, et al } \\
.2020)\end{array}$ & الديون طويلة الأجل/ إجمالي الأصول & الرافعة المالية طويلة & LFL \\
\hline $\begin{array}{l}\text { (Mateev,et al ., 2013; Ezeoha., } \\
\text { 2008;Rahman, et al .,2020) }\end{array}$ & الديون قصيرة الأجل/إجمالي الاصول & الر افعة المالية قصيرة & SFL \\
\hline $\begin{array}{l}\text { (Cekrezi, 2013; Chandra, 2014; Al- } \\
\text { Nsour, O. J. 2019) }\end{array}$ & صافي الربح/حق الملكية & العائد على حق & ROE \\
\hline \multicolumn{4}{|c|}{ Control Variables المتغيرات الرقابية } \\
\hline $\begin{array}{l}\text { Ahmed et al .,2010: Alipour et al., } \\
\text { 2015) }\end{array}$ & صافي الأصول الثابتة/ الأصول التشغيلية & الاصول الملموسة & TANG \\
\hline $\begin{array}{l}\text { (Ahmed Sheikh and Wang, 2013; Al- } \\
\text { Nsour, O. J. 2019) }\end{array}$ & اللوغاريتم الطبيعي لإجمالي الأصول & 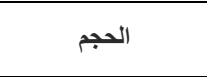 & SIZE \\
\hline ( Asiri، et al.,2014) & 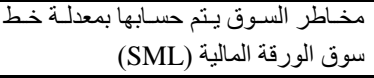 & المخاطرة (بيتا) & BETA \\
\hline \multicolumn{4}{|c|}{ المتغير التابع Depended Variable } \\
\hline $\begin{array}{l}\text { (Bae, et al.,2013;Wang, 2013; Asiri, } \\
\text { et al.,2014; Laz_ar,2016;Al Nsour, } \\
\text { O. J. 2019) }\end{array}$ & 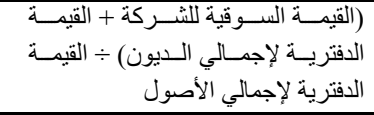 & قيمة السوقية للشركة & TQ \\
\hline
\end{tabular}




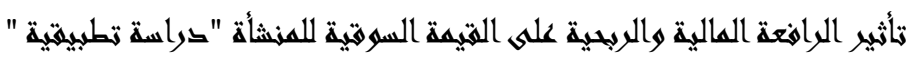
د/ هحمت سمير هحمد المترليه

\section{تاسعاً: منهج البحث.}

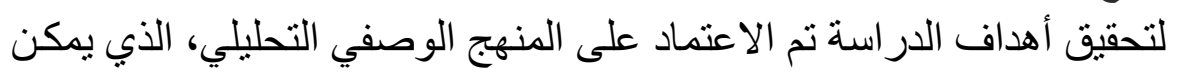

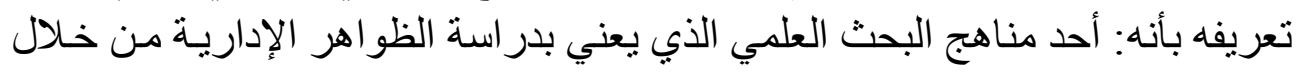

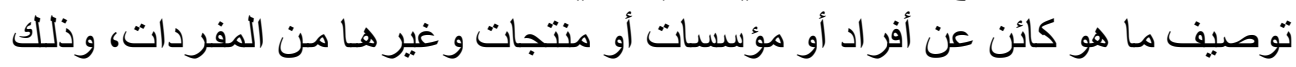

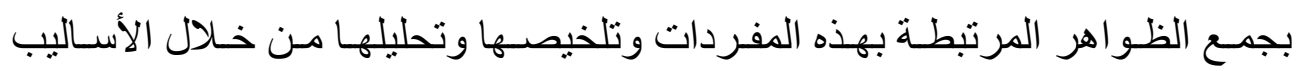

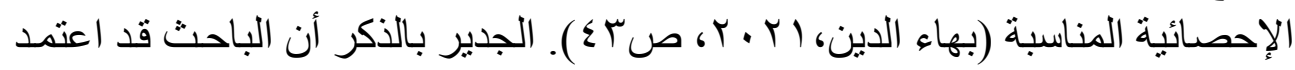

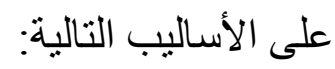
أ. البحث المكتبي: قام الباحث بالاطلاع على الكتب والدوريات والبحوث التي التي

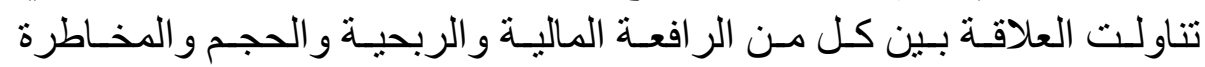

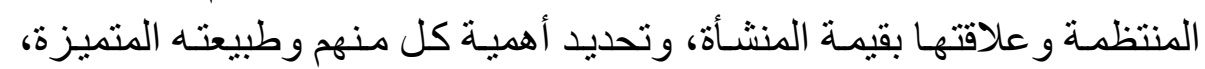

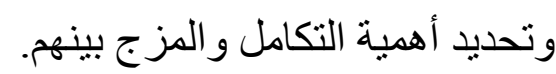
ب. البحث التطبيقي: قام الباحث باتخاذ قطاع السياحة و الترفيه كمجال تطبيقي للبحث،

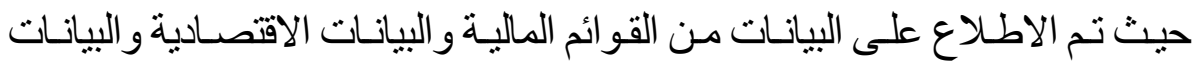

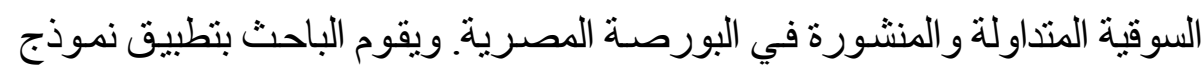

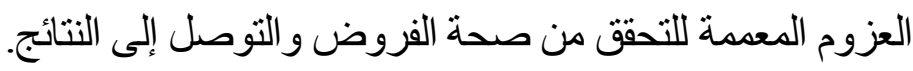
عاثر اً: أساليب التحليل الإحصائي:

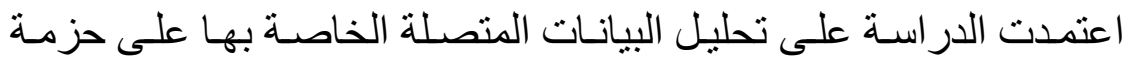

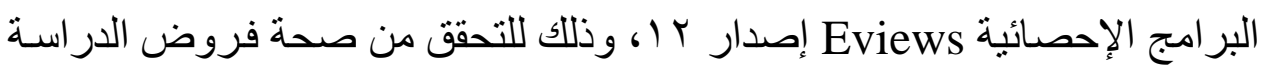

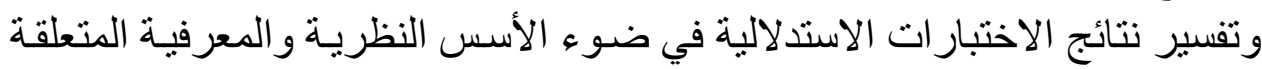
بمشكلة الدراسة، وقد اعتمد الباحث الأساليب التالية:

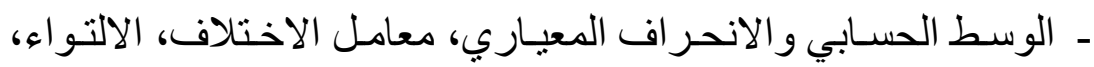

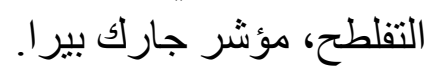

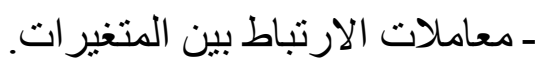
ـ ـ الاستقر ار و التكامل و التز امن للبيانات.

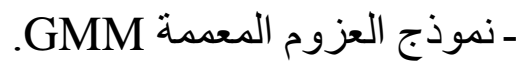




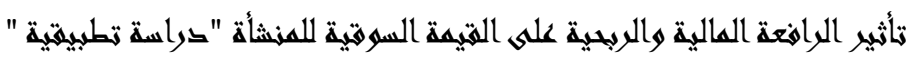
د/ هحمت سمير هحمد المترليه

\section{حادي عشر: مجتمع وعينة الاراسة:}

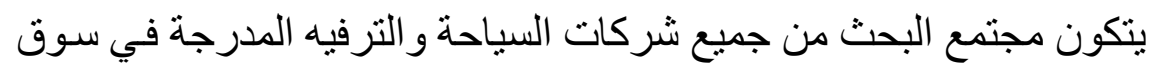

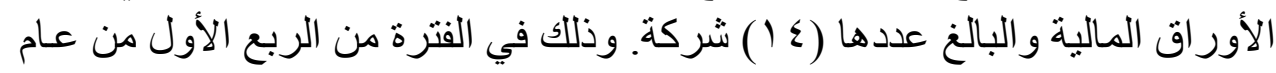

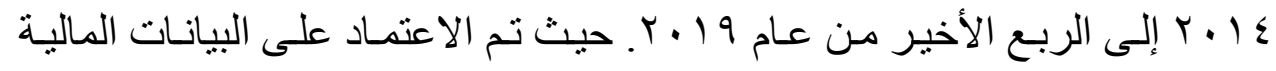

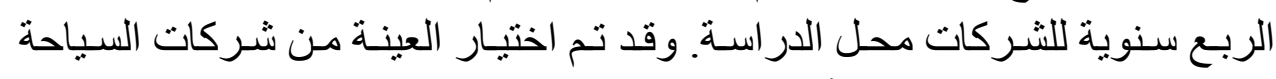

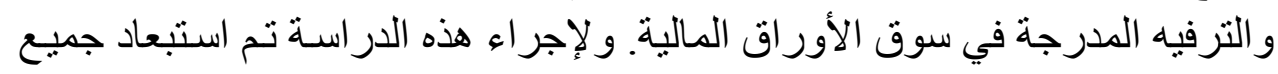
الثركات التي لا تستوفي الثروط التروفي التالية:

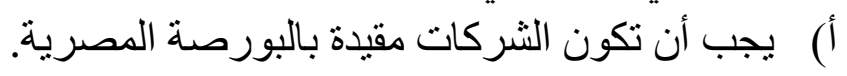

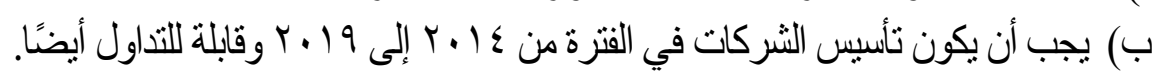

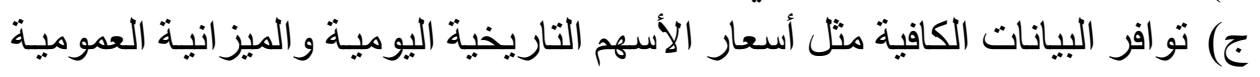

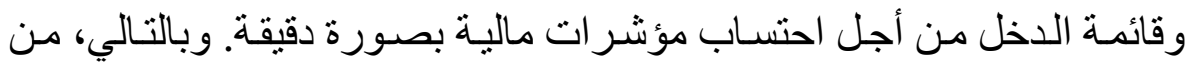

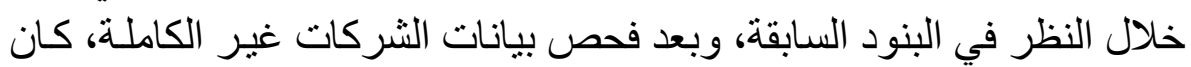

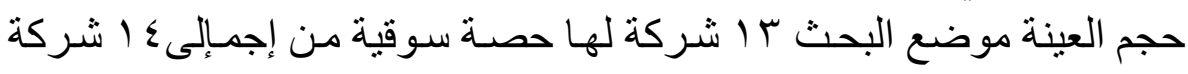

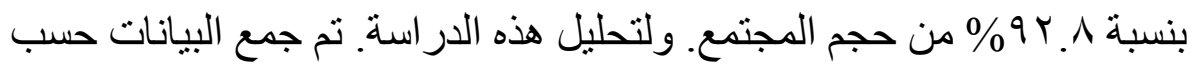

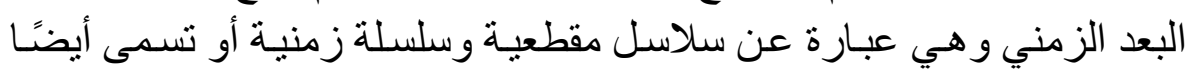

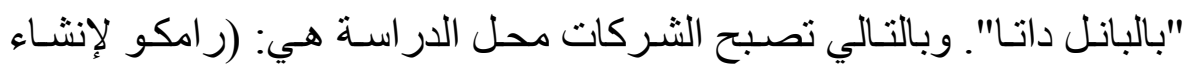
القرى السياحية، الو ادي للاستثمار السياحي، المصرية للمنتجعات السياحية،

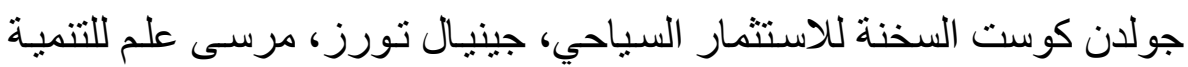

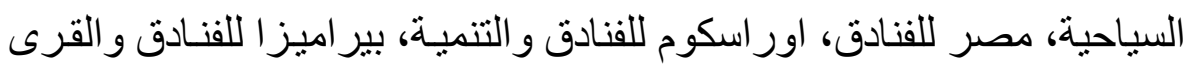

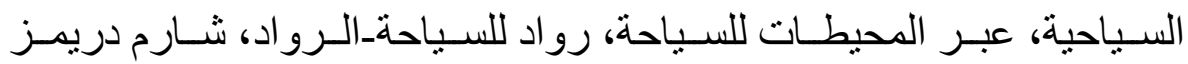

للاستثمار السياحي، المصرية للمشروعات السياحية الدولية).

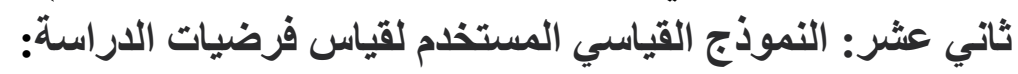

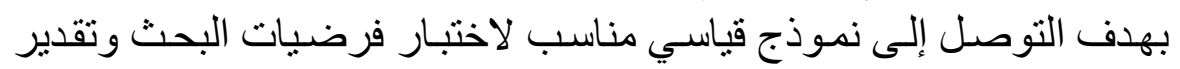

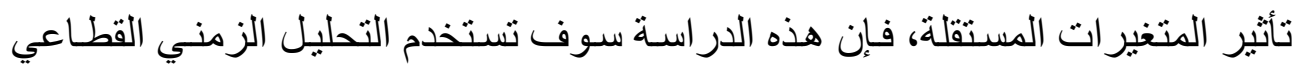
المستعرض، المعروف بإسـ بيانات البانل (Panel Data)، وذلك باستخدام نموذج الته 


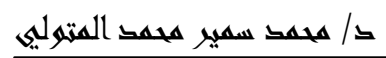

العزوم المعممة (GMM). ويتميز هذا النموذج بإمكانية معالجة مشاكل التحيز الناتجة

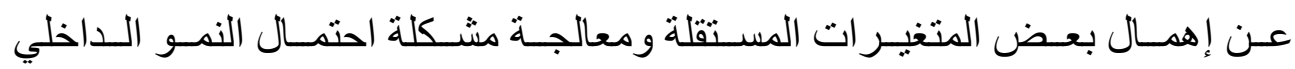

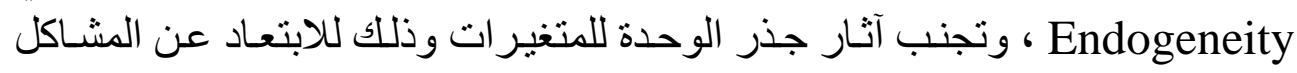

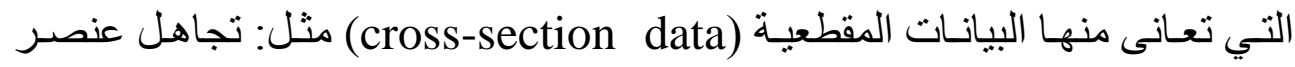

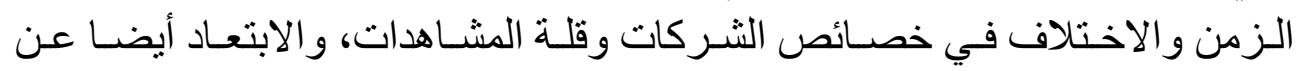
المشاكل التي تعاني منها السلاسل الزمنية(Time series data) ، مثل إهمال بيانـات

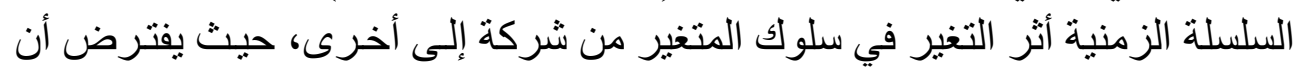

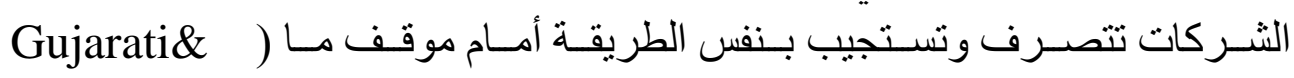
Porter,2009). وفيما يلي المعادلات المر اد تقدير معلماتها:

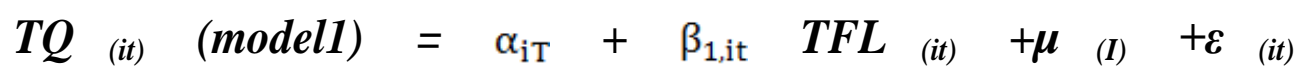
(1)

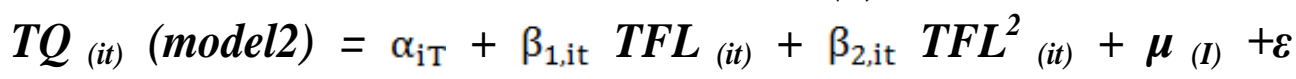
(it)

$T Q_{(i t)}\left(\right.$ model3) $=\alpha_{\mathrm{iT}}+\beta_{1, \mathrm{it}} \boldsymbol{T F L _ { ( i t ) }}+\beta_{2, \mathrm{it}} \boldsymbol{B E T A}(i t)+\beta_{3, \mathrm{it}}$ $T A N G_{(i t)}+\beta_{4, \text { it }} S I Z E_{(i t)}+\mu_{(I)}+\varepsilon_{(i t)}$

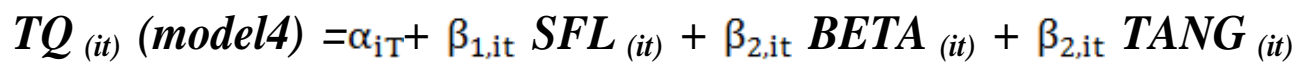
$+\beta_{4, \mathrm{it}} \operatorname{SIZE} E_{(i t)}+\mu_{(I)}+\varepsilon_{(i t)} \cdot(4)$

TQ ${ }_{(i t)}\left(\right.$ model5) $=\alpha_{\mathrm{iT}}+\beta_{1, \mathrm{it}}$ LFL $_{(i t)}+\beta_{2, \mathrm{it}} \boldsymbol{B E T A}_{(i t)}+\beta_{2, \mathrm{it}}$ TANG $\boldsymbol{G}_{(i t)}$ $+\beta_{4, \mathrm{it}} \operatorname{SIZE} E_{(i t)}+\mu_{(I)}+\varepsilon_{(i t)} . .(5)$

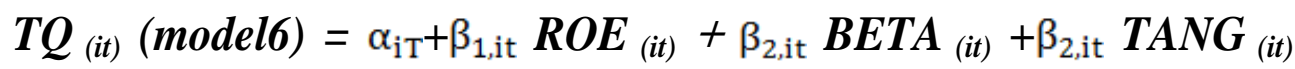
$+\beta_{4, \mathrm{it}} S I Z E_{(i t)}+\mu_{(I)}+\varepsilon \ldots . .(6)$ 
تأثير الراهعة المالية والربهية على المتيمة السولهية للمنشأة "قراسة تطبيتمية " د/ هممك سمير هحمك المترليى

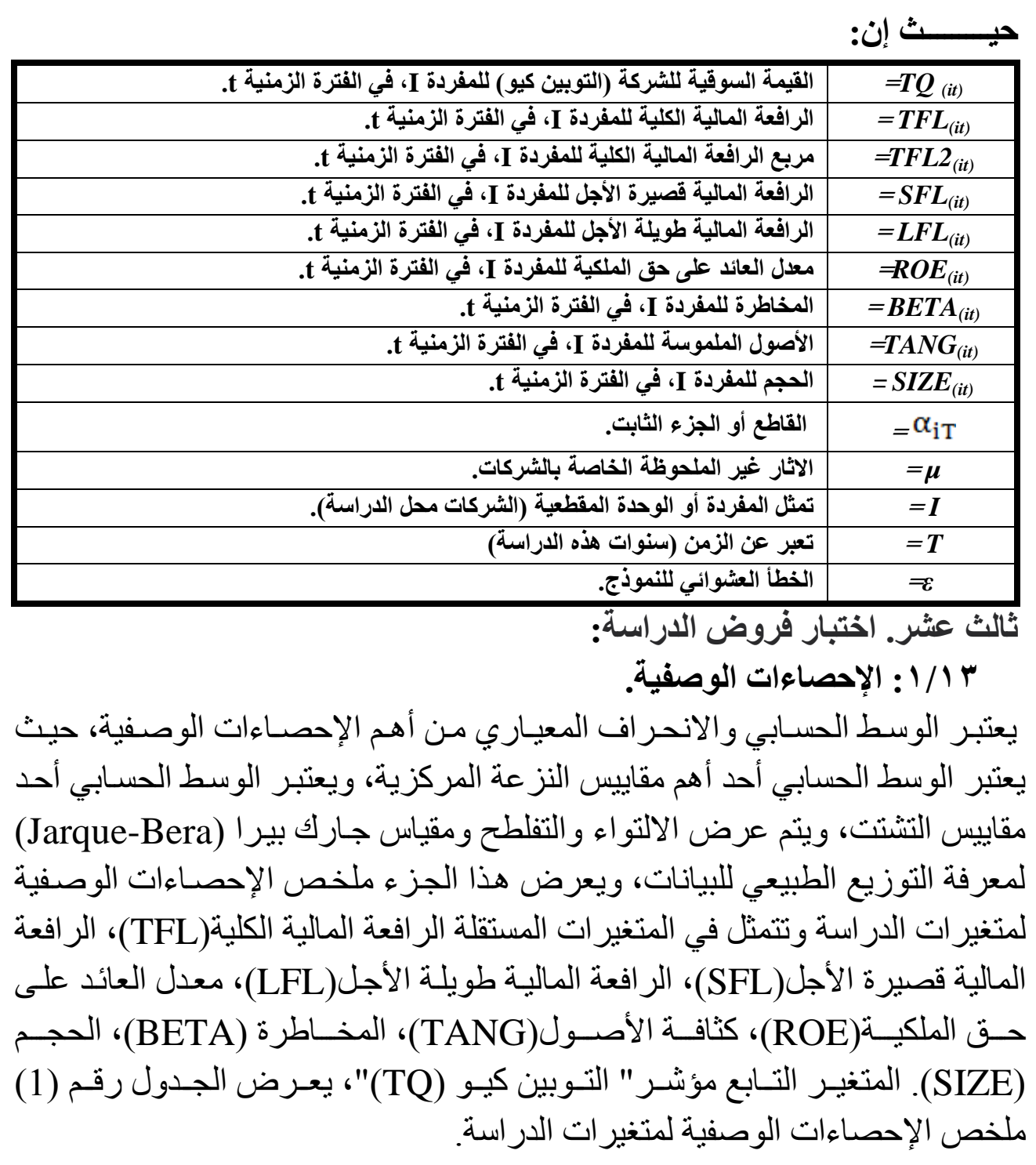

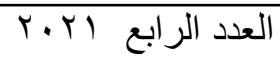




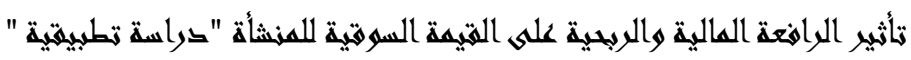
ث/ محمق سمير هحمت المترليه

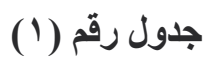

الإحصاءات الوصفية لمتفيرات الاراسة (1)

\begin{tabular}{|c|c|c|c|c|c|c|c|c|}
\hline BETA & SIZE & TANG & ROE & SFL & LFL & TFL & TQ & المتغيرات \\
\hline 0.608 & 5.135 & 0.250 & 0.030 & 0.040 & 0.082 & 0.122 & 0.737 & Mean \\
\hline 0.570 & 5.800 & 0.106 & 0.007 & 0.000 & 0.000 & 0.000 & 0.724 & Median \\
\hline 1.549 & 9.097 & 0.966 & 0.154 & 0.571 & 0.648 & 0.648 & 3.315 & Maximum \\
\hline 0.000 & 0.000 & 0.000 & -0.043 & 0.000 & 0.000 & 0.000 & 0.000 & Minimum \\
\hline 0.458 & 2.843 & 0.258 & 0.054 & 0.085 & 0.156 & 0.182 & 0.576 & Std. Dev. \\
\hline 0.097 & 0.781 & 0.835 & 0.987 & 2.675 & 1.999 & 1.220 & 1.032 & Skewness \\
\hline 1.685 & 2.360 & 2.573 & 3.023 & 7.544 & 6.011 & 3.177 & 4.880 & Kurtosis \\
\hline 22.94 & 37.06 & 38.63 & 50.76 & 1321.2 & 325.7 & 77.89 & 101.4 & Jarque-Bera \\
\hline 0.000 & 0.000 & 0.000 & 0.000 & 0.000 & 0.000 & 0.000 & 0.000 & Probability \\
\hline 189.7 & 1602. & 78.18 & 9.515 & 12.50 & 25.67 & 38.17 & 230.1 & Sum \\
\hline 65.31 & 2515.3 & 20.84 & 0.923 & 2.270 & 7.646 & 10.36 & 103.4 & $\begin{array}{c}\text { Sum Sq. } \\
\text { Dev. }\end{array}$ \\
\hline 312 & 312 & 312 & 312 & 312 & 312 & 312 & 312 & $\begin{array}{c}\text { Observation } \\
\text { s }\end{array}$ \\
\hline
\end{tabular}

- مخرجات برنامج 12, Eviews

هيضـح مـن الجدول السـابق أن الوسط الحاسبي لمقاييس الر افعـة الماليـة القصيرة

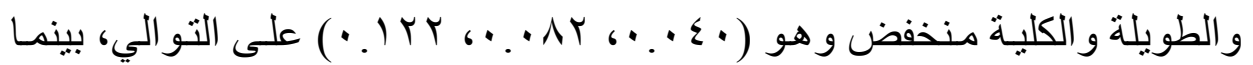

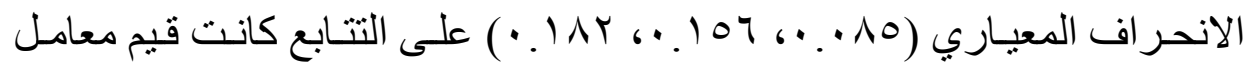

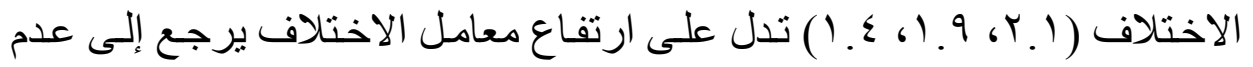

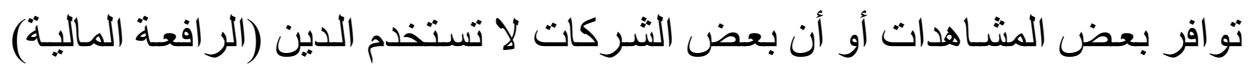

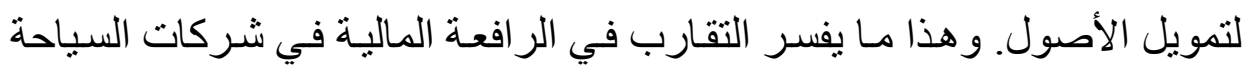

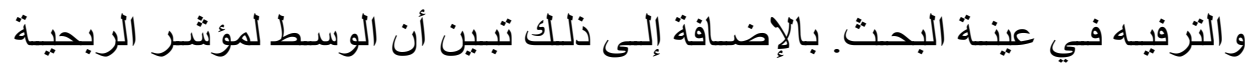

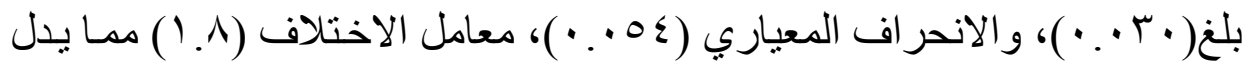
على اختلاف عو ائد الجنيه المملوكة في شركات السياحة و الترفيه في عينة البحث.

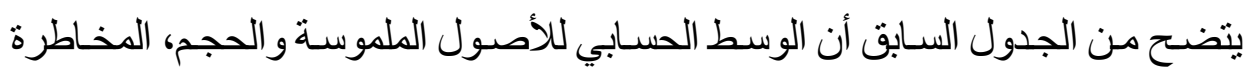

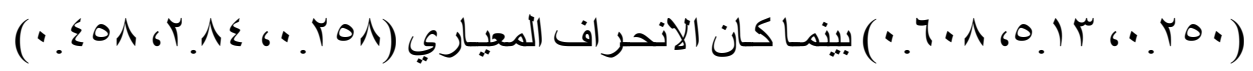




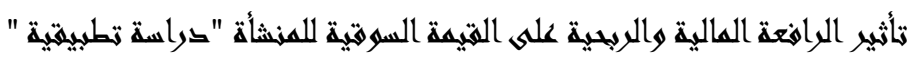

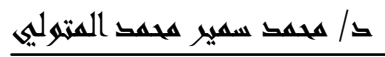

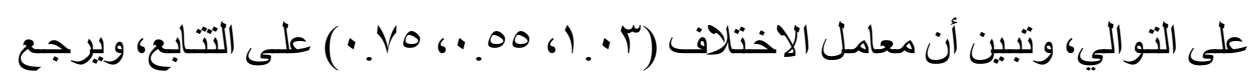
هذا التقارب إلى عدم اعتماد بعض الثركات في عينة البحث على الدين.

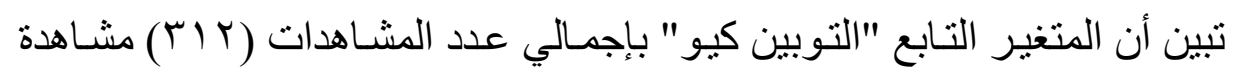

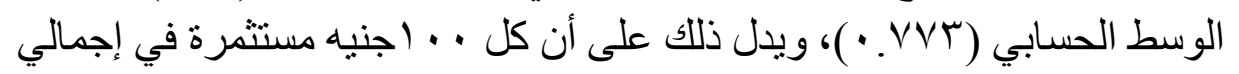

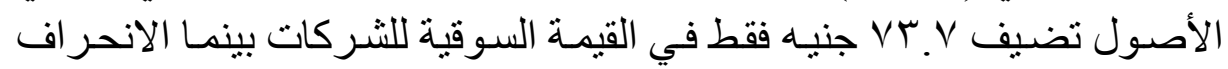

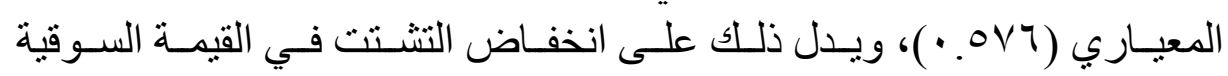

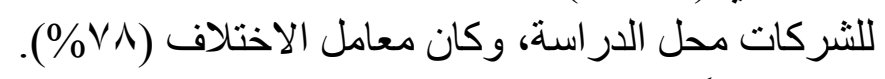

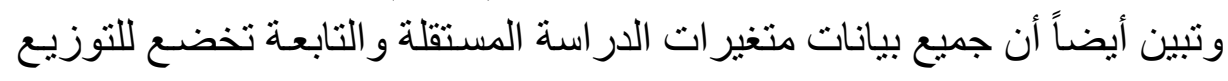

الطبيعي من خلال مقاييس الالتو اء و التفلطح وجارك كات بير ا (Jarque-Bera).

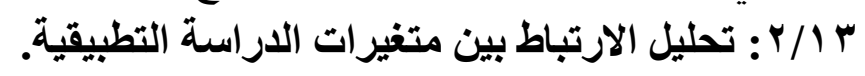

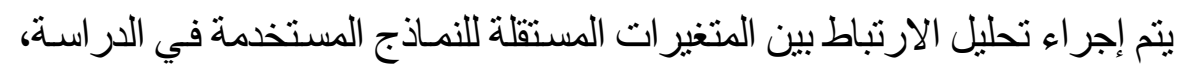

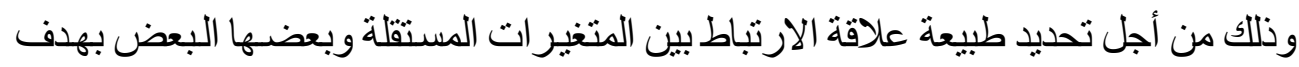

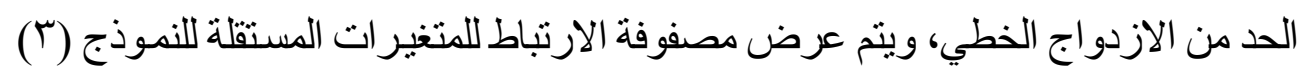

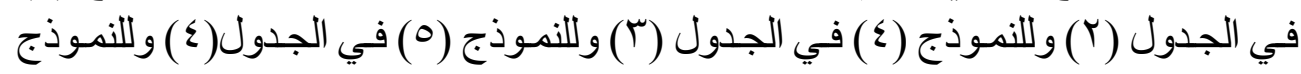
(7) في الجدول(0) من أجل فحص الارتباط الموجود بين المتغيرات:

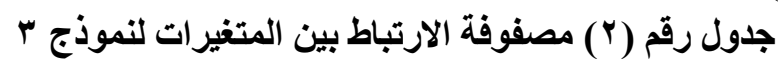

\begin{tabular}{|c|c|c|c|c|}
\hline BETA & SIZE & TANG & TFL & المتغيرات \\
\hline & & & 1.00 & TFL \\
\hline & & 1.00 & $0.174^{*}$ & TANG \\
\hline & 1.00 & $0.255^{*}$ & $0.129^{*}$ & SIZE \\
\hline 1.00 & $0.151^{*}$ & 0.080 & $0.163^{*}$ & BETA \\
\hline
\end{tabular}

* دلالة على أن العلاقة بين المتفيرين أقل ه ه. .

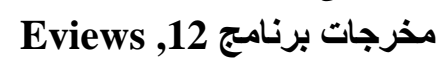




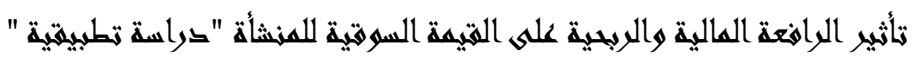
د/ هحمت سمير هحمد المترليه

جدول رقم (r) مصفوفة الارتباط بين المتغيرات للنموذج ؛

\begin{tabular}{|c|c|c|c|c|}
\hline BETA & SIZE & TANG & LFL & المتغيرات \\
\hline & & & 1.00 & LFL \\
\hline & & 1.00 & 0.176 & TANG \\
\hline & 1.00 & $0.255^{*}$ & $0.303^{*}$ & SIZE \\
\hline 1.00 & $0.151^{*}$ & 0.080 & 0.088 & BETA \\
\hline
\end{tabular}

* دلالة على أن العلاقةة بين المتغيرين أقل ه ه .

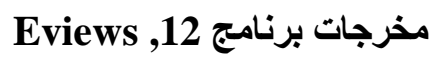

جدول رقم (؛ ) مصفوفة الارتباط بين المتغيرات ل نموذجه

\begin{tabular}{|c|c|c|c|c|}
\hline BETA & SIZE & TANG & SFL & ت المتغير \\
\hline & & & 1.00 & SFL \\
\hline & & 1.00 & 0.049 & TANG \\
\hline & 1.00 & $0.255^{*}$ & $\mathbf{0 . 3 6 1}^{*}$ & SIZE \\
\hline 1.00 & $0.151^{*}$ & $\mathbf{0 . 0 8 0}$ & $\mathbf{0 . 1 8 6}^{*}$ & BETA \\
\hline
\end{tabular}

* دلالة على أن العلاقة بين المتغيرين أقل ه ه •.

مخرجات برنامج 12, Eviews

جدول رقم (0) مصفوفة الارتباط بين المتغيرات لنموذج 12

\begin{tabular}{|c|c|c|c|c|}
\hline BETA & SIZE & TANG & ROE & المتغيرات \\
\hline & & & 1.00 & ROE \\
\hline & & 1.00 & 0.005 & TANG \\
\hline & 1.00 & $0.255^{*}$ & $-0.175^{*}$ & SIZE \\
\hline 1.00 & $0.151^{*}$ & 0.080 & $-0.209^{*}$ & BETA \\
\hline
\end{tabular}

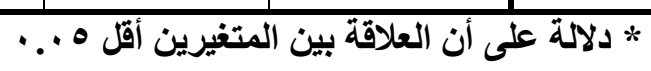

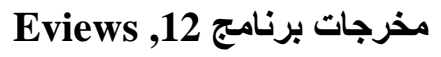

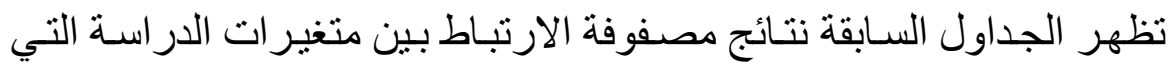

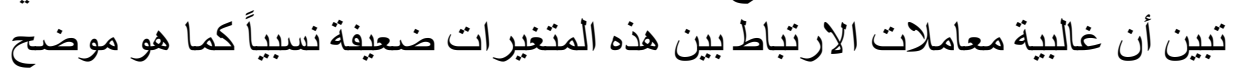

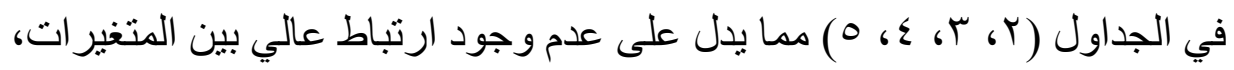

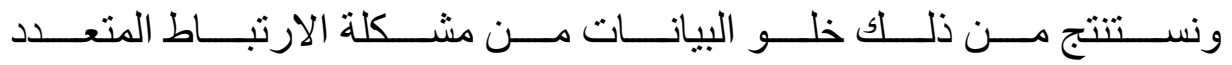

.(Multicollinearity) 


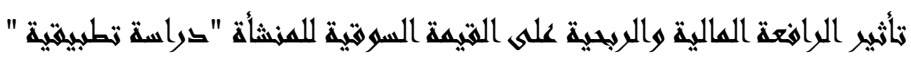
ك/ هحم سهير هحم المتنوليه

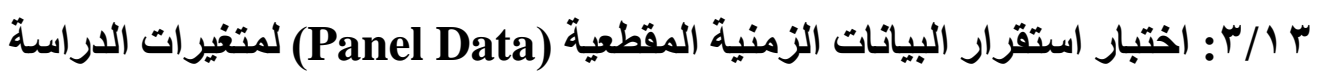

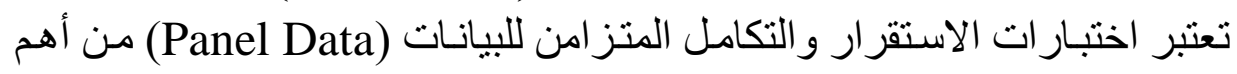

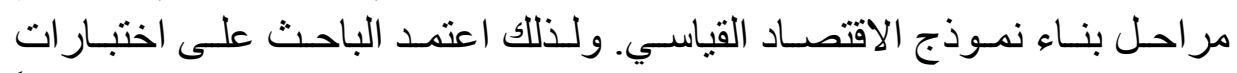

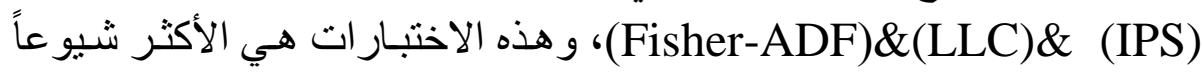

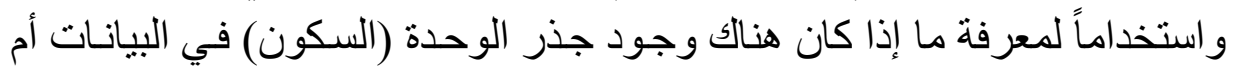

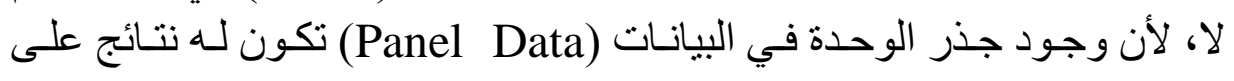

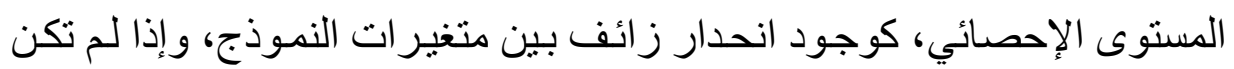

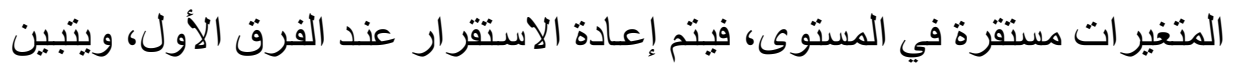
أن البيانات مستقرة عند المستوى. وكانت النتائج كما يلي:

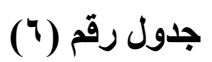

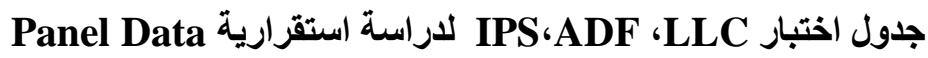

\begin{tabular}{|c|c|c|c|c|c|c|}
\hline \multicolumn{2}{|c|}{$\begin{array}{c}\text { (IPS) } \\
\text { Im, Pesaram and } \\
\text { Shin2003 }\end{array}$} & \multicolumn{2}{|c|}{$\begin{array}{c}\text { (Fisher-ADF) } \\
\text { Fisher and Dickey, } \\
\text { Fuller }\end{array}$} & \multicolumn{2}{|c|}{$\begin{array}{c}\text { (LLC) } \\
\text { Liven,lin and chu2002 }\end{array}$} & \multirow{2}{*}{ المتغير } \\
\hline Statistic & Prob. & Statistic & Prob." & Statistic & .Prob & \\
\hline-4.906 & 0.0225 & $\begin{array}{l}57.531 \\
\end{array}$ & 0.0000 & 1.1175 & 0.0681 & TQ \\
\hline $\begin{array}{l}-1.199 \\
\end{array}$ & 0.1152 & 36.996 & 0.0053 & 0.6139 & $\overline{0.0363}$ & TFL \\
\hline 6.071 & 0.0000 & 4.7056 & 0.0992 & 4.0477 & 0.0000 & SFL \\
\hline $\begin{array}{l}-7.298 \\
\end{array}$ & 0.0000 & 89.623 & 0.0000 & -4.9092 & 0.0000 & $\begin{array}{l}\text { LFL } \\
\end{array}$ \\
\hline $\begin{array}{l}-1.685 \\
\end{array}$ & 0.0459 & 30.095 & 0.0365 & $\begin{array}{c}-0.3633 \\
\end{array}$ & $\overline{0.0582}$ & ROE \\
\hline 4.982 & 0.0000 & 7.8511 & 0.0308 & \begin{tabular}{|c|}
3.1777 \\
\end{tabular} & 0.0993 & $\overline{\text { BETA }}$ \\
\hline $\begin{array}{l}-6.504 \\
\end{array}$ & 0.0000 & 67.656 & 0.0000 & -4.4819 & 0.0000 & TANG \\
\hline \begin{tabular}{|l|l|}
-1.481 \\
\end{tabular} & 0.0492 & 30.114 & 0.0363 & -0.3624 & 0.3585 & $\begin{array}{l}\text { SIZE } \\
\end{array}$ \\
\hline
\end{tabular}

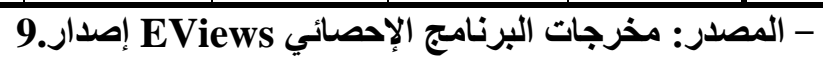

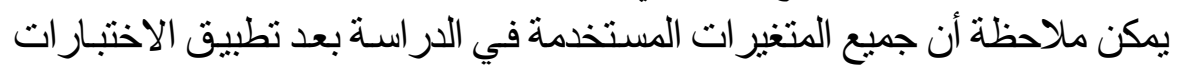

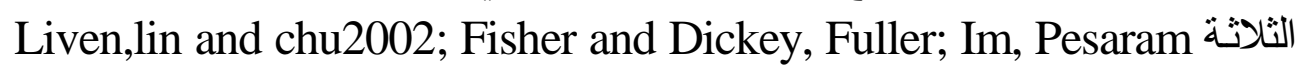

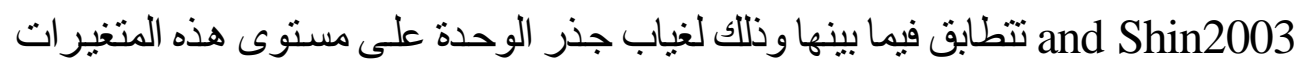
و هـي: التوبين كيو، الر افعـة الماليـة الكليـة، الر افعـة الماليـة طويلـة الأجل، الر افعـة الماليـة 


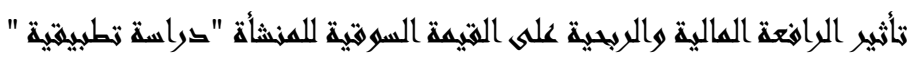
ك/ محمق سمير هحمد المتنوليه

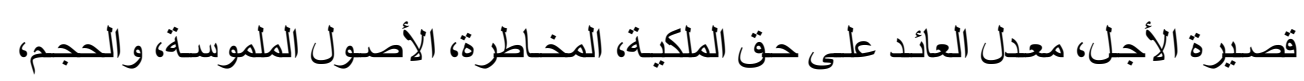
وبالتالي تعتبر هذه المتغيرات مستقرة حيث أن (Prob > 0.05).

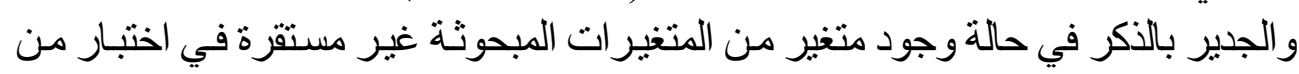
الاختبار ات السابقه الإشارة اليها، يتم اختبار المتغير صاحب الغئ الاختبار الأعلى قيمة. ب ا / اء : اختبار صحة الفرض الأول: لاختبار الفرض الأول من الدراسة و التوصن الأول إلى النتائج التي من خلالهـا يتم

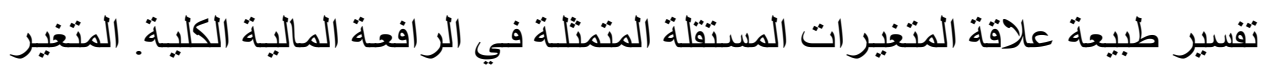

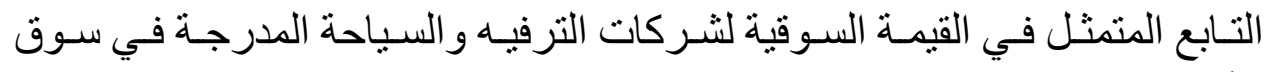

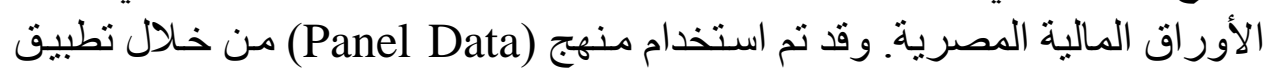

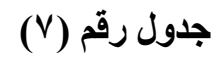

$$
\begin{aligned}
& \text { نموذج GMM، كانت النتائج كما يلي: }
\end{aligned}
$$

معلمات المتغيرات المستقلة (الرافعة المالية الكلية) على القيمة

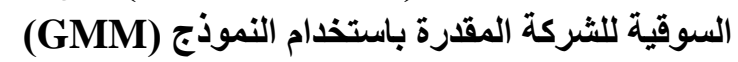

\begin{tabular}{|c|c|c|c|}
\hline \multicolumn{3}{|c|}{$\begin{array}{c}\text { نموذج العزوم المعممة) } \\
\text { generalized method of moments }\end{array}$} & $\begin{array}{c}\text { المتغير } \\
\text { Variable }\end{array}$ \\
\hline Prob & t-Statistic & Coefficient & Constant \\
\hline 0.0000 & 16.95621 & 0.650622 & (C) \\
\hline 0.0001 & 4.065881 & 0.710602 & TFL \\
\hline \multicolumn{3}{|c|}{0.050627} & R-squared \\
\hline \multicolumn{3}{|c|}{0.047565} & Adjusted R-squared \\
\hline \multicolumn{3}{|c|}{2.298595} & Durbin-Watson stat \\
\hline \multicolumn{3}{|c|}{0.737571} & Mean dependent var \\
\hline \multicolumn{3}{|c|}{0.059967} & S.D. dependent var \\
\hline \multicolumn{3}{|c|}{310.0000} & J-statistic \\
\hline \multicolumn{3}{|c|}{0.000000} & Prob(J-statistic) \\
\hline \multicolumn{3}{|c|}{312} & No. of observations \\
\hline
\end{tabular}

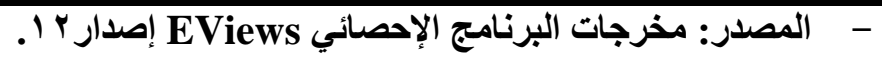

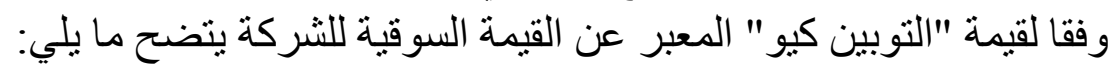




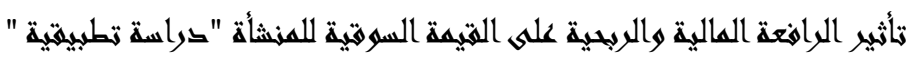

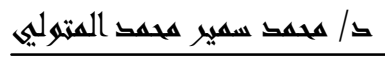

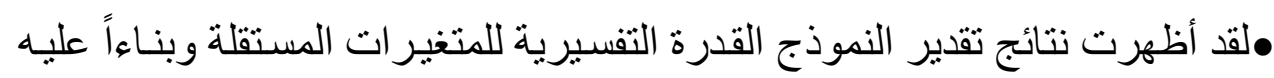

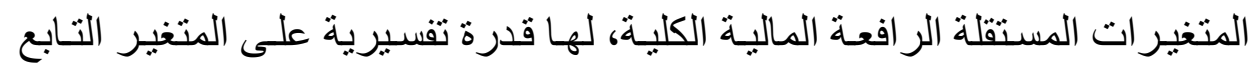

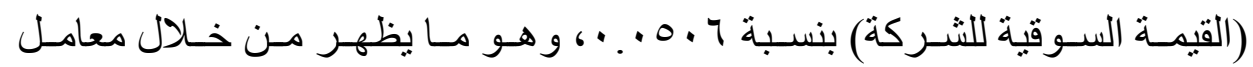

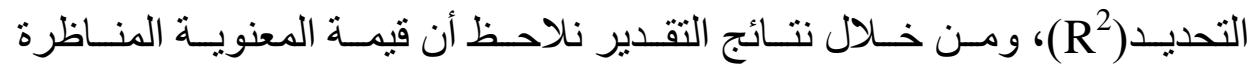

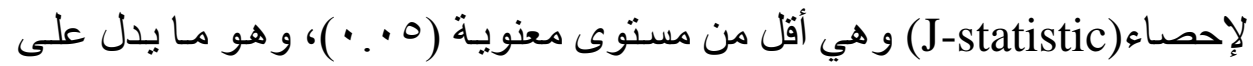

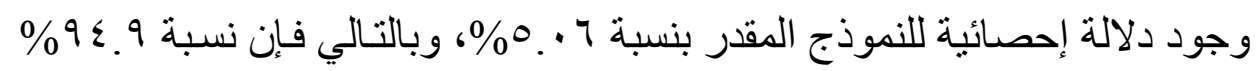

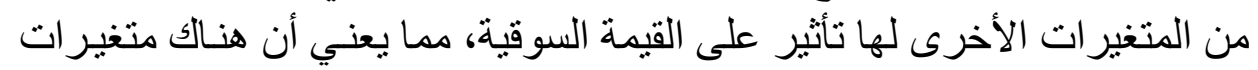

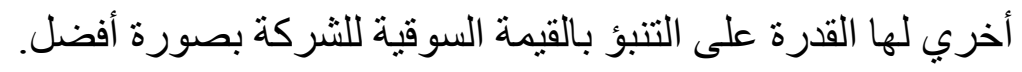

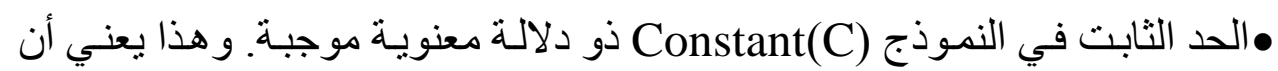

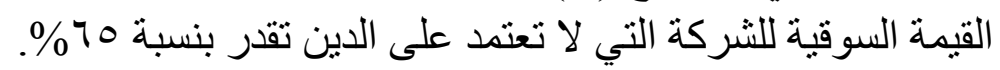

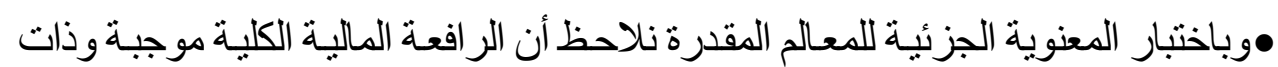

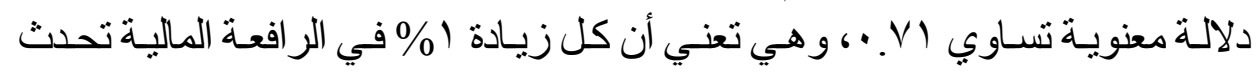

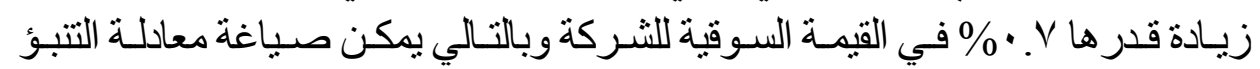
بالقيمة السوقية للثركة في ضوء تفسير الر افعة المالية للثركة على النحو التالي: Y1 = 0.650622 + 0.710602* TFL MOGEL (1)

وبنـاءاً على النتائج السـابقة: يتم رفض فرض العدم القائل " لا يوجد تأثير

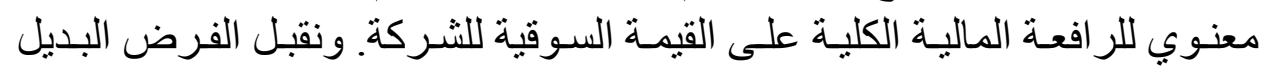

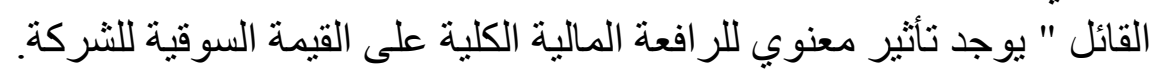
ب / / ه : اختبار صحة الفرض الثاني.

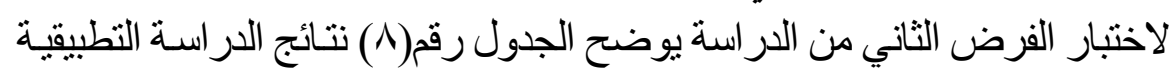

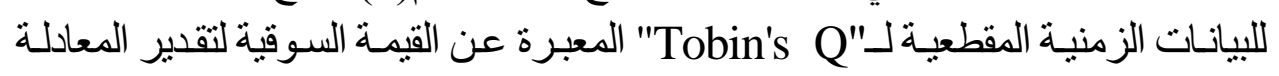

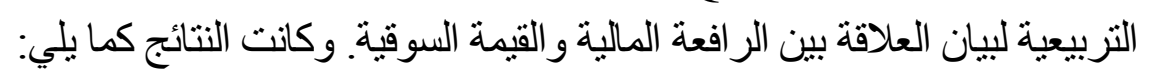




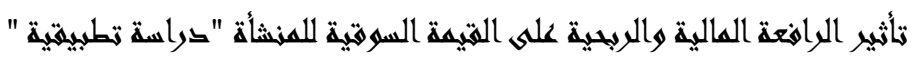
د/ هحمد سمير هحمت المتزليه

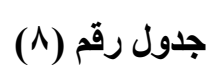

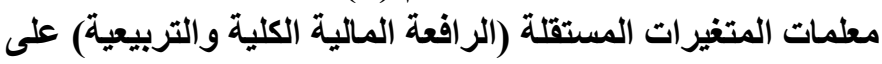

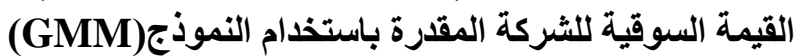

\begin{tabular}{|c|c|c|c|}
\hline \multicolumn{3}{|c|}{$\begin{array}{c}\text { نموذج العزوم المعممة) } \\
\text { generalized method of moments }\end{array}$} & $\begin{array}{c}\text { المتغير } \\
\text { Variable }\end{array}$ \\
\hline Prob & t-Statistic & Coefficient & Constant \\
\hline 0.0000 & 16.44223 & 0.654505 & (C) \\
\hline 0.3720 & 0.894086 & 0.508516 & TFL \\
\hline 0.7091 & $\mathbf{0 . 3 7 3 4 3 3}$ & 0.432571 & TFL $^{2}$ \\
\hline \multicolumn{3}{|c|}{0.051056} & R-squared \\
\hline \multicolumn{3}{|c|}{0.044913} & Adjusted R-squared \\
\hline \multicolumn{3}{|c|}{1.300418} & Durbin-Watson stat \\
\hline \multicolumn{3}{|c|}{0.737571} & Mean dependent var \\
\hline \multicolumn{3}{|c|}{0.576623} & S.D. dependent var \\
\hline \multicolumn{3}{|c|}{309.0000} & J-statistics \\
\hline \multicolumn{3}{|c|}{0.000000} & Prob(J-statistic) \\
\hline \multicolumn{3}{|c|}{312} & No. of observations \\
\hline
\end{tabular}

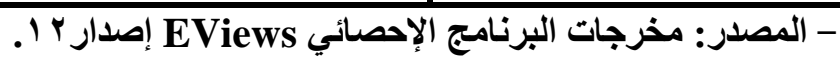

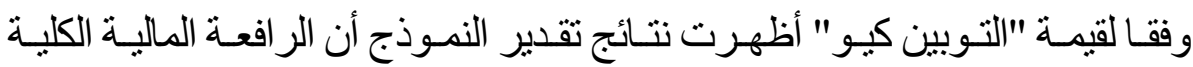

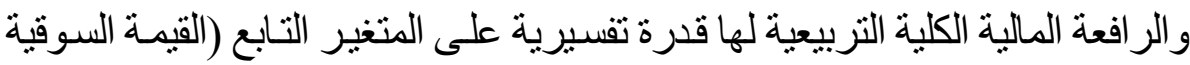

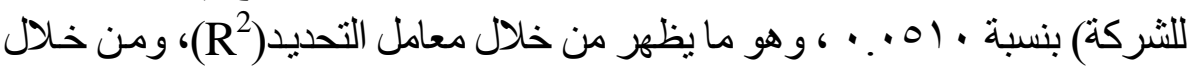

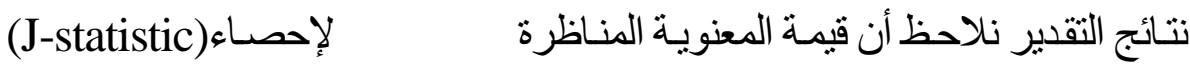

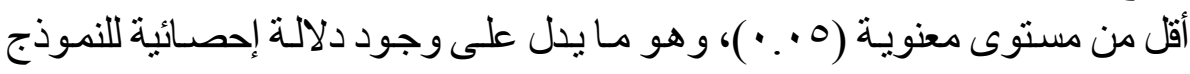

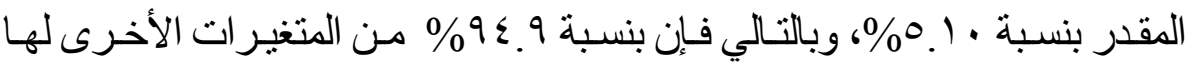

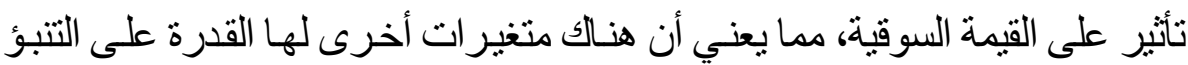
بصورة أفضل على القيمة السوقية للثركة.

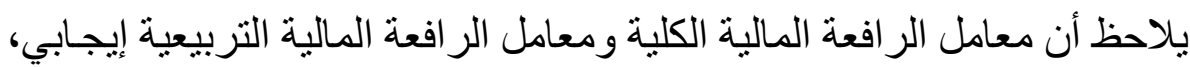

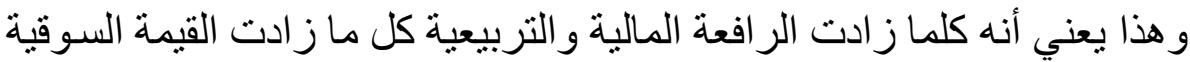
ولكنه تأثثر غير معني انه كان 


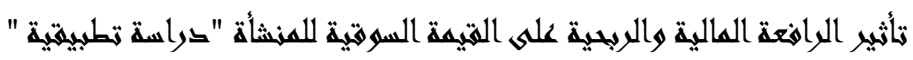
ك/ هحمت سميز هحمد المترليى

معامل التحديد R-squared للنموذج معنوي. ولكن معاملات التقدير للر افعة

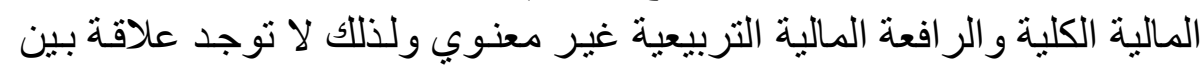

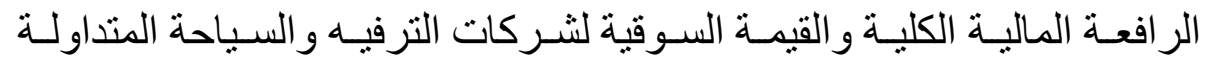

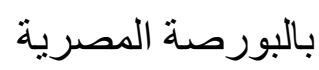

وبناءاً على النتائج التي تم التوصل إلبها سابقاً يمكن قبول الفرض العدم القائل

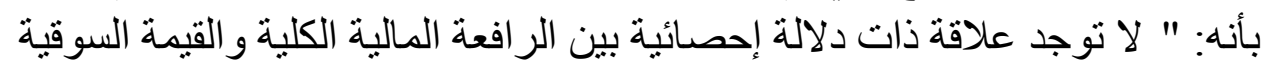

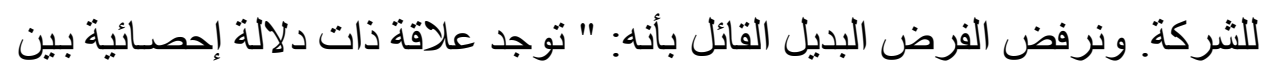

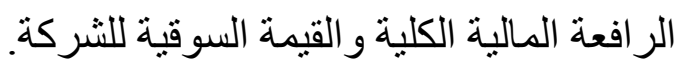
r/

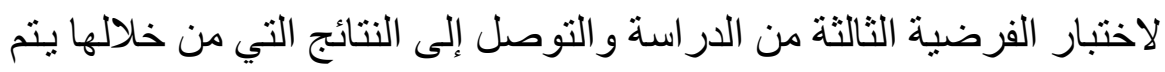

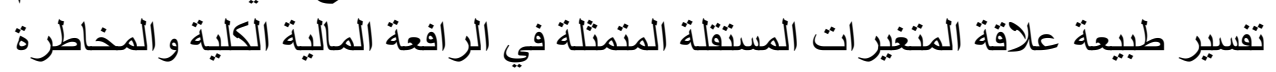

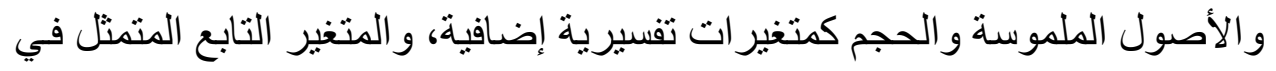

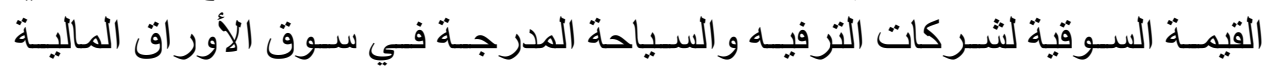

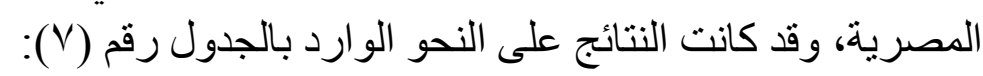

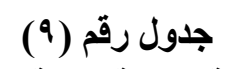

معلمات المتغيرات المستقلة (الرافعة المالية الكلية، الأصول الملموسة، الحجمة المبة، المخاطرة)

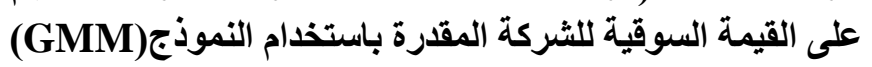

\begin{tabular}{|c|c|c|c|}
\hline \multicolumn{3}{|c|}{$\begin{array}{c}\text { نموذج العزوم المعممة) } \\
\text { generalized method of moments } \\
\text { gened }\end{array}$} & $\begin{array}{c}\text { المتغير } \\
\text { Variable }\end{array}$ \\
\hline Prob & t-Statistic & Coefficient & Constant \\
\hline 0.0002 & 3.797669 & 0.229194 & (C) \\
\hline 0.0973 & 1.663269 & 0.281772 & TFL \\
\hline 0.0000 & 7.535378 & 0.839193 & TANG \\
\hline 0.3068 & 1.023612 & 0.013426 & SIZE \\
\hline 0.0000 & 4.382604 & 0.320095 & BETA \\
\hline \multicolumn{3}{|c|}{0.290041} & R-squared \\
\hline \multicolumn{3}{|c|}{0.280791} & Adjusted R-squared \\
\hline \multicolumn{3}{|c|}{2.314373} & Durbin-Watson stat \\
\hline
\end{tabular}




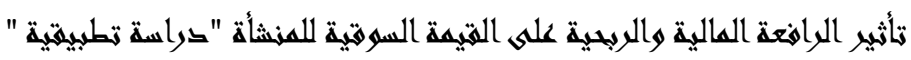
د/ هحمت سمير هحمد المترليه

\begin{tabular}{|c|c|}
\hline (GMM) نموذج العزوم المعمدة & (المتغئ| \\
generalized method of moments & Variable \\
\hline $\mathbf{0 . 7 3 7 5 7 1}$ & Mean dependent var \\
\hline $\mathbf{0 . 5 7 6 6 2 3}$ & S.D. dependent var \\
\hline 307.0000 & J-statistic \\
\hline $\mathbf{0 . 0 0 0 0 0 0}$ & Prob(J-statistic) \\
\hline 312 & No. of observations \\
\hline
\end{tabular}

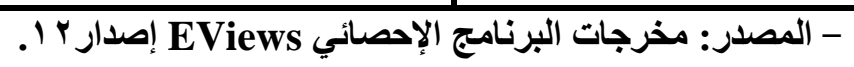

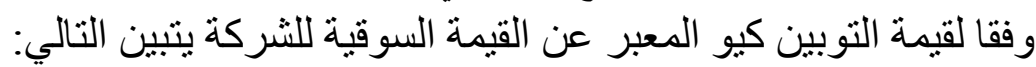
لقد أظهرت نتائج تقدير النموذج القدرة التفسيرية للمتغير ات المستقلة المتمثلة في: الر افعة المالية، الأصول الملموسة، و الحجم، المخاطرة، لها قدرة الفيرة تفسيرية

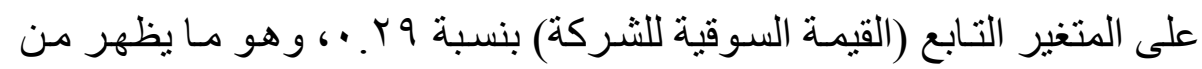

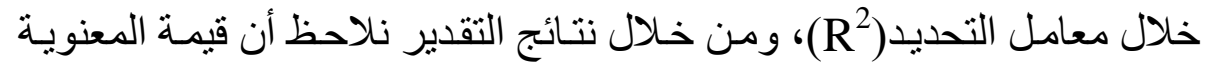

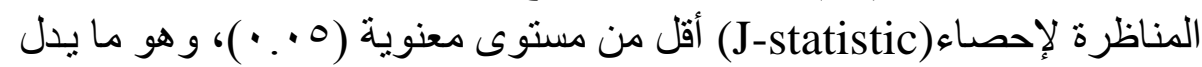

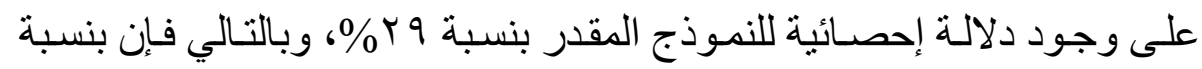

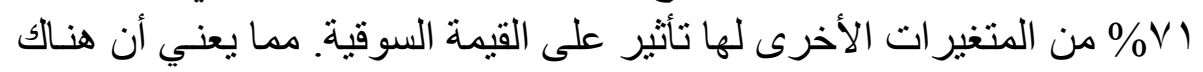

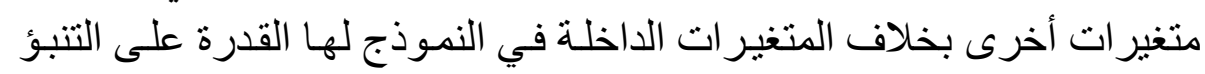
بصورة أفضل على القيمة السوقية للشركة.

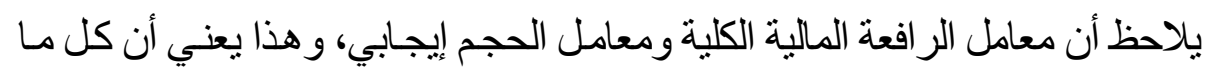

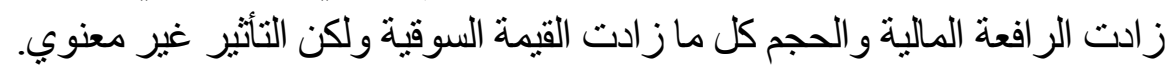
معامل التحديد R-squared للنموذج معنوي، ولكن معاملات التقدير للر افعة معات

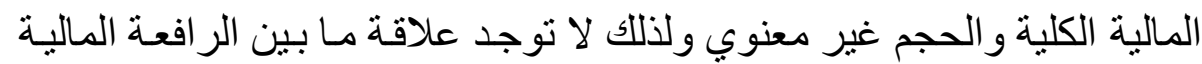

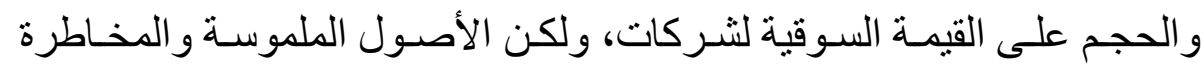

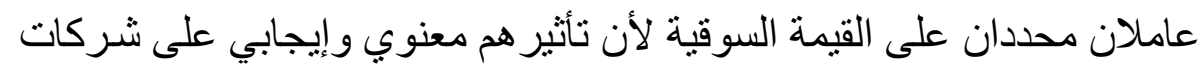

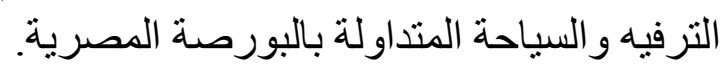




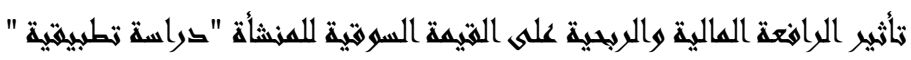
ك/ محمد سمير هحمد المترليى

وبناءاً على النتائج التي تم التوصل إليها سابقاً يمكن قبول الفرض العدم القائل

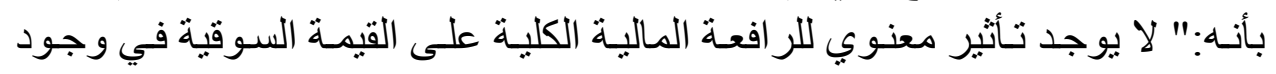

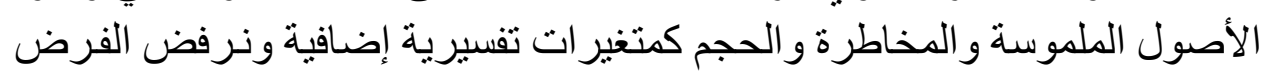

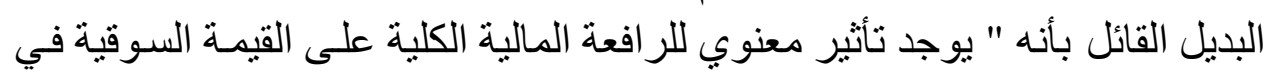

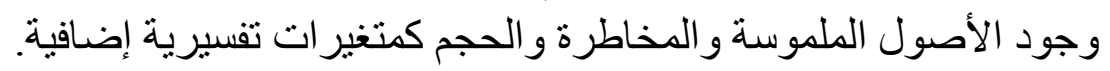

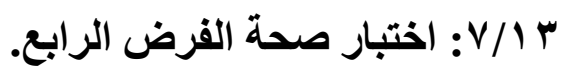

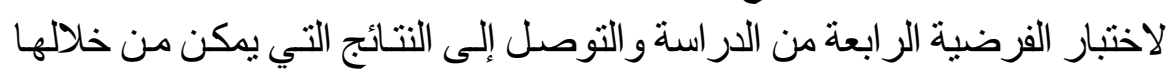

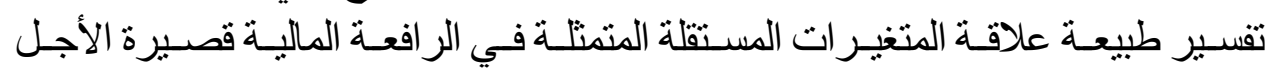

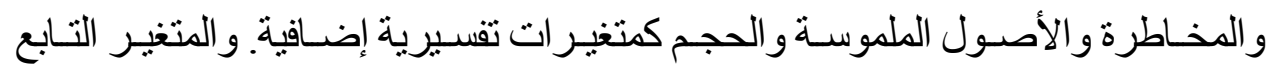

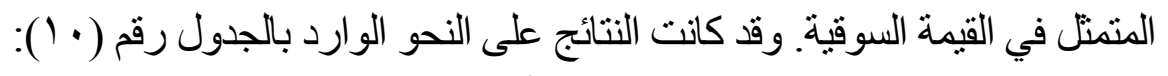

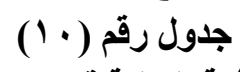

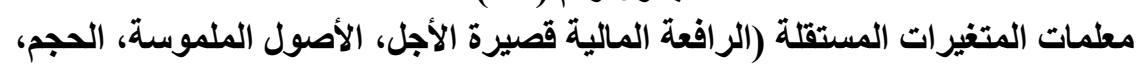

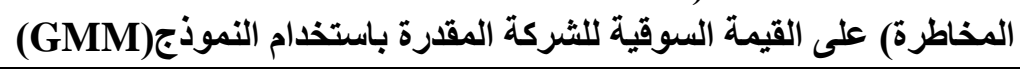

\begin{tabular}{|c|c|c|c|}
\hline \multicolumn{3}{|c|}{$\begin{array}{c}(\text { GMM) نموذج العزوم المعقمة) } \\
\text { generalized method of moments }\end{array}$} & $\begin{array}{c}\text { المتغير } \\
\text { Variable }\end{array}$ \\
\hline Prob & t-Statistic & Coefficient & Constant \\
\hline 0.0001 & $\mathbf{3 . 9 4 4 7 5 8}$ & 0.236456 & (C) \\
\hline 0.0053 & 2.807971 & 0.970653 & SFL \\
\hline 0.0000 & 7.854818 & 0.866692 & TANG \\
\hline 0.0002 & 0.842449 & 0.010647 & SIZE \\
\hline 0.0000 & 4.338772 & 0.313020 & BETA \\
\hline \multicolumn{3}{|c|}{$\mathbf{0 . 3 0 1 5 8 1}$} & R-squared \\
\hline \multicolumn{3}{|c|}{0.292481} & Adjusted R-squared \\
\hline \multicolumn{3}{|c|}{2.312097} & Durbin-Watson stat \\
\hline \multicolumn{3}{|c|}{0.737571} & Mean dependent var \\
\hline \multicolumn{3}{|c|}{0.576623} & S.D. dependent var \\
\hline \multicolumn{3}{|c|}{307.0000} & J-statistic \\
\hline \multicolumn{3}{|c|}{0.000000} & Prob(J-statistic) \\
\hline \multicolumn{3}{|c|}{312} & No. of observations \\
\hline
\end{tabular}

- الصصدر: مخرجات البرنامج الإحصائي EViews إصدار ז . . 


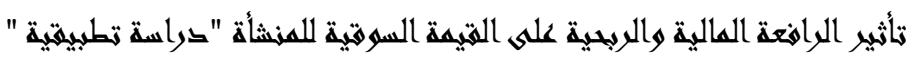
ك/ محمد سمير هحمد المترليه

وفقا لقيمة التوبين كيو المعبر عن القيمة السوقية للشركة يتضح التالي:

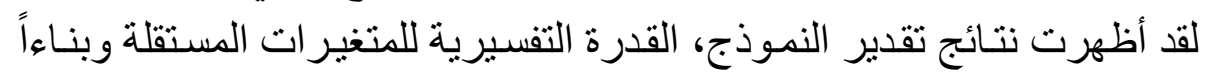

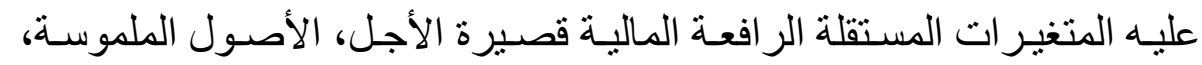

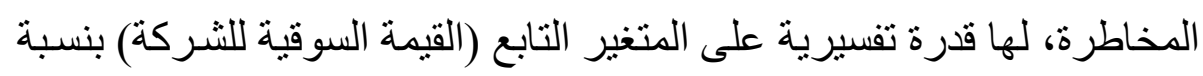

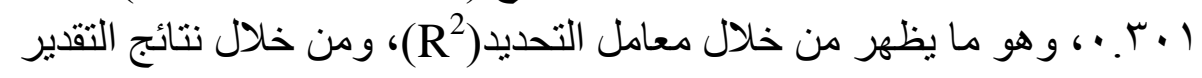

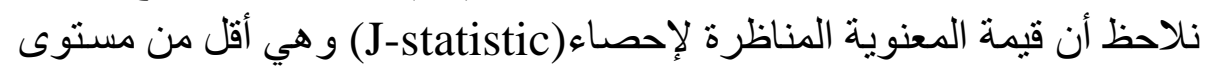

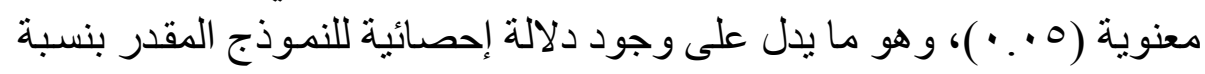

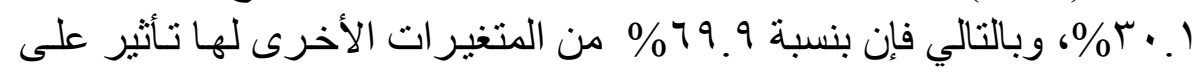

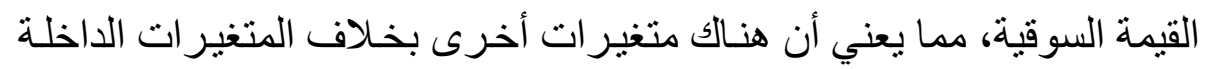

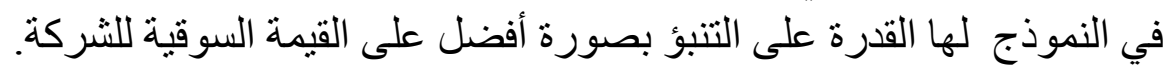

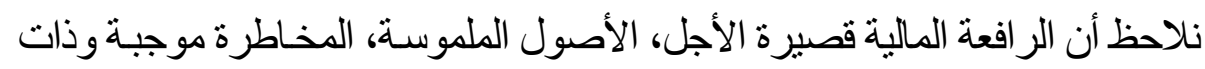

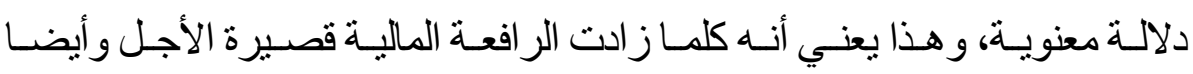

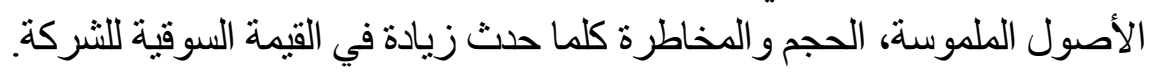

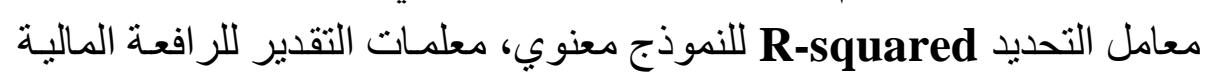

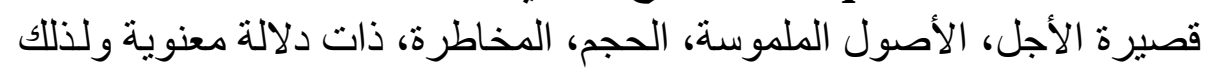

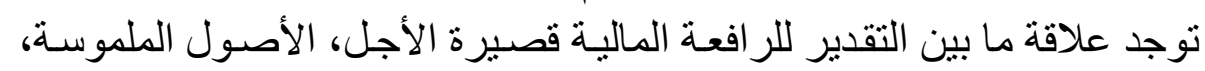

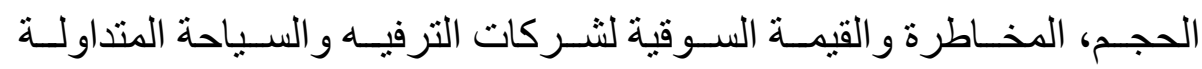

بالبورصة المصرية ويصبح النموذج المقدر يساوي:

Y1 = 0.236 + 0.970* SFL + 0.8666* TANG + 0.010 *SIZE + 0.313 *
BETA ... MOGEL (4)

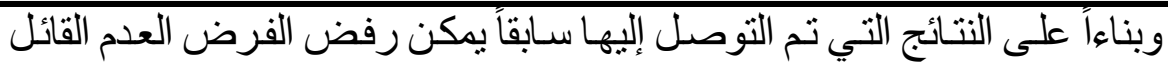

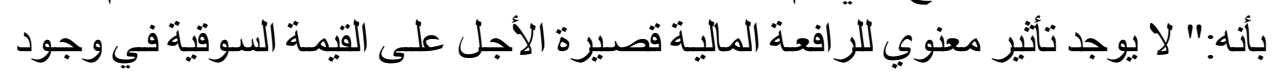

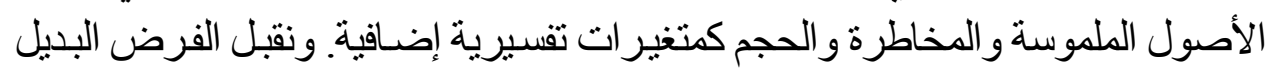

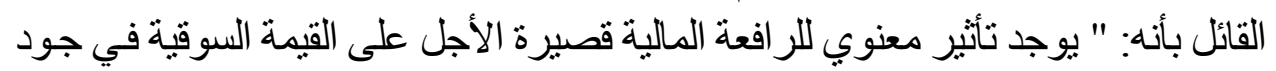
الأصول الملموسة و المخاطرة و الحجم كمتغير الئر تلفسيرية إضافية. 


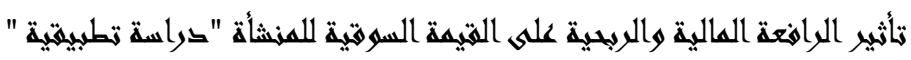
כ/ هحم سمير هحمق المترليه

\section{1/1 : اختبار صحة الفرض الخامس:}

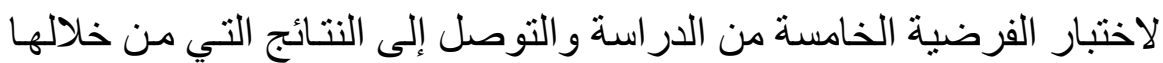
يتم تفسير طبيعة علاقة المتغير ات المستقلة المتمثلة في الر افعة المالية قصيرة الأجل

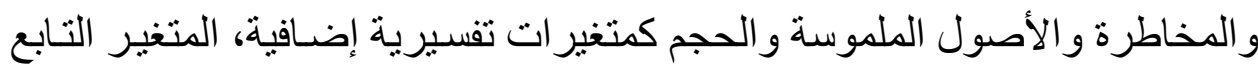

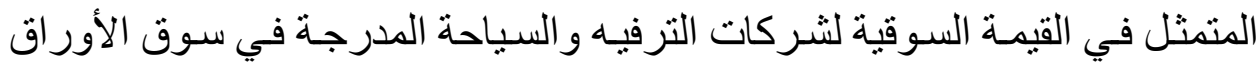
المالية المصرية، وكانت النتائج كالتالي:

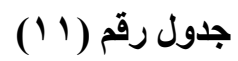

معلمات المتغيرات المستقلة (الرافعة المالية طويل الأجل، الأصول الملموسة، الحجم، المخاطرة)

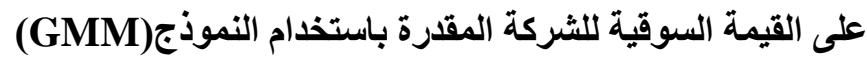

\begin{tabular}{|c|c|c|c|}
\hline \multicolumn{3}{|c|}{$\begin{array}{c}\text { نموذج العزوم المعممة (GMM) } \\
\text { generalized method of moments }\end{array}$} & $\begin{array}{c}\text { المتغير } \\
\text { Variable }\end{array}$ \\
\hline Prob & t-Statistic & Coefficient & Constant \\
\hline 0.0003 & 3.703702 & 0.224202 & (C) \\
\hline 0.7322 & 0.342487 & 0.064482 & LFL \\
\hline 0.0000 & 7.558886 & 0.847791 & TANG \\
\hline 0.1018 & 1.641211 & 0.020721 & SIZE \\
\hline 0.0000 & 4.242020 & 0.311126 & BETA \\
\hline \multicolumn{3}{|c|}{$\mathbf{0 . 2 8 3 9 1 7}$} & R-squared \\
\hline \multicolumn{3}{|c|}{0.274587} & Adjusted R-squared \\
\hline \multicolumn{3}{|c|}{2.314060} & Durbin-Watson stat \\
\hline \multicolumn{3}{|c|}{0.737571} & Mean dependent var \\
\hline \multicolumn{3}{|c|}{0.576623} & S.D. dependent var \\
\hline \multicolumn{3}{|c|}{307.0000} & J-statistic \\
\hline \multicolumn{3}{|c|}{0.000000} & Prob(J-statistic) \\
\hline \multicolumn{3}{|c|}{312} & No. of observations \\
\hline
\end{tabular}

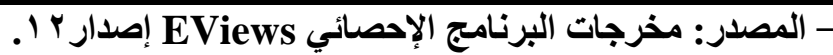

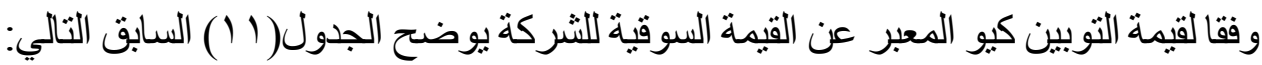

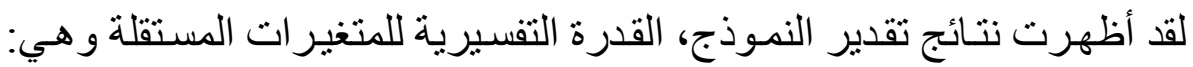

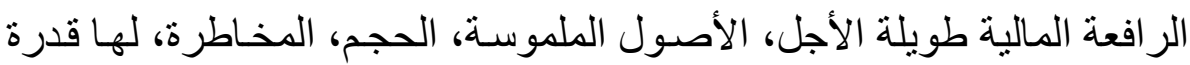

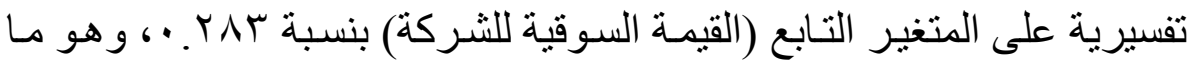




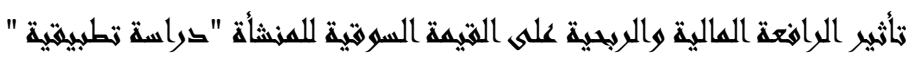
د/ هحمت سمير هحمد المترليه

يظهر من خلال معامل التحديد(R2)، ومن خلال نتائج التقدير نلاحظ أن القيمة

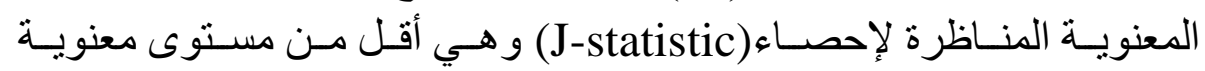

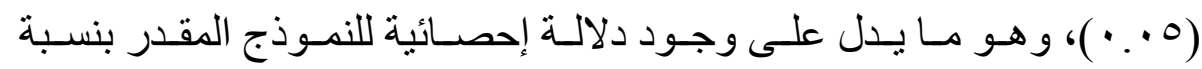

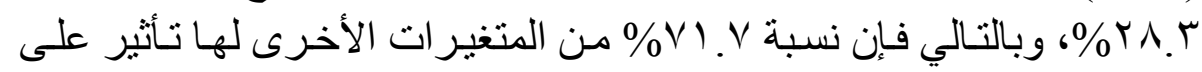

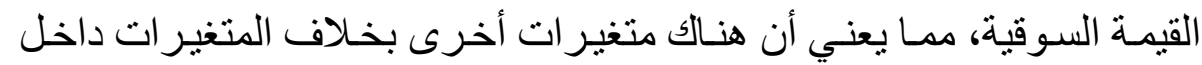
النموذج لها القدرة على التنبؤ بصورة أفضل على القيل القيمة السوقية للشركة.

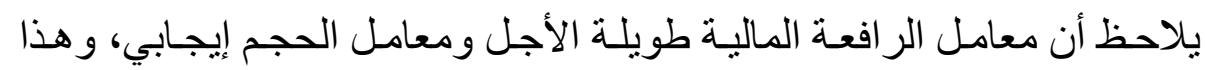

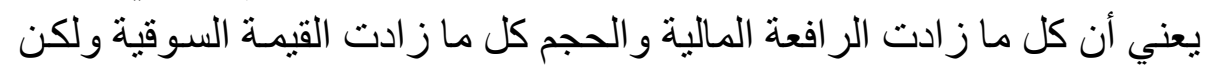

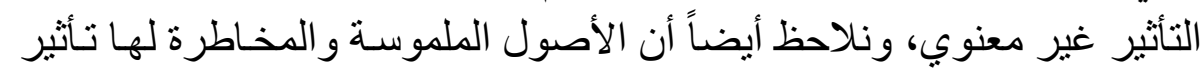
إيجابي ومعنوي على القيمة السوقية للشركة.

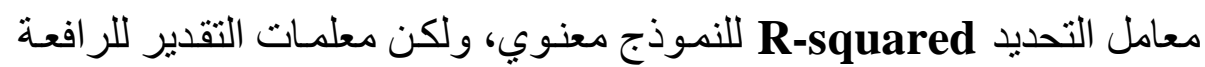

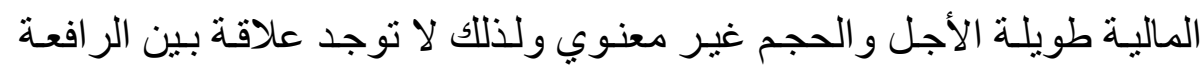

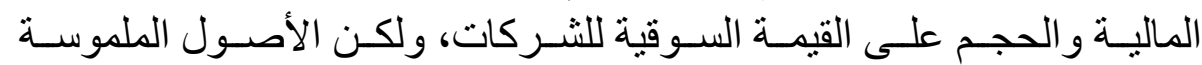

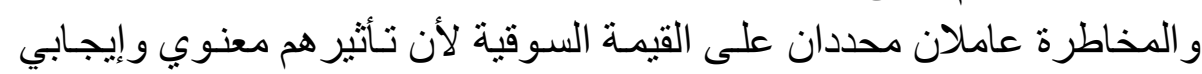

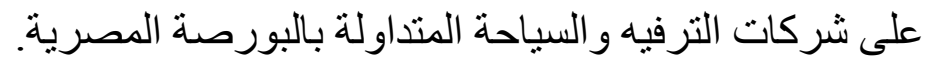

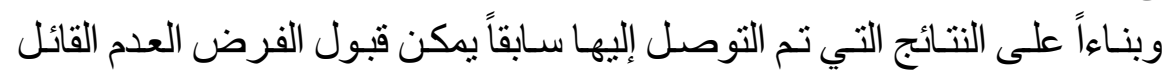

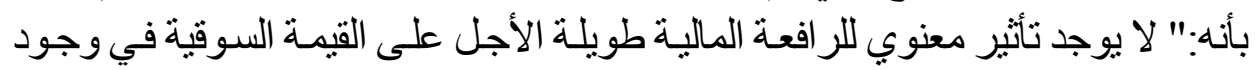

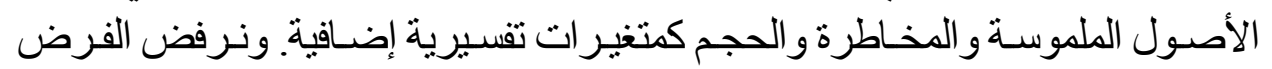

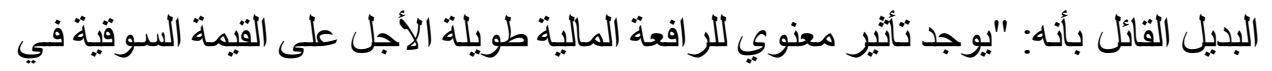

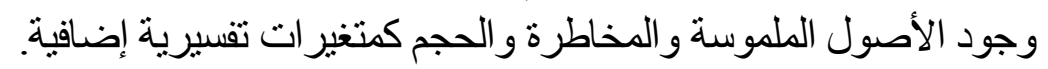
r 1/ 9/ اختبار صحة القرض السادس:

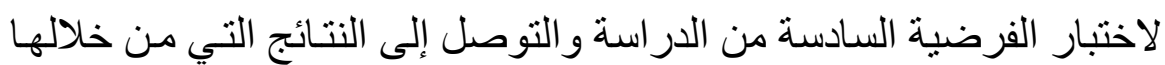

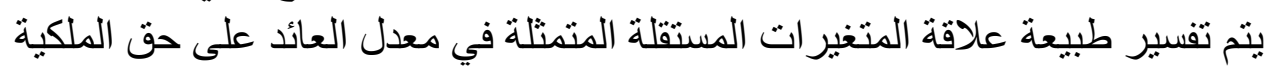

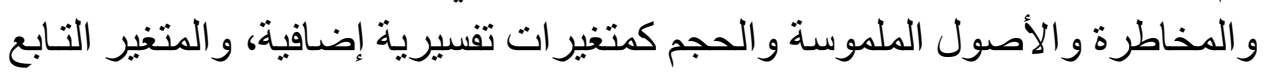
المتمثل في القيمة السوقية. وكانت النتائج كالتالي: 


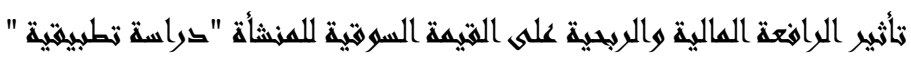

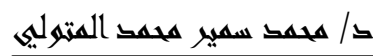

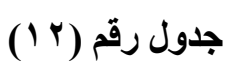

معلمات المتغيرات المستقلة (الربحية، الأصول الملموسة، الحجم، المخاطرة)

على القيمة السوقية للشركة المقدرة باستخدام النموذج)(GMM) (لماتهول

\begin{tabular}{|c|c|c|c|}
\hline \multirow[b]{2}{*}{ Prob } & \multicolumn{2}{|c|}{$\begin{array}{r}\text { نموذج العزوم المعممة) } \text { (GMM) } \\
\text { generalized method of moments }\end{array}$} & $\begin{array}{c}\text { المتغير } \\
\text { Variable }\end{array}$ \\
\hline & t-Statistic & Coefficient & \multirow{2}{*}{$\begin{array}{l}\text { Constant } \\
\text { (C) }\end{array}$} \\
\hline 0.0419 & 1.472405 & 0.092862 & \\
\hline 0.0000 & 5.270786 & 2.648072 & ROE \\
\hline 0.0000 & 7.731747 & 0.827175 & TANG \\
\hline 0.0213 & 2.314922 & 0.026997 & SIZE \\
\hline 0.0000 & 5.079332 & 0.358529 & BETA \\
\hline \multicolumn{3}{|c|}{0.343089} & R-squared \\
\hline \multicolumn{3}{|c|}{0.334530} & Adjusted R-squared \\
\hline \multicolumn{3}{|c|}{2.426226} & Durbin-Watson stat \\
\hline \multicolumn{3}{|c|}{0.737571} & Mean dependent var \\
\hline \multicolumn{3}{|c|}{0.576623} & S.D. dependent var \\
\hline \multicolumn{3}{|c|}{307.0000} & J-statistic \\
\hline \multicolumn{3}{|c|}{0.000000} & Prob(J-statistic) \\
\hline \multicolumn{3}{|c|}{312} & No. of observations \\
\hline
\end{tabular}

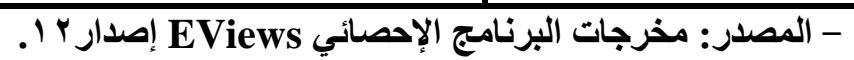

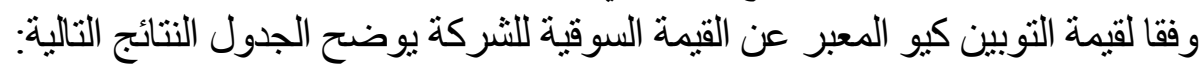
لقد أظهرت نتائج تقدير النموذج، القدرة التفسيرية للمتغير ات المستقلة وبناءاً عليه

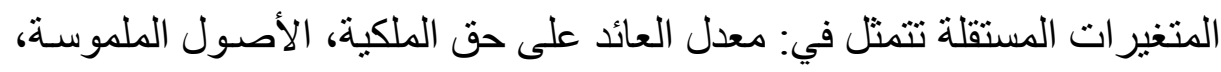

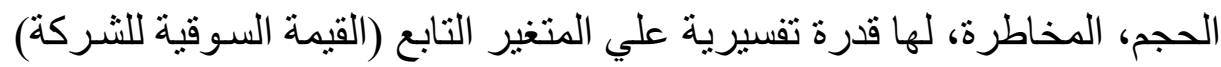

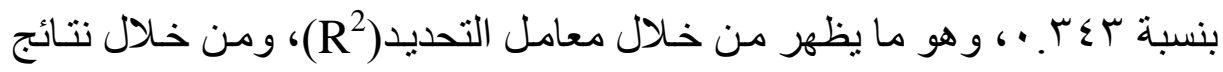

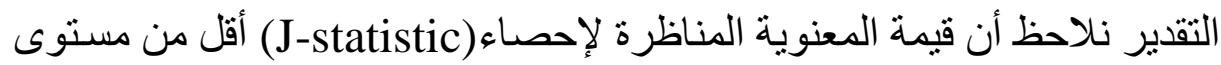

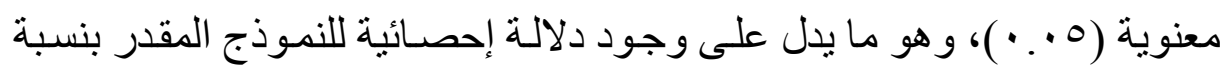

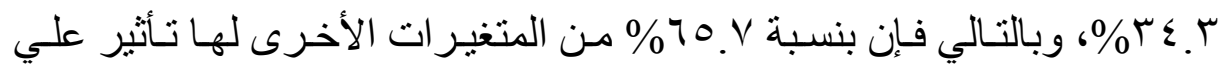

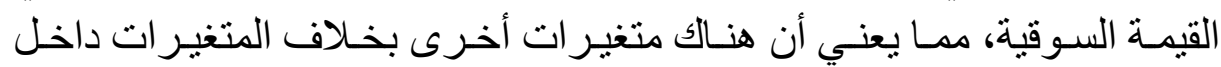
النموذج التي لها القدرة على التنبؤ بصورة أفضل علي القيمة السوقية للثركة. 


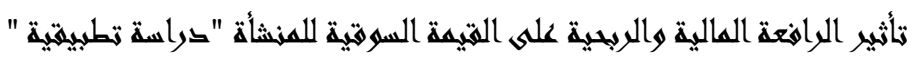

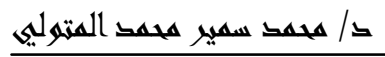

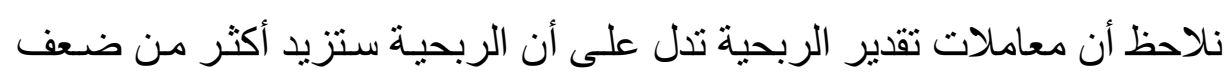

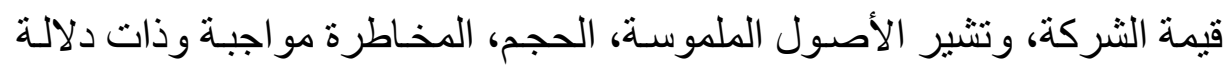

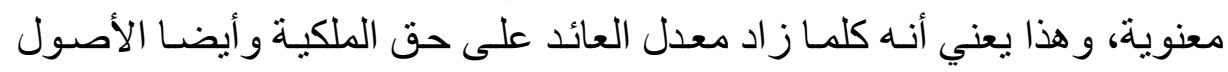

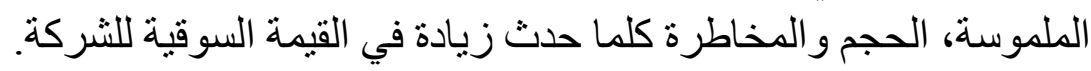

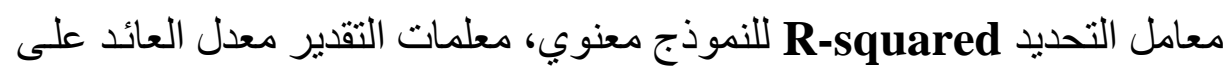

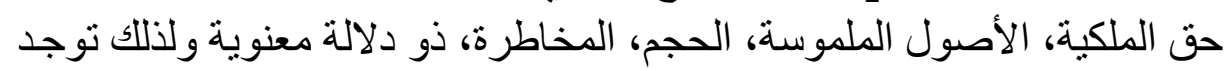

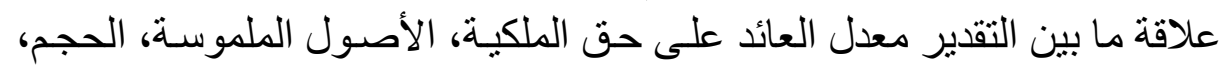

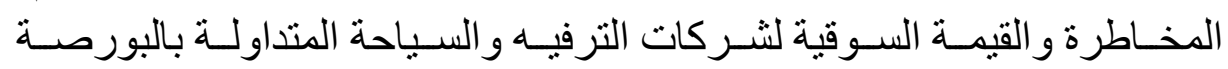
المصرية ويصبح النموذج المقدر يساوي:

Y1 $=0.092+2.648 *$ ROE $+0.827 *$ TANG + 0.026*SIZE + 0.358*
BETA ... MOGEL (6)

وبناءاً على النتائج التي تم التوصل إلبها سابقاً يمكن رفض الفرض العدم القائل

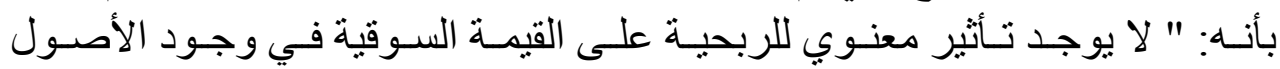

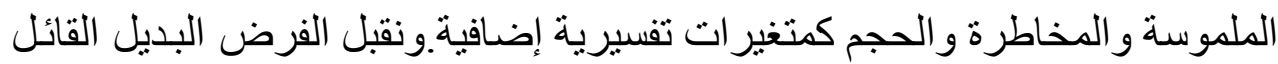
بأنه:" يوجد تأثثر معنوي للربحية على القيمـة السوقية في وجود الأصـول الملموسـة و المخاطرة و الحجم كمتغير ات تفسيرية إضافية.

رابع عشر: مناقشة النتائج:

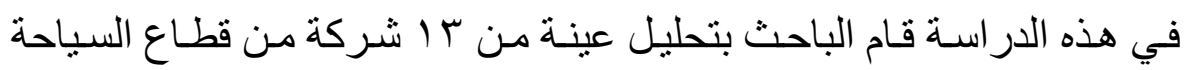

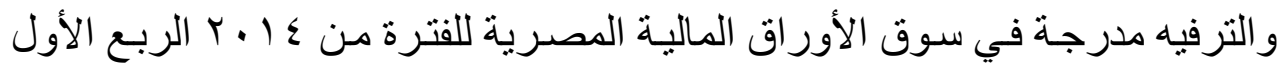

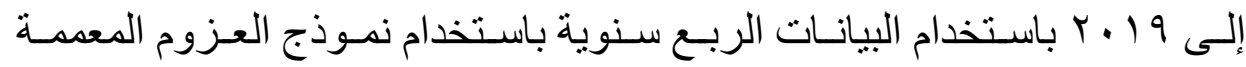
Generalized Method of Moments(GMM) بإجمالي عدد المشـاهدات ب آس مشـاهدة. تتو افق نتـائج هذه الدر اسـة مـع بعض نتائج

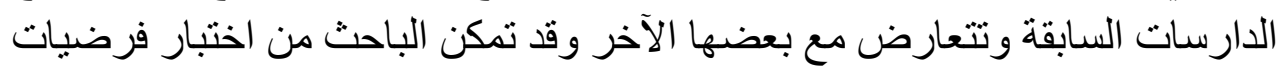

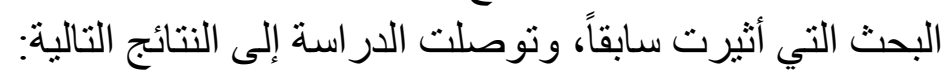




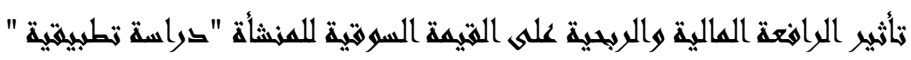

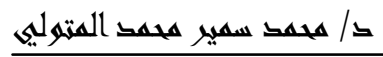

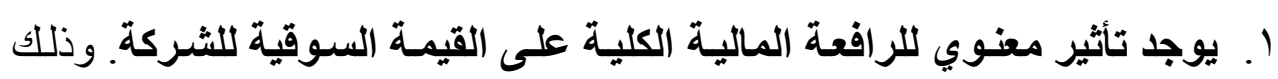

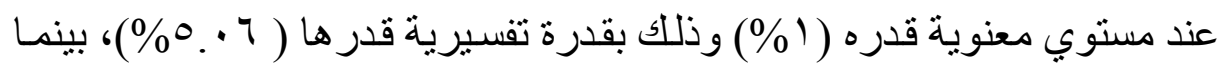

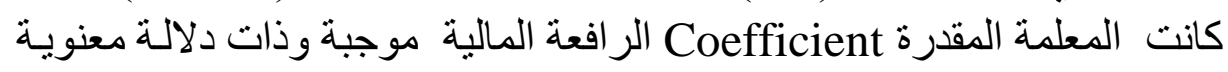

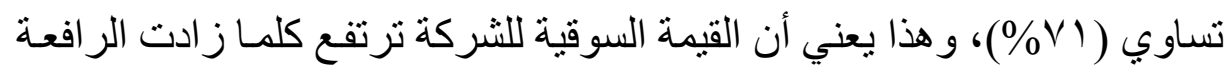

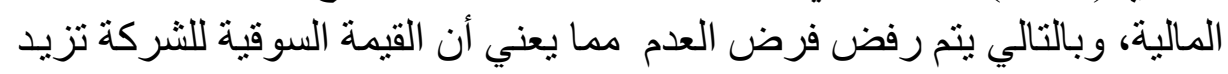

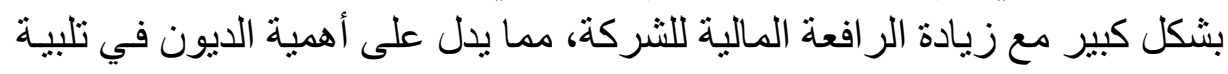

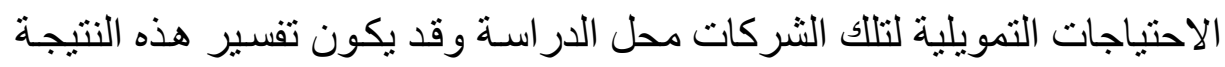

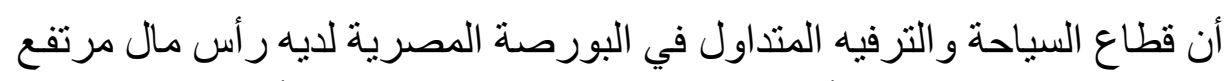

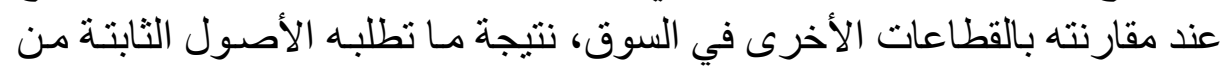

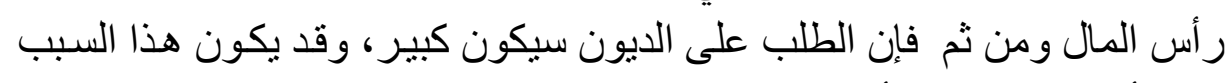

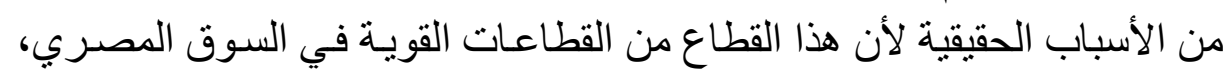

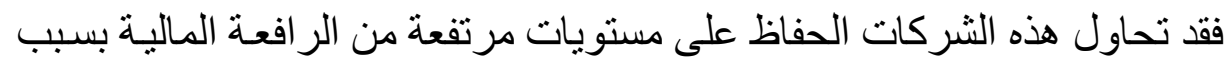

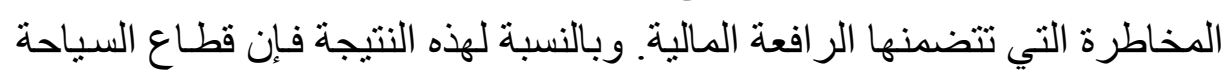

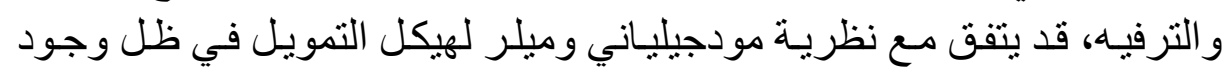
ضر ائب (Miller ,1963،Modigliani)

2. ل التوجد علاقـة ذات دلالـة إحصـائية بـين الرافعـة الماليـة الكليـة والقيمـة السـوقية

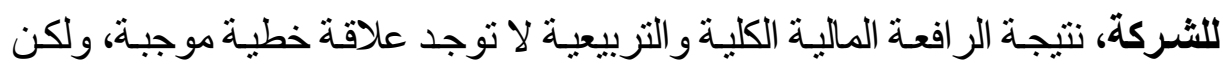

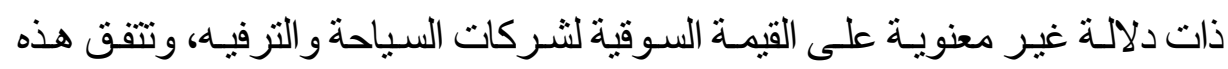
النتيجة مع نظرية مودجيلياني وميلر لهيكل التمويل في ظل عدم وجود ضلئ ضر ائب.

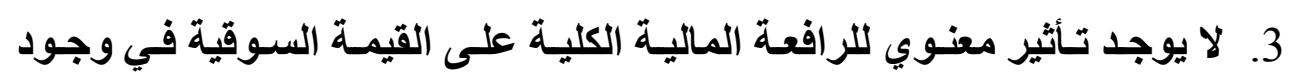

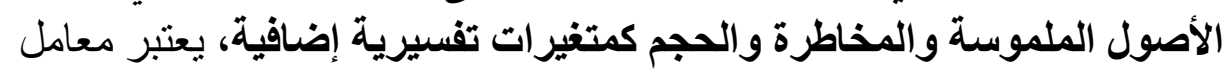

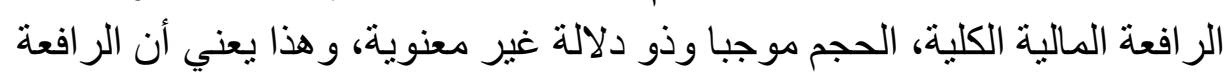

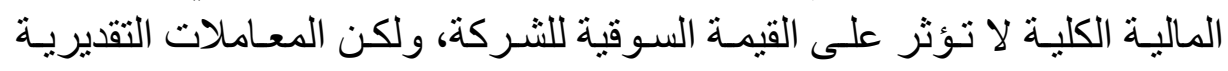

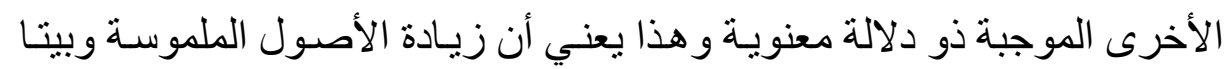

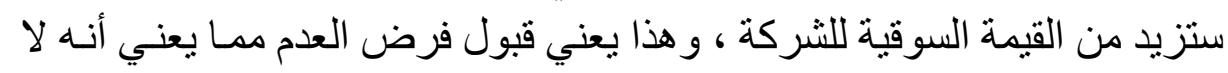




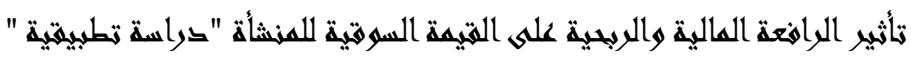

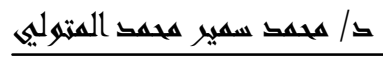

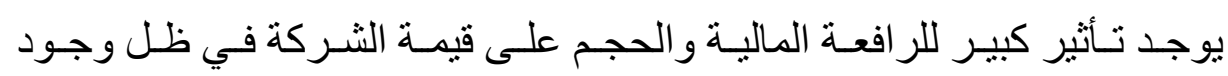

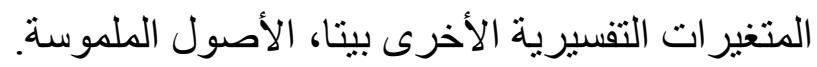

4. يوجد تأثير معنوي للرافعة الماليـة قصيرة الأجل على القيمـة السوقية في وجود

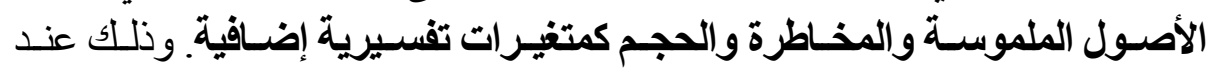
مستوى معنوية قره (1\%) بقدرة تفسيرية (10.1\%) ) بلينما كانت المعلمـات المقدرة

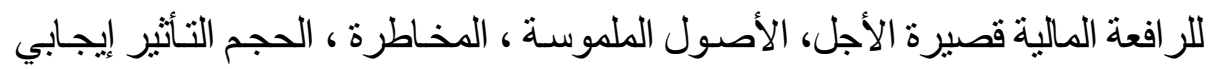

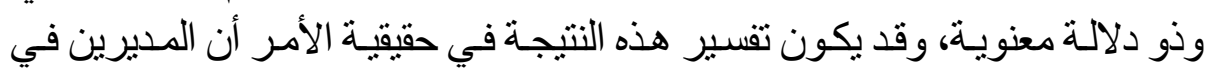

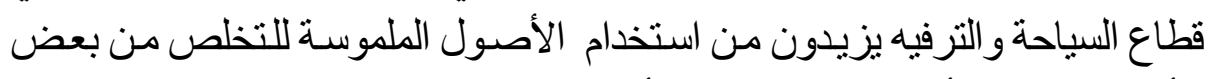

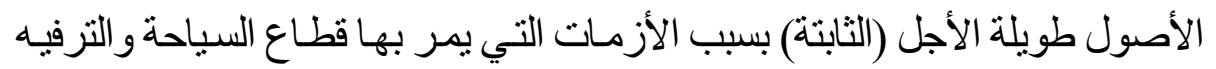

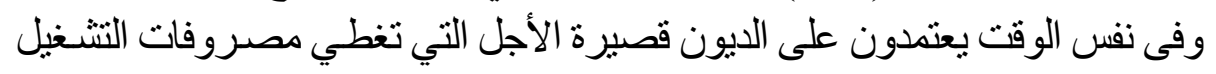

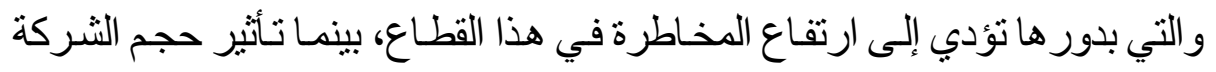

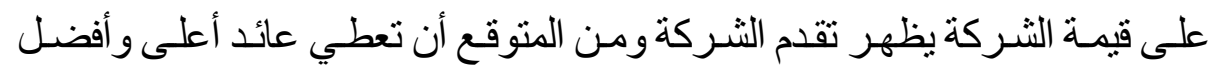

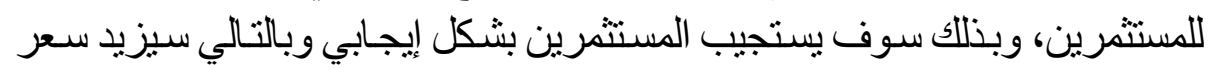

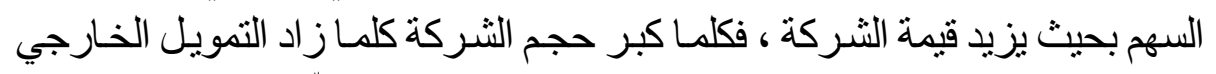

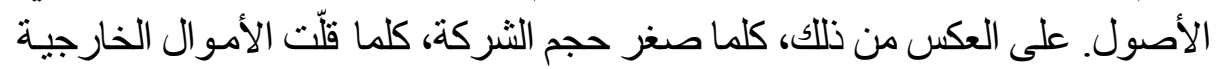
التي تحتاجها الثركة.

5. لا يوجد تـأثير معنـوي للرافعة الماليـة طويلـة الأجل على القيمسة السـوقية في

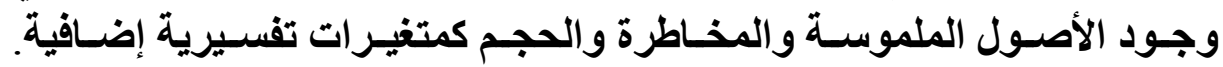

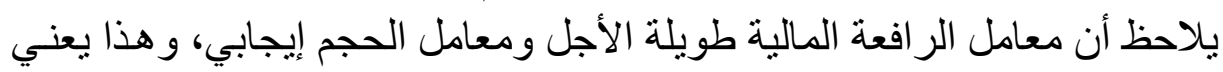

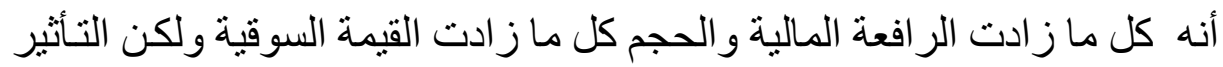

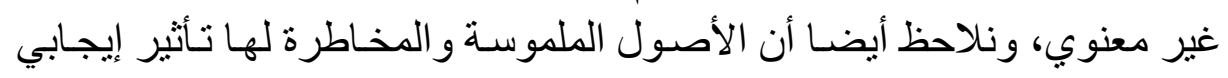

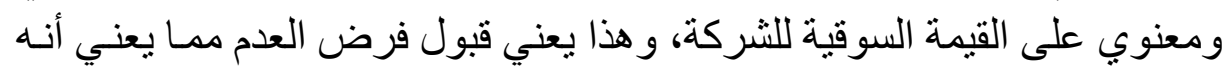

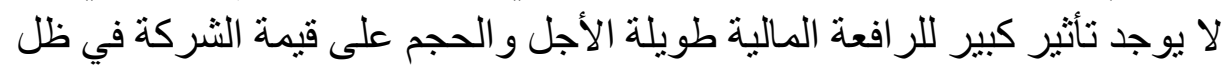

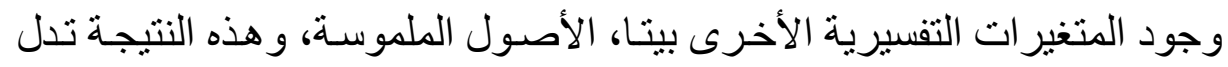

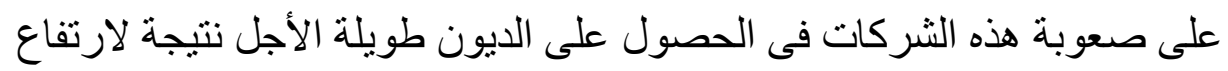




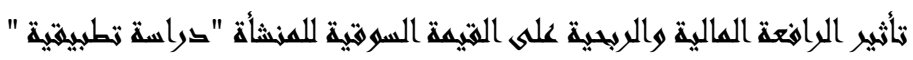

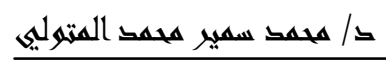

المخـاطر المصـاحبة لهـا وعدم وجـود الضـمانات الكافيـة للحصـول على الديون طويلة الأجل.

6. يوجد تأثثير معنوي للربحية على القيمـة السوقية في وجود الأصسول الملموسـة

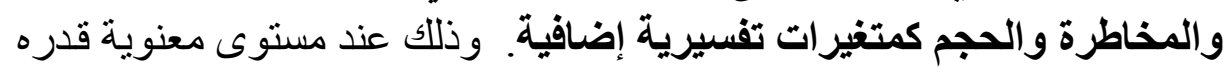

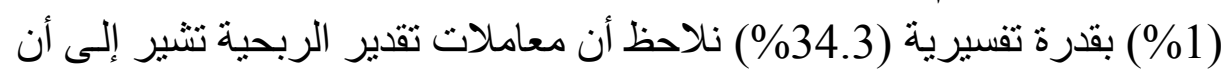

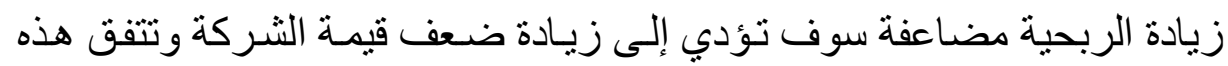

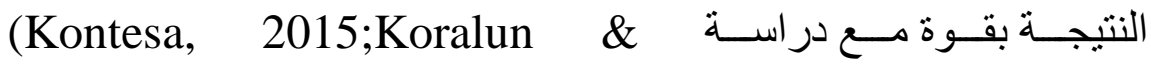

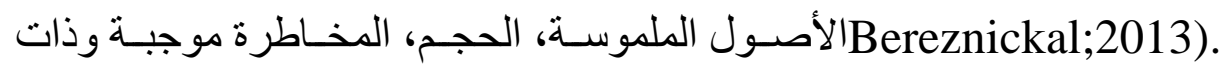

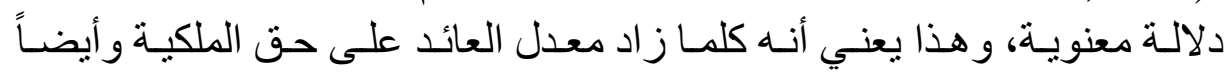

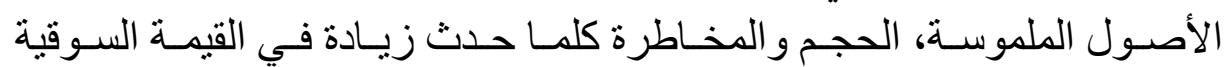
للشركة، وزيادة القيمة السوقية ستؤدي إلى زيادة قدرة الثركة على جنى الثي الأربـاح

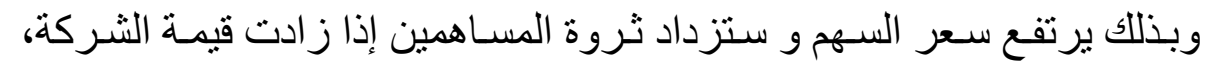

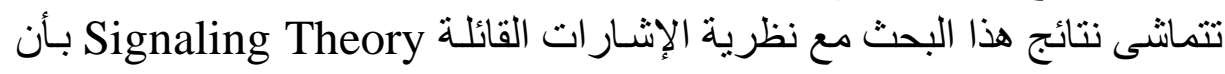

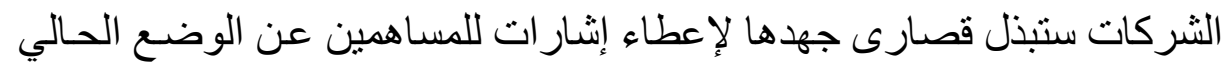

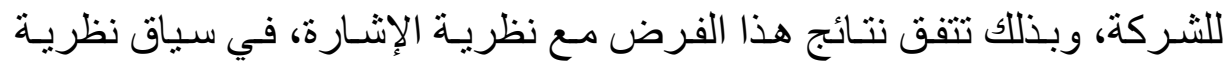

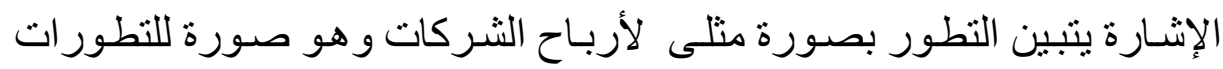

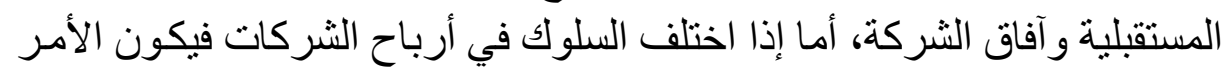

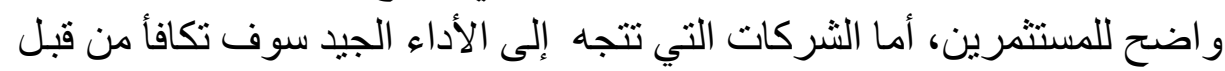

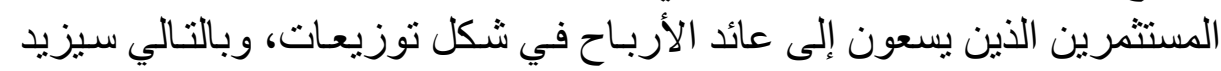
سعر سهم الثركة ويزيد من قيمة الثركة في السوق. 


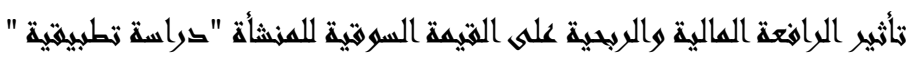
د/ هحمد سمير هحمت المتزليه

\section{خامس عشر: التوصيات:}

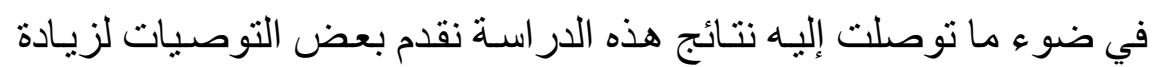

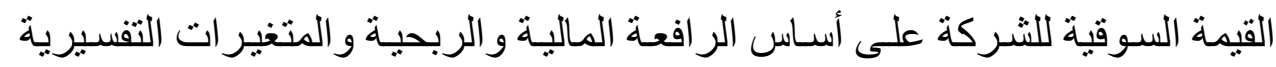
الأخرى المتمثلة في الأصول الملموسة و الحجم و المخاطرة على المئل النحو التالي:

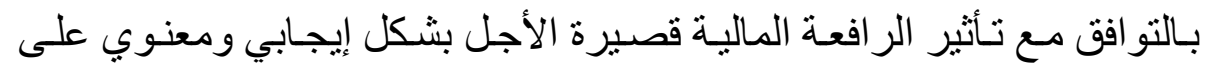

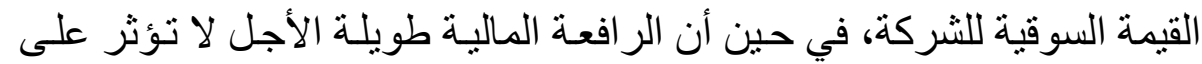

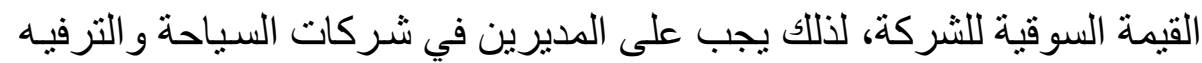

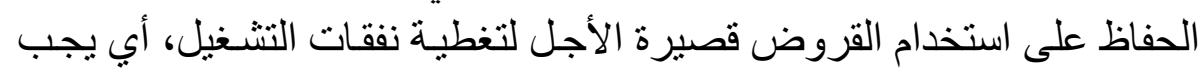

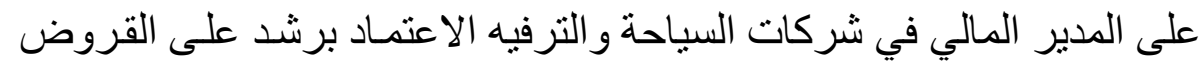

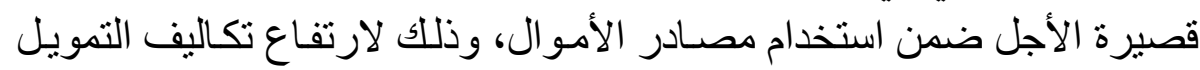
الخاصة بها، وزيادة الاعتماد على الأرباح المحتجزة في حالة تو افر ها.

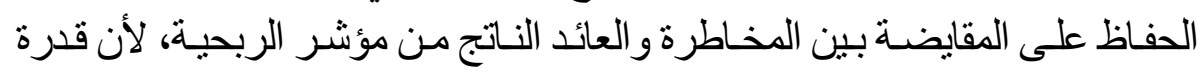

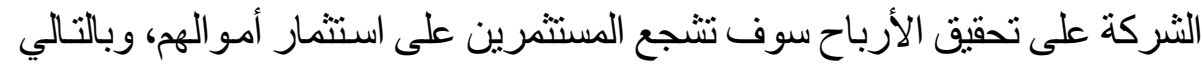

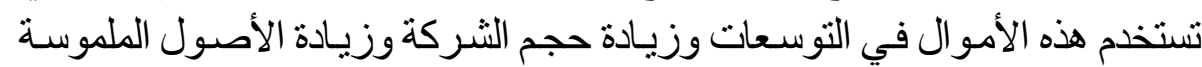
وزيادة العائد على المدى الطويل مما ينعكس على قيمة الثركة.

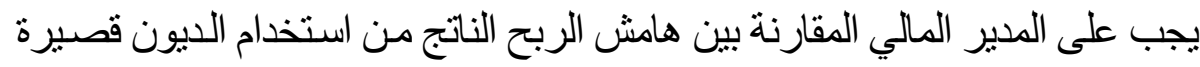

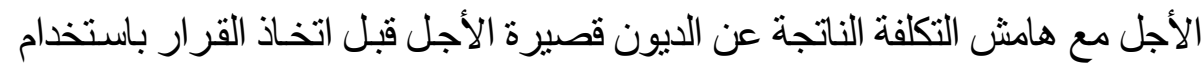
هذه الديون في تغطية نفقات التشغيل بشركات السياحة و الترفيه.

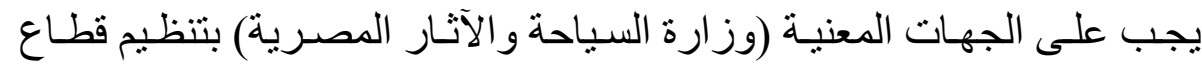

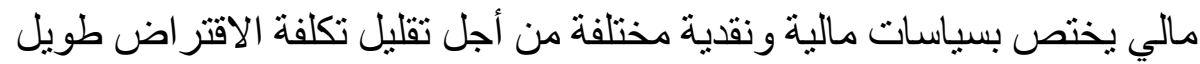

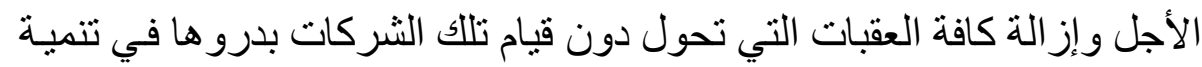

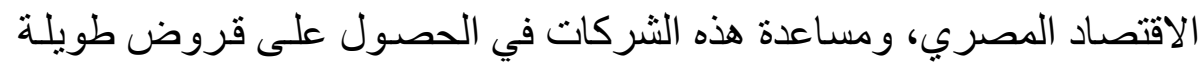

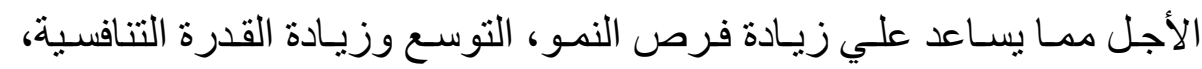

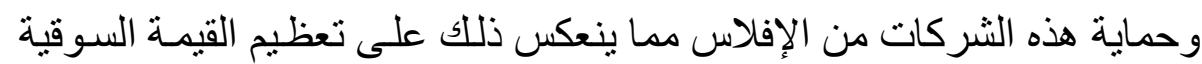
لشركات السياحة و الترفيه المتداولة بالبورينة الافهة المصرية. 


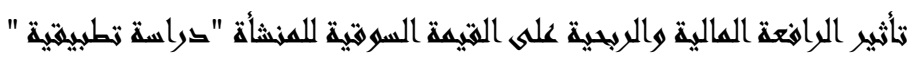

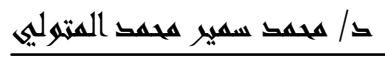

يجب على مجلس إدارة هذه الشركات أن يأخذ بعين الاعتبار محددات قرارات

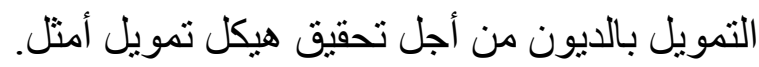

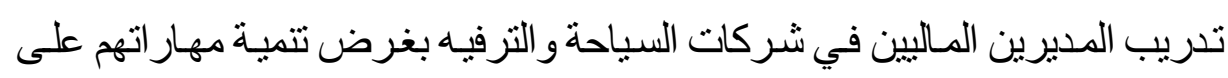
كيفية المفاضلة بين مصادر الأمو ال وما سيعقبه من تعظيم في قيمة المنشأة. سادس عشر: حدود الاراسة والبحوث المستثبلية: حدود الدراسة:

تقتصر الدراسـة على الديون كأحد عناصـر هيكل التمويـل دون حقوق الملكيـة وذلك التك

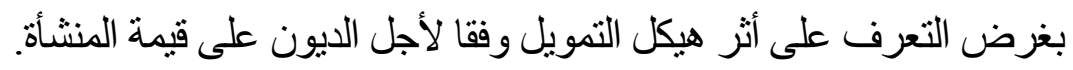

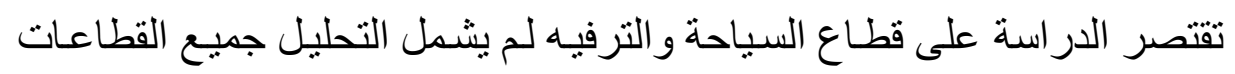

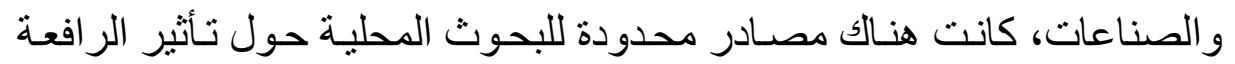

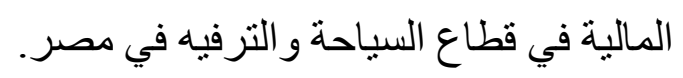

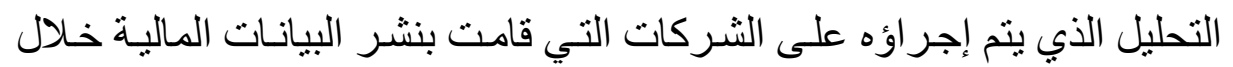
فترة الدر اسة. ب) البحوث المستقبلية: يمكن إيجاز الموضوعات الموصي بها كدراسات مستقبلية على النحو التالي:

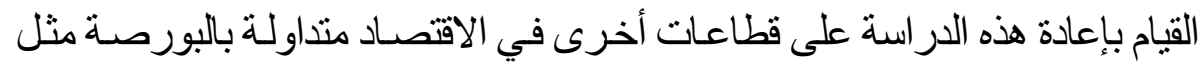

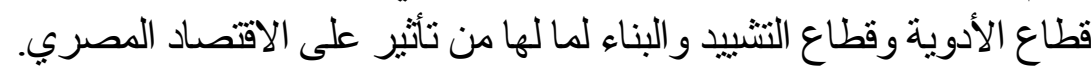
در اسة تأثير هيكل التمويل كمتغير وسيط بين الربحية، النمو، المخاطرة و الحجم

$$
\text { على قيمة المنشأة. }
$$

انعكاسات الصورة الذهنية لثركات السياحة و الترفيه على قيمتها السوقية

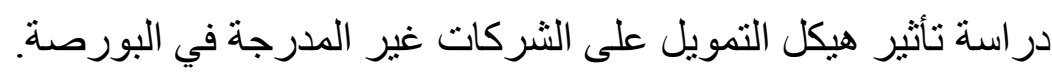

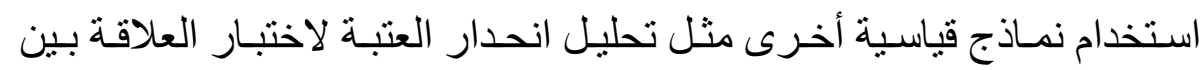
الر افعة المالية وقيمة الثركة. 


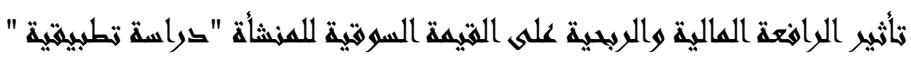
כ/ هحمל سمير هحمق المتهوليه

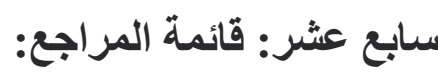

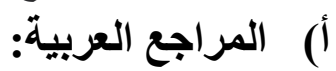

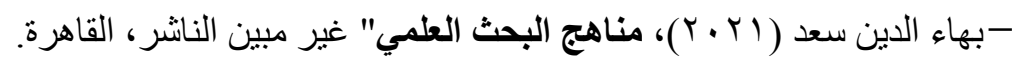

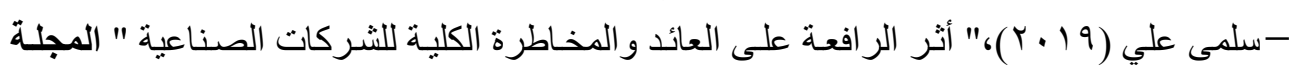

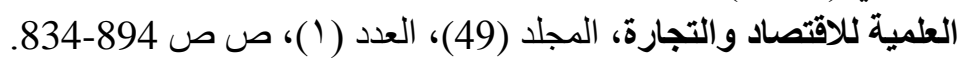

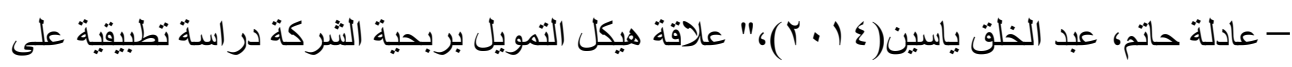

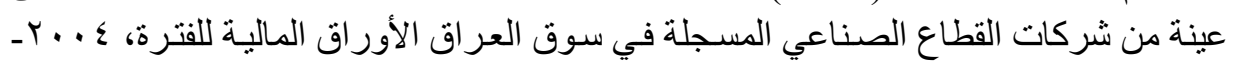

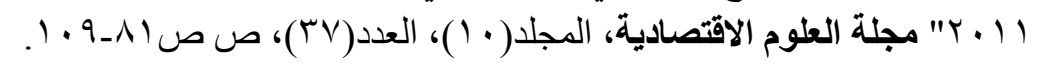

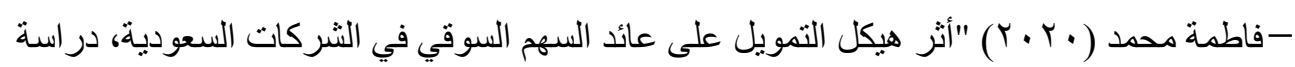

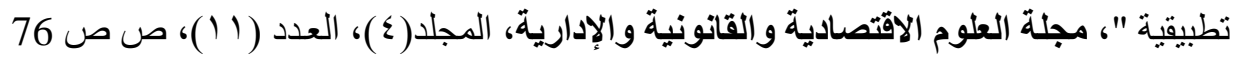
.58

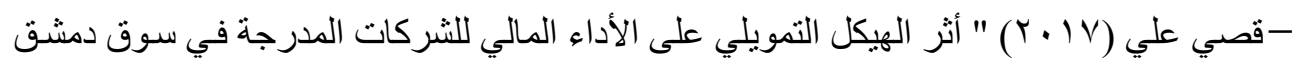

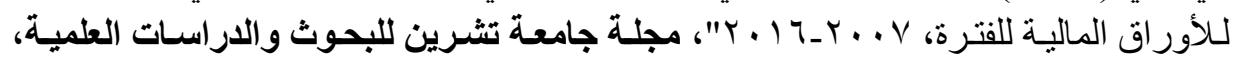

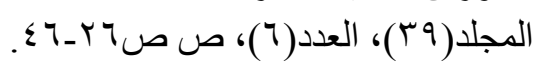

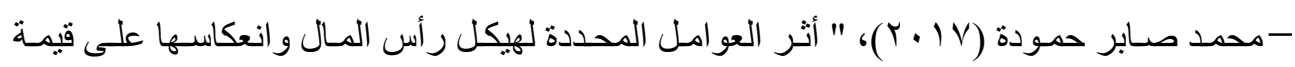

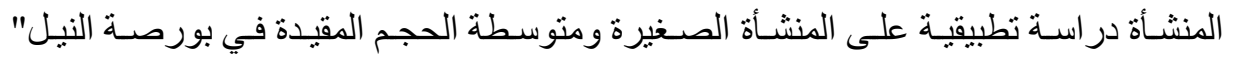

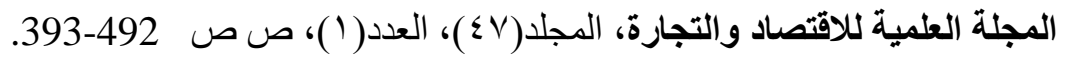

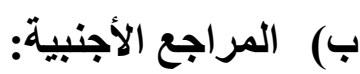

- Abdullah, M. N., Parvez, K., Karim, T., \& Tooheen, R. B. (2015). The impact of financial advantage and market size on stock returns on the Dhaka stock exchange: Evidence from selected stocks in the manufacturing sector. International Journal of Economics, Finance and Management Sciences, 3(1), PP.10-15.

- Abor, J., \& Biekpe, N. (2009). "How Do We Explain the Capital Structure of SMEs in Sub-Saharan Africa? Evidence from Ghana", Journal of Economic Studies, Vol. 36, No. 1, PP. 83-97. 


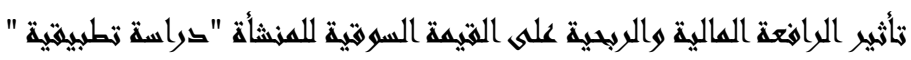

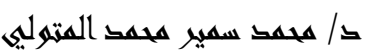

- Aggarwal, D., \& Padhan, P. C. (2017). Impact of capital structure on firm value: Evidence from Indian hospitality industry. Theoretical Economics Letters, 7(4), PP. 982-1000.

- Ahmed Sheikh, N. and Wang, Z. (2013), "The impact of capital structure on performance: an empirical study of non-financial listed firms in Pakistan", International Journal of Commerce and Management, Vol. 23 No. 4, pp. 354-368.

- Ahmed, N., Ahmed, Z., \& Ahmed, I. (2010). Determinants of capital structure: A case of life insurance sector of Pakistan. European Journal of Economics, Finance and Administrative Sciences, 24(24), PP. 7-12.

- Alipour, M., Mohammadi, M. \& Derakhshan, H., (2015), "Determinants of Capital Structure: An Empirical Study of Firms in Iran", International Journal of Law and Management, Vol. 57, No. 1, PP. 53-83.

- Al-Najjar, B., and Al-Najjar, D., (2017), "The impact of external financing on firm value and a corporate governance index: SME evidence" Journal of Small Business and Enterprise Development, Vol.24, No.2, pp.411-423

- Al-Nsour, O. J. (2019). Capital Structure, Profitability and Firm's Value: Evidence from Jordan. "Journal of Finance and Accounting, Vol.10, No.20, PP. ,73-80

- Al-Sleha, Z. A. F. (2020). Impact of Financial Leverage, Size and Assets Structure on Firm Value: Evidence from Industrial Sector, Jordan. International Business Research, 13(1), PP. 109- 120.

- Al-Taani, K., (2013), "The Relationship between Capital Structure and Firm Performance: Evidence from Jordan ", Journal of Finance and Accounting, Vol. 1, No. 3, PP. 41-45.

- Antwi, S., Mills, E. F. E. A., \& Zhao, X. (2012). Capital structure and firm value: Empirical evidence from Ghana. International Journal of Business and Social Science, 3(22). ISO 690, PP. 103-111. 


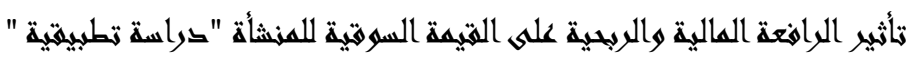

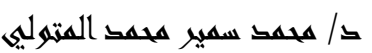

- Asiri, B. K., \& Hameed, S. A. (2014). Financial ratios and firm's value in the Bahrain Bourse. Research Journal of Finance and Accounting, 5(7), PP.1-9. https://core.ac.uk/reader/234629860

- Bae, S., Kwon, T. \& Lee, J., (2008), "Corporate Diversification, Relatedness, and Firm Value: Evidence from Korean Firms", AsiaPacific Journal of Financial Studies, Vol. 37, No. 6, PP. 1025- 1064.

- Baker, M., and J. Wurgler (2002). "Market timing and capital structure”. Journal of Finance, 57 (1), PP. 1-32.

- Chandra, T., Junaedi, A. T., Wijaya, E., Suharti, S., Mimelientesa, I., \& Ng, M. (2019). The effect of capital structure on profitability and stock returns: Empirical analysis of firms listed in Kompas 100. Journal of Chinese Economic and Foreign Trade Studies. Vol. 12 No. 2, pp. 74-89.

- Chen, C. R. and T. L. Steiner. (2000). "Tobin's Q, Managerial Ownership, and Analyst Coverage: A Non-Linear Simultaneous Equations Model". Journal of Economics and Business, 52, pp. 365-382

- Chen, S. \& Chen, L., (2011), "Capital Structure Determinants: An Empirical Study in Taiwan", African Journal of Business Management, Vol. 5, No. 27, PP. 10974-10983.

- Chen, W.P., Chung, H., Hsu, T.L., and Wu, S., (2010), "External financing needs, corporate governance, and firm value", Corporate Governance: An International Review, Vol.18, No.3, pp.234-249.

- Dang, T. D., \& Do, T. V. T. (2021). Does Capital Structure Affect Firm Value In Vietnam?.Investment Management and Financial Innovations, 18(1), 33-41

- Drobetz, W. \& Fix, R., (2003), "What are the Determinants of the Capital Structure: Some Evidence from Switzerland", Working Paper, University of Basel, Basel, April. 


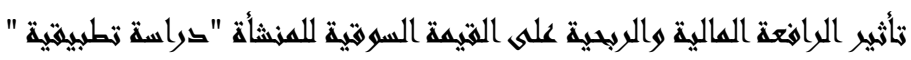

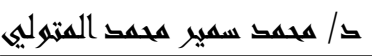

- Ezeoha, A., (2008), "Firm Size and Corporate Financial-Leverage Choice in a Developing Economy Evidence from Nigeria", the Journal of Risk Finance, Vol. 9, No. 4, PP. 351-364.

- Financial performance on stock returns "a case of Pakistan textile industry", Middle-East Journal of Scientific Research, Vol. 16 No. 2, pp. 289-295.

- Gujarati, D.N. and Porter, D.C., (2009), "Basic Econometrics". 5th Edition, McGraw Hill Inc., New York.

- Handoo, A. \& Sharma, K., (2014), "A Study on Determinants of Capital Structure in India", IIMB Management Review, Vol. 26, PP. 170-182.

- Hermuningsih, S. (2013). Profitability, growth opportunity, capital structure and the firm value. Bulletin of Economic Monetary and banking, 16(2), 115-136.

- Ibrahim, H. \& Masron, T., (2011), "Capital Structure and the Firm Determinants: Evidence from Small and Medium Enterprises (SMEs) in Malaysia", International Conference on Economics, Trade and Development, IPEDR Vol. 7, PP.25-28.

- Ibrahim, U. A., \& Isiaka, A. (2020). Effect of financial advantage on firm value: Evidence from selected firms quoted on the Nigerian stock exchange. European Journal of Business and Management, 12(3), PP. 124-135.

- Ishari, M. P. S., \& Abeyrathna, S. P. G. M. (2016). The Impact of Financial Leverage on Firms' Value (Special Reference to Listed Manufacturing Companies in Sri Lanka). International Journal of Advancement in Engineering Technology, Management and Applied Science, 3(7), PP. 100-104.

- Jiahui, M., (2015), "Relationship between Capital Structure and Firm Performance, Evidence from Growth Enterprise Market in China", Management Science and Engineering, Vol. 9, No. 1, PP. 45-49. 


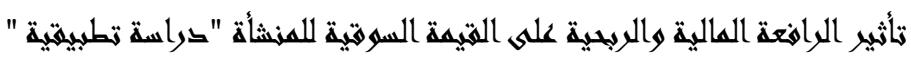
د/ هحمל سمير هحمت المترليه

- Kausar, A. et al. (2014). "Capital Structure and Firm Value Empirical Evidence from Pakistan". Asian Journal of Research in Economics and Finance, 1 (1), PP. 11-22.

- Kontesa, Maria, (2015),'Capital structure, profitability, and Firm Value, What's New?" Research Journal of Finance and Accounting, Vol. 6, No. 20, PP. 185-192.

- Koralun, Julia, Bereznicka. 2013. How Does Asset Structure Capital Structure With corelate. Cross-Industry and Cross-Size Analysis of the EU Countries. Universal Journal of Accounting and Finance, Vol. 1, No. 1, pp. 19-28.

- Kruk, S. (2021). Impact of Capital Structure on Corporate ValueReview of Literature. Journal of Risk and Financial Management, 14(4), PP.155-165.

- Laz_ar, S. (2016), "Determinants of firm performance: evidence from Romanian listed companies", Review of Economic and Business Studies, Vol. 9 No. 1, pp. 53-69.

- Le Thi, P. V., Phan, T., \& Nguyet, B. (2013). Impact of state ownership on funding decisions: Experimental evidence in Vietnam. Development \& Integration Journal, 22(32), PP. 50-57.

- LUU, D. H. (2021). The Impact of Capital Structure on Firm Value: A Case Study in Vietnam. The Journal of Asian Finance, Economics and Business, 8(5), PP.287-292.

- Mahdaleta, E., Muda, I., \& Nasir, G. M. (2016). Effects of capital structure and profitability on corporate value with company size as the moderating variable of manufacturing companies listed on Indonesia Stock Exchange. Academic Journal of Economic Studies, 2(3), PP. 30-43.

- Mai, T. G. (2020). The impact of capital structure on the value of firms in the plastic and packaging industry listed in Vietnam. Economy and Development Journal, 280, pp59-67. 


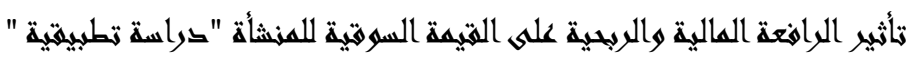

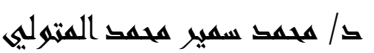

- Maksum, N. A., \& Sirojuzilam, E. (2018). VALUE OF THE FIRM IN CAPITAL STR UCTURE PERSPECTIVE (Case study of tourism companies in Indonesia Stock Exchange). Economy and Development Journal, 6(1).pp20-41

- Manu, R., Alhabsji, T., Rahayu, S., and Nuzula, N., (2019), "The effect of corporate governance on profitability, capital structure and corporate value", Research Journal of Finance and Accounting, Vol.10, No.8, pp.202-214.

- Mateev, M., Poutziouris, P. \& Ivanov, K., (2013), "On the Determinants of SME Capital Structure in Central and Eastern Europe: A Dynamic Panel Analysis", Research in International Business and Finance, Vol. 27, No. 1, PP. 28-51.

- Modigliani, F. and M. H. Miller (1963). "Corporate income taxes and the cost of capital: a correction". The American Economic Review, 53, PP.443-53

- Modigliani, F., \& Miller, M. H. (1958). The Cost of Capital, Corporation Finance and the Theory of Investment. The American Economic Review, 48(3), PP. 261-297. Retrieved from

- Myers, S. C. (1977). Determinants of corporate borrowing. Journal of Financial Economics, 5(2), PP.147- 175.

- Myers, S. C. (1984). "The capital structure puzzle". Journal of Finance, 39 (3), PP. 575-592.

- Nsour, O. J. (2019). Capital Structure, Profitability and Firm's Value: Evidence from Jordan. Research Journal of Finance and Accounting, Vol.10, No.20, 2019,pp73-80

- Pacheco, Luis. (2016). Capital structure and internationalization: The cast of Portugese industrial SMEs. Research in International Business and Finance 38: PP.531-45. [CrossRef]

- Rahayu, S.M., Saif, S., and Saif, M., (2019), "the reciprocal relationship between profitability and capital structure and its impacts 


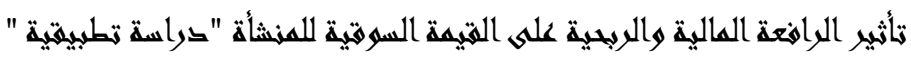

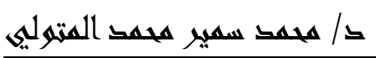

on corporate values of manufacturing companies in Indonesia", International Journal of Productivity and Performance Management, DOI 10.1108/IJPPM-05-2018-0196.

- RAHMAN, M. M., SAIMA, F. N., \& JAHAN, K. (2020). The Impact of Financial Leverage on Firm's Profitability: An Empirical Evidence from Listed Textile Firms of Bangladesh. The Journal of Business Economics and Environmental Studies, 10(2), PP.23-31.

- Rajhans, R. K. (2013). Financial determinants of firm's value: Evidence from Indian firms. International Journal of Business Economics \& Management Research, 3(500), PP. 1-12. https://ssrn.com/abstract=2305950

- Saleem, F., Rafique, B., Mehmood, Q., Irfan, M., Saleem, R., Tariq, S., \& Akram, G. (2013). The determination of capital structure of oil and gas firms listed on Karachi stock exchange in Pakistan. Interdisciplinary journal of contemporary research in business, 4(9), PP.225-235.

- Sudrajat, J., \& Setiyawati, H. (2021). Role Of Firm Size and Profitability On Capital Structures And Its Impact Over Firm Value. International Journal of Economics, Finance \& Accounting, 2(1), PP. 13-26.

- Wira, V. (2021). The Effects of Financial Performance toward Firm Value on Tourism, Hotel and Restaurant, and Transportation Sectors Listed on Indonesia Stock Exchange. Journal innovation Business, 9(1), PP.141-149. 